\title{
Christian and Western Jewish Dialects of NENA
}

Moving further westwards into the Jewish NENA dialectal landscape, we encounter the Jewish dialects, known as lishana deni 'our language', such as 'Amedia, Betanure, Dohok and Zakho, and the Jewish Barzani cluster, both west of the Great Zab river. Since they share numerous features with the local Christian varieties, against their Trans-Zab peers, they are studied alongside the Christian dialects of NENA. The distribution of major clusters in NENA dialects is displayed in Map 3 below. Apart from the core of the Christian, i.e. Assyrian or Chaldean, communities in Southeast Turkey, Northwest Iraq and Norwest Iran, there are four clusters of Christian dialects:

- Western: Christian villages near Cizre, Şırnak and Pervari in the Şırnak and Siirt provinces of Turkey, south of the Bohtan river;

- Southern: Christian - mainly Chaldean and Syriac Catholic — communities on the Nineveh Plains near Mosul, such as Alqosh, Telkepe (Tall Kayf), Baghdeda (Qaraqosh) and Karamlesh;

- Eastern: Christian-mainly Chaldean - communities in the Arbel governate of Northeast Iraq, including Shaqlawa, 'Ankawa and Koy Sanjaq;

- Southeastern: Christian varieties of Sulemaniyya (Khan 2004a) and Sanandaj—also known as Senaya, Kurdish Sine (Panoussi 199o)—in Iranian Kurdistan.

Since many of these dialects are still in need of documentation and the data from those that have been documented are not fully publicly accessible, we will not be able to offer a full picture in this chapter. Importantly, considerable mixing has taken place among speakers since they left their original towns. As a result of displacement, several communities came to interact with speakers of dialects they otherwise would not have interactions with in their original homeland. Southeast Turkey, especially the Hakkari province, and Northwest Iraq used to consist of several densely populated areas with tribal affiliations, such as:

- the Atrush area, near Dohok, including Azakh, Hermashe and Ten;

- the Șapna Valley, including C./J. 'Amedia, C./J. Aradhin (Krotkof 1982), C. Bebede, C. Dehe and C. Mangesh (Sara 1974);

- Lower Barwar, i.e. C. Barwar (NW Iraq; Khan 2008a) and J. Betanure (NW Iraq; Mutzafi 2008a);

- Upper Barwar, i.e. Qodshaneș (Talay 2008)

- the Hakkari province of Turkey: Upper/Lower Tyari, such as Ashitha, Bne- 


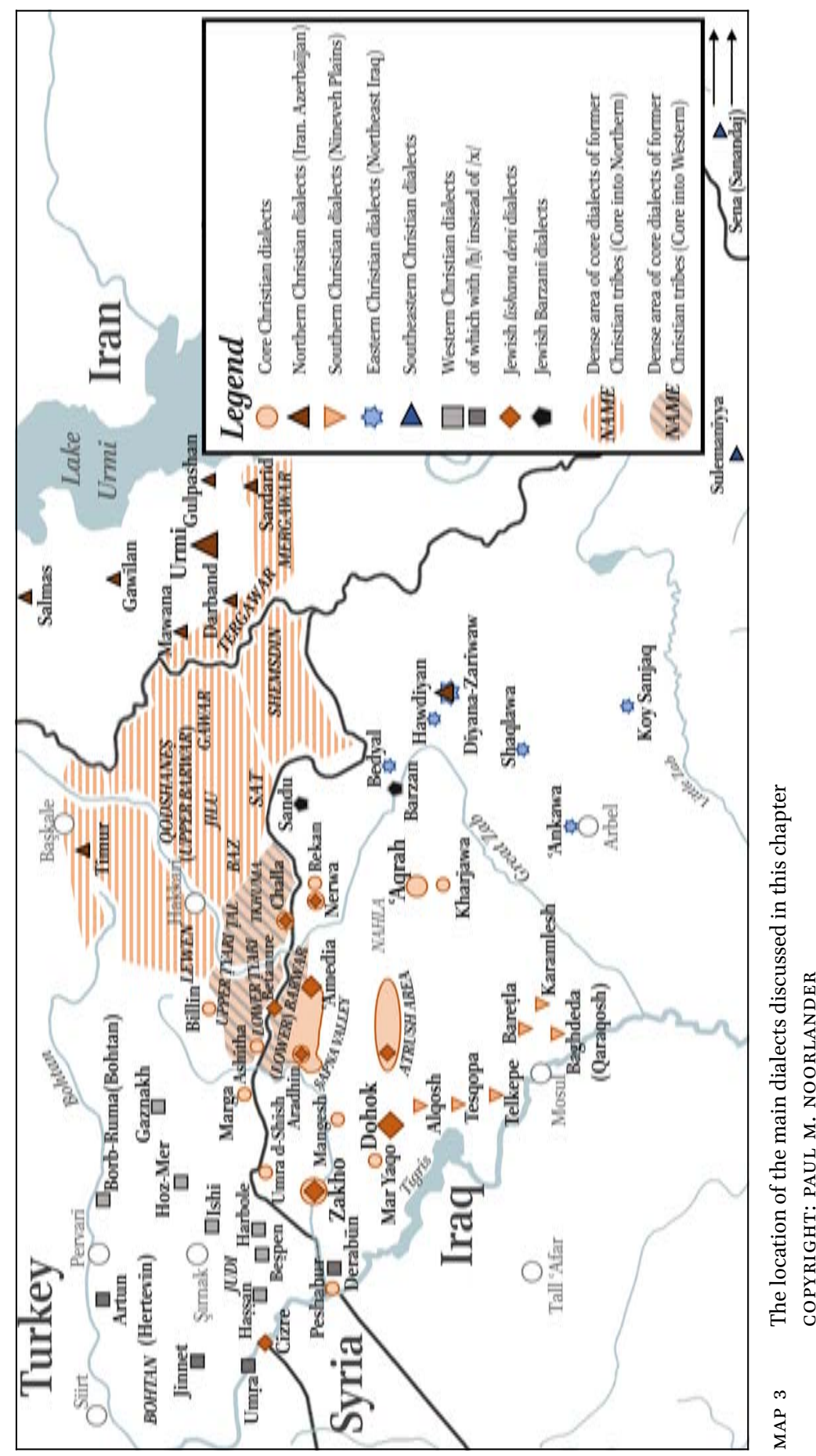


Matha, Bne-Lagippa, Bne-Rumta and Walțo, as well as Țal, Tkhuma, Challa, Baz, Jilu, Gawar and Sat (Talay 2008);

- Timurnaye, Saranaye and other communities in the Van province of Turkey (Nolduz and Albak).

Many of these communities originating in SE Turkey found refuge in Iraq, e.g. in Nahla along the Khazir river near 'Aqrah, and the Khabur valley in NW in Syria after World War I (Talay 2008, 2009). These dialects often preserve archaisms, and are closely related to C. Jilu (SE Turkey; Fox 1997) in the north and J./C. Nerwa (NW Iraq; Talay 2001). The western dialects in NW Iraq, such as Zakho (Hoberman 1993) and Peshabur (Coghill 2013), are somewhat distinct from these. The originally SE Turkish dialect of Marga is closely related to these varieties, possibly due to displacement from Turkey to Levo, NW Iraq.

In the northwestern periphery in the Siirt provinces of SE Turkey, there once was a cluster of Christian dialects in Artun (Hertevin, Turk. Ekindüzü; Jastrow 1988), Umṛa (Dera, Turk. Dereköyu; Hobrack 20oo) and Jinnet (Turk. Bağpınar). These typically exhibit a uvular / $\mathrm{h} /$ where other dialects have velar /x/ (Talay 2009, 44), e.g. Umṛa ḩzeli 'I saw'. A few villages in Borb-Ruma (Bohtan, Fox 2009) share with Jinnet the pronunciation of /o/ instead of /a/ in stressed open syllables, but not the uvular /h/, i.e. xmora 'doney' like hmora against xmara elsewhere, while Artun has uvular /h/ but not /o/, i.e. hmara. Furthermore, there used to be communities around Mount Judi (Cudi) in the Şrnak province, such as Hașșan (Hassane, Turkish Kösreli; Jastrow 1997; Damsma forthcoming), Beșpen (Sinha 2000) and Harbole.

In most cases the Jewish and Christian communities, even of the same towns, still maintained rather different dialects. National borders do not necessarily coincide with dialectological borders. Some of Christian dialects near Rewandiz, such as Diyana (Napiorkowska 2015), bear a strong resemblance to the Christian dialects of Iranian Azerbaijan, and C. Sulemaniyya in NE Iraq shows close affinity with C. Sanandaj in W Iran. The dialects in the 'Aqrah (Akre) district constitute a small, separate cluster that has distinctive preverbal progressive particles, similarly to J. Barzan, J./ C. Shaqlawa, J. Dobe, J. Arbel and C. Koy Sanjaq further east in Iraq (Mutzafi 2004b).

Unsurprisingly, the literature presents diverging views on the characterization of the alignment patterns in the aforementioned NENA dialects. Doron and Khan (2012) consider the majority of these dialects in question to show a type of extended ergative, arguing they have extended the L-suffixes to all transitive verbs ( $q$ țil-li 'I killed', qim-li 'I rose'). Similarly, Mengozzi (2002b, 45, fn. 144) refers to the same phenomenon as theoretically "post-ergative" and Barotto (2015) as marked nominative. Except for Coghill (2016), verbal forms like qțil-a- 
le and qtal-le are referred to as ergative constructions, especially in contradistinction to passive constructions (e.g. Khan 2016:723), and the L-suffixes as markers of the ergative subject. By contrast, the other verbal person marking strategies in most of these dialects are subsumed under accusative alignment in Barotto (2015) and Coghill (2016), primarily because they parallel the morphosyntax of qațal-.

Mengozzi (2005) and Barotto $(2015)^{1}$ point to a "decay of ergativity", leading to a gradual replacement by novel accusative constructions reminiscent of Kurdish (Dorleijn 1996). Mengozzi (2002b, 46 fn. 147), without going into detail, suggests a few factors that are key to the alignment variation, which can be summarized as follows: system-internal pressure from the main inflectional system (qațal-), morphological disambiguation, the order of A and P ("actant order"), tense-aspect distinctions, and pragmatics. My own more detailed research confirms that these are indeed important factors, but, on closer examination, do they promote accusative alignment? Haig (2008) demonstrates that crosssystem harmonization has affected the alignment systems in Iranian. To what extent do we observe this in these NENA dialects, and, what patterns unfold as a result? And to what extent does it make sense to treat part of their morphosyntax as (extended) ergative, as some scholars have claimed? These are the central questions of this chapter.

In addressing the issue of alignment identification, it may be worthwhile to reiterate that, in our approach, ergative alignment hinges on the grouping of $\mathrm{s}$ with $\mathrm{P}$ in some morphosyntactic way. Thus, while the qțil-a-le verbal forms tend to be taken for granted as ergative and L-suffixes as markers of the ergative subject contrasted with qațl- or the passive, if there is no grouping on any level for S and P, it makes no sense to speak of ergativity. By the same taken, verbal person markers, such as the L-suffixes, are not considered to have inherent syntactic role marking properties associated with a particular alignment pattern. Thus when so-called 'ergative L-suffixes' or 'markers of the ergative subject' are extended, this does not mean that ergativity is also extended. At the same time there are constructions that may seem to be simply accusative at first face value and have been analyzed as such, because they are analogical or based on qatal-, but, in fact when one considers them in relation to intransitive constructions, these cannot be unambiguously subsumed under accusative alignment.

1 Cf. Khan (2013) and Coghill (2016). 
Alignment typology studies similarities and/or differences, focusing on the relationship between $\mathrm{S}$ and $\mathrm{P}$ or $\mathrm{A}$, and not a given transitive or intransitive construction per se. This is also what makes such a study especially complex for NENA dialects, since this relationship is not always symmetric (either synchronically or diachronically) and it is difficult to make generalizations. Constraints and conditions may not be equally relevant to all grammatical functions nor equally relevant to all dialects. We will divide these into clausal and verb-related factors (i.e. tense-aspect) and argument-related factors (e.g. third vs. non-third person, full nominal vs. pronominal), always in some way involving at least $P$.

In considering tense, aspect and mood, sharp distinctions of the kind that contrast past and present or imperfective and perfective cannot always be maintained in NENA. Both simplex and compound verbal forms can be used to express various situation types and clausal properties. For example, the compound 'perfect' may also be used to express narrative perfective past in certain dialects, thereby functioning similarly to qtal-le. For practical reasons, however, I will refer to the simplex forms as the preterit and the compound verbal forms as the compound perfect, reflecting different construction types.

With respect to argument-related properties, the cross-indexing of the object is always conditioned in NENA dialects. There is no difference across dialects in this respect, but there are considerable differences in the morphological marking and affix order of the transitive constructions.

\subsection{Preliminary Notes on Morphosyntax}

\subsubsection{Person Marking in Transitive Perfective Past Constructions}

While prepositional pronominal objects are common in Trans-Zab Jewish dialects, most NENA dialects prefer to express pronominal objects via verbal affixes. In a few dialects in the (north)west, pronominal objects are also expressed independently by means of prepositions. As we will see in this chapter, these independent object pronouns have a different status in the system than those in Trans-Zab Jewish dialects.

\subsubsection{1 qam-qațal-le}

Among Christian dialects of Northern Iraq and lishana deni Jewish dialects, the so-called qam-qațl-construction is by far the most common expression for verbal forms in the perfective past containing two dependent person markers. The TAм marker qam- and its dialectal variants, e.g. qam- kam- (various), $q a-$ (C. Koy Sanjaq), tam- (C. Sulemaniyya and Sanandaj), gəm- (C. Peshabur), gəb- 
(C. Mar Yaqo), are simply prefixed to the qața-verbal form like other preverbal TAM modifications, for example:

(1) The qam-qațal-preterit (J. Dohok; Molin 2021)

a. $k$ - šaql-i-la

IND- take ${ }_{\text {IPFV }}$ A:3PL-P:3FS

'They take her.'

b. qam- šaql-i-la

PFV- take ${ }_{\mathrm{IPFV}}-\mathrm{A}: 3 \mathrm{PL}-\mathrm{P}: 3 \mathrm{FS}$

'They took her.'

Although it is based on qatal-, it is equivalent to qtil- in the expression of the perfective past when both A and P are expressed in verbal person marking. This is illustrated by J. Dohok below:

(2) J. Dohok (NW Iraq; Molin 2021)

Pan qțl-lu 'əmma-u-əosri naše,
DEM:PL killed:PFV-A:3PL hundred-and-twenty people:MPL,
qam-qațl-i-lu
PFV-kill-A:3PL-P:3PL
'They killed a hundred and twenty people, they killed them.'

A similar preverb qam- occurs in other varieties, where it expresses the indicative-progressive, cp. (Mutzafi 2002a, 70)

J. Bejil (NW Iraq) ～qam-pātzx- $\varnothing \quad$ 'He is opening'

C. Bedyal (NE Iraq) ma-k-pātax- $\varnothing$ 'He is opening'

These indicative-progressive preverbs should not be conflated with the perfective past preverb qam-, which is confined to transitive perfective past constructions and presumably not historically related to the above progressive marker. One may compare this to the Arabic preverbs qad- in Classical Arabic and $q a(d-)$ or $d a$ - in Baghdadi Arabic, which are also not historically related, e.g. (Rubin 2005, 33-34, 136-137)

$\begin{array}{ll}\text { PAST/PERFECT } & q a d \quad<* q d m \text { 'go/do before' } \\ \text { PRESENT/PROGRESSIVE } & q a(d)-\quad<{ }^{*} q^{\prime} d \text { 'sit' }\end{array}$


Although the historical background of the perfective past preverb qam-is shrouded in mystery, two possible candidates have been suggested, namely (i) the verb $q d m$ 'go before' 2 and (ii) the verb qym 'stand up'. ${ }^{3}$ The first, * $q d m$, 'He went before', which could explain the variant tam- of the preverb in C. Sanandaj and C. Sulemaniyya, e.g. tam- $<$ tam $<$ q $\underline{\text { tam }}<$ qdam 'He went before'. The same shift could be observed in the related preposition "qodām 'before', which has the various reflexes $q a-, k a-, t a$ - and $t a^{-}{ }^{4}$ in NENA dialects. The second etymology, "qym, parallels the possible grammaticalization of the indicative preverb $k$ - from * $q \bar{a}$ eem- 'standing', the original active participle of the same verb, and coincides with variants kəm- $<{ }^{*} q \partial m$ - in, for instance, Christian dialects of the Nineveh Plains. Moreover, Pennacchietti (1994, 269-270, 276-277) maintains that the qam-qațl-preterit spread from the Nineveh Plains in Iraq into the west and northeast of the NENA-speaking area, which could even point to Arabic influence.

None of these suggested etymologies, however, explain why the above construction is favored for the transitive perfective past. Fassberg (2015) is a notable exception and offers the following account. The original $/ \mathrm{m} /$ of the preverb is historically related to the augment of stem derivations II and III. This seems to me a plausible explanation why the distinction between stem I and II verbs, for instance, is neutralized in the qam-qatal-preterit as well as why there is a close link with transitive coding. The initial $/ \mathrm{m} /$ - of derived forms, e.g. II ${ }^{\circ} \mathrm{mpalat}-\varnothing$-la 'He brings her out', coincides with the final $/ \mathrm{m} /$ of the preverb qam-, e.g.

$$
\text { qam + mpalat- } \varnothing-l e=q a-m-p a l a t-\varnothing-l a
$$

The preverb qam, therefore, serves as a transitivizer alongside a preverbal TAMmarker, since the original transitivizer $m$ - would have been extended through analogy to stem II verbs to the transitive verbs belonging to stem I. It extended in this particular construction, presumably because of their matching vowel templates, e.g.

$$
\begin{array}{llll}
\text { II }{ }^{\circ} m p a l a t ̦-l a & : & \text { I } & \circ \\
\text { II } & q a \text { ațal-la, } \\
&
\end{array}
$$

2 See Maclean (1895, 82), Rubin (2005, 34), Khan (2008a, 8o).

3 See Pennacchietti (1997), Fassberg (2015), Khan (2021).

4 Possibly through misperception even țla- < $q \underline{d} \bar{a}<{ }^{*} q \underline{d} \bar{a} m$. 
Be that as it may, the cross-dialectal distribution and morphosyntax of qamqatal-le as a transitive perfective past construction, which are further discussed in $\S 4.4 .5$, have important repercussions for how one understands the alignment in these dialects.

\subsubsection{Prepositional Object Marking}

In dialects in the west and north of the NENA-speaking area, it is common for speakers to employ prepositional object pronouns instead of or alongside the aforementioned qam-qațal-preterit, ${ }^{5}$ e.g.

\section{(3) C. Upper Ṭyari (Walțo, SE Turkey; Talay 20o9, 34.12) pram-le 'all-e did-e slaughter ${ }_{{ }_{\mathrm{PFV}}}-\mathrm{A}: 3 \mathrm{MS}$ OBJ-3MS POss-3MS 'He killed him.'}

Apart from ('al)l-, these prepositions are often the same as the marker of goals or recipients, such as $q a(d)$ - 'to, for' in (4) below, characteristic of Christian dialects in Iranian Azerbaijan. An unusual preposition is (5) ('ab)b- 'in, at; with; against' found in a few Judi dialects (SE Turkey) and in Hakkari, presumably also derived from its goal marking function 'at', as it is used in ditransitives, for example, in C. Lewen, SE Turkey (Talay 2009, 112.37). Prepositions can be extended with the linker $d$ - or the independent possessive pronominal base did- or diyy- depending on the dialect, e.g. $q a-d i y-{ }^{+} u x$ in (4).

(4) C. Sardarid (NW Iran; Younansardaroud 2001, 205, 232.4, transcription modified)

may $x z i-l a \quad q a-\mathbf{d i y}^{-}{ }^{+} \boldsymbol{u x}$

who see $_{\mathrm{PFv}}-\mathrm{A}: 3 \mathrm{MS}$ OBJ- LK-2MS

'Who saw you $_{\mathrm{Ms}}$ ?' (lit. Him saw to-you $\mathrm{Ms}_{\mathrm{M}}$ )

(5) C. Gaznakh (SE Turkey; Gutman 2015, 315, glossing adapted) nšiq-li biy-ux

kiss $_{\mathrm{PFV}}-\mathrm{A}: 1 \mathrm{SG}$ ОВJ-2MS

'I kissed уои $_{\mathrm{Ms}}$ ' (lit. Me kissed at-you ${ }_{\mathrm{Ms}}$ )

5 This is similar to the Trans-Zab Jewish varieties, see $§$ 3.1.2.2. 


\subsubsection{Primary and Secondary L-suffixes $\left(\mathrm{L}_{2}\right.$-sets $)$}

The at least originally independent prepositional pronouns can become increasingly dependent on the verbal base qțil- and end up as a dependent series. The ('al)l-series usually attach to a preceding verbal form, e.g.

\begin{tabular}{|c|c|c|}
\hline & {$\left[\begin{array}{lll}\mathrm{V} & \mathrm{A} & \mathbf{P}\end{array}\right]$} & \\
\hline C. Asitha ${ }^{6}$ & $\begin{array}{l}\text { xzé -le -llan } \\
\text { 'He saw us.' }\end{array}$ & $<\quad x z e-l e+$ 'all-an \\
\hline C. Upper Tyari ${ }^{7}$ & $\begin{array}{l}x z e ́ \quad-l i \quad-l l \varepsilon h \varepsilon \\
\text { 'I saw them.' }\end{array}$ & $<\quad x z e-l i+{ }^{\prime} a l l-\varepsilon h \varepsilon$ \\
\hline
\end{tabular}

The resulting dependent person markers can become morphologically indistinct from L-suffixes in numerous dialects, except for the third persons, where a distinction may be observed, for instance in the dialects of the Hakkari province, ${ }^{8}$ e.g. (Talay $2011,5^{6-57}$ ) respectively:

$\begin{array}{llll} & {[\mathrm{v}} & \mathrm{A} & \mathbf{P}] \\ \text { (most) } & x z e ́ & -l e & -l e \\ \text { Upper Barwar } & x z e ́ & -l e & -l u \\ \text { Țal } & x z e ́ & -l e & -l e w \\ \text { Baz } & x z e ́ & -l e & -l o v\end{array}$

Where the respective allomorphs of the secondary $\mathrm{L}_{2}$-suffixes are identical to the primary $\mathrm{L}_{1}$-suffixes, I will treat these as an instance of a single set of $\mathrm{L}_{\mathrm{1}^{-}}$ suffixes. This stacking of L-suffixes, discussed further in $\S$ 4.4.3. will thus be treated as a construction distinct form the prepositional pronominal objects.

\subsubsection{The Copula and Compound Veral Forms \\ 4.1.2.1 The Copula}

The form and syntax of the copula is highly diverse across these varieties of NENA. In contradistinction to the Trans-Zab Jewish varieties, the basic copula is often mobile and does not occupy a fixed clause-final or post-predicate position. The forms vary considerably across the NENA dialects, as illustrated in (6).

6 SE Turkey, Borghero $(2006,193)$.

7 Walțo, SE Turkey, Talay (2009, 34.19).

8 This also applies to some SE Trans-Zab Jewish dialects such as Saqiz, see § 3.1.2.2. and § 3.3.1.2. 
(6) The basic copula

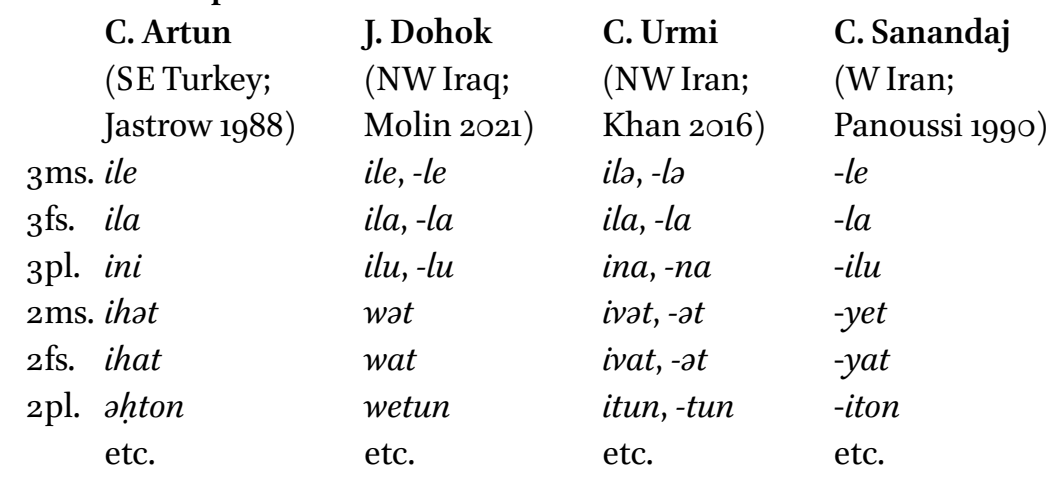

Reduced variants of these forms can become identical to the L-suffixes and Esuffixes, respectively. The ramifications of this for the alignment in indicative present clauses has not been addressed in the literature, but deserves further investigation. In some dialects, such as Jewish lishana deni varieties, the third person copula forms can be morphologically identical to the L-suffixes, but remain distinct only by not affecting the stress of their host. Compare J. Dohok góra-le 'He is a man', which is góra 'man' without the copula, and 'gor-á-le 'she marries him', which is gór- $a$ 'she marries' without the L-suffix. ${ }^{9}$ Molin (2021), who- as far as I am aware-is the only one who has raised this issue so far, points out that third person subjects of such intransitive clauses, i.e. -le 'he is', is expressed in a similar way to the object of corresponding transitive clauses, i.e. -le 'him', both expressing the indicative present. Christian dialects in NE Iraq in particular, such as Hawdiyan, have a pre-predicate /1/-copula identical with the L-suffixes, e.g. C. Hawdiyan le 'atya 'He has come'.

Khan (2001, 2012) maintains the NENA third person copula forms that betray an /1/-element are diachronically related to the L-suffixes via a presentative construction * $\bar{\imath}-l e$ 'behold, him, ${ }^{\prime}{ }^{10}$ where $\bar{\imath}$ is a fossilized 3 fs. pronoun, e.g. *hi 'she', as in the deictic copulas like hawle 'here he is' < "hä-'aw-le 'behold that, him. Other scholars (Retsö 1987, 220; Rubin 2005, 45) trace 'ile 'he is' back to *it $\underline{t}$ - 'there is'll and *-le 'to him', similarly to the predicative possessor 'at-le 'he

\footnotetext{
9 Contrast with Ṭuroyo gáwro-no ' $\mathrm{I}_{\mathrm{M}}$ am a man' and 'goráš-no-le ' $\mathrm{I}_{\mathrm{M}}$ pull him'.

10 It seems plausible to me that the third person plural forms in some NENA varieties, such as $-n i$ in C. Artun (Hertevin, SE Turkey), are ultimately cognate with Țuroyo -ne, both going back to a third person pronoun, and not presentative/deictic.

11 This existential used to inflect for person, gender and number by means of pronominal suffixes in Syriac, e.g. 'it-ēh 'she is', cp. nehz-ēh 'he may see her'. This etymology certainly holds for Țuroyo kat-in the relative copula, e.g. $d$-kat-yo 'that he is' $<{ }^{*} d-k i t$ 'that there is'
} 
has' This etymology is reminiscent of the verb-like expression of ability in several dialects, which would have undergone the same phonetic development, e.g. 'ibe 'he is able' < *it- 'there is' and *-be 'in him.'.2 In some dialects, such as C. Peshabur, the past third person copulas are almost identical to the inflection of the predicative possessor, compare wā-le 'he was' and lay-wā-le 'he wasn't' with 'at-wā-le 'he had' and lat-wä-le 'he hadn't' (Coghill 2013, 44-45).

Furthermore, according to Khan, the $/ \mathrm{w} /$ or $/ \mathrm{y} /$-elements in at least the first/second persons in NENA possibly betray relics of the pronouns * $h u$ ' $h e^{\prime}$ or * $h i$ 'she'. It cannot be excluded, however, that the variation in the respective dialects may simply have developed via different strategies that resolve hiatus in the spread of the initial ' $i$ - to the entire paradigm, as for instance in the second person forms:

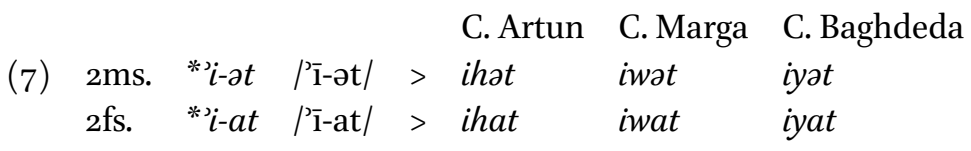

This is similar to the spread of the initial /'a/ to the entire paradigm of independent pronouns in analogy to isg. 'ana, compare:

\begin{tabular}{|c|c|c|c|c|c|c|}
\hline & & & 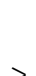 & C. Artun & C. Marga & C. Baghdeda \\
\hline $2 \mathrm{fs}$. & ${ }^{*} a-a t$ & /'ā-at/ & $>$ & 'ahat & 'ayat & 'ahat \\
\hline
\end{tabular}

The initial vowels, i.e. /i/ for the copula and /a/ for the equivalent independent pronoun, incidentally serve to inflectionalize pronouns, where the initial vowel can be considered a base with suffixes, e.g. i-hat, 'a-hat. Glides that are inserted to resolve a hiatus can vary between $/ \mathrm{y} /$ and $/ \mathrm{w} /$ elsewhere in Northeastern and Central Neo-Aramaic dialects as well as in Kurdish (Hasan and Rasheed 2016). In C. Borb-Ruma (Bohtan, SE Turkey; Fox 2009, 23) the sequence /oə/ even fluctuates between oha, oya and owa, e.g.

(9) Borb-Ruma (Bohtan, SE Turkey; Fox 2009, 23)

2ms. *a-at $\mid$ ā-at/ > ohat oyat owat

and yo 'he', which contains the same original existential kit 'there is' as the predicative possessor, e.g. kat-le 'he has'.

12 Similarly, Țuroyo ki-be 'I am able' < *kitt-be. 
A historical connection with the verb hwy 'be' cannot be altogether excluded, however. The analogy to this verb arguably played a role in the inflectionalization of prononominal copulas, which was facilitated by the phonetic correspondence of $/ \mathrm{w} /$ to the second radical of $h w y$ (Khan 2001 and elsewhere). We cannot preclude that past tense copula forms like C. Marga wewa 'He was', wiwa 'They were', which inflect like 'be', i.e. hawewa, hawiwa, respectively, could have been derived directly from this verb; similarly, the negated copulas, such as C. Marga lawe 'he is not', lawi 'they are not', are presumably derived from the verb 'be' le hawe, le hawi, respectively.13

Finally, the first and second person forms of the basic copula can also be phonetically reduced with loss of the glide, resulting in forms that closely approximate the E-set, as illustrated below for C. Barwar. Such allomorphs of the copula will be referred to as secondary E-suffixes or $\mathrm{E}_{2}$-set. When they are identical to the primary E-suffixes, it becomes debatable whether they still comprise a distinct set.

(10) C. Barwar (NW Iraq; Khan 2008a, 181-182)

$\begin{array}{llll} & \text { BASIC COPULA } & \text { SHORT COPULA } & \text { E-SET } \\ \text { 1ms. } & -i w a n & -i n,-\varepsilon n & -\partial n \\ \text { 1fs. } & -i w a n & -i n,-\varepsilon n & -\partial n \\ \text { 1pl. } & -i w a x & -i x,-\varepsilon x & -\partial x\end{array}$

\subsubsection{Compound Verbal Forms}

Contrasting with Trans-Zab Jewish varieties of NENA, simplex and compound verbal forms follow the same pattern in the majority of NENA dialects. Jewish dialects to the west of the Greater Zab river, for instance, group s and A both in the simplex form based on qtil-, i.e. the preterit, and in compound forms based on qtila, i.e. the compound perfect. The same holds for the majority of Christian dialects, although, here, the copula freely cliticizes to the resultative participle. Compare the following ims. forms of the $q-y-m$ 'rise' and $g-r-\check{s}$ 'pull':

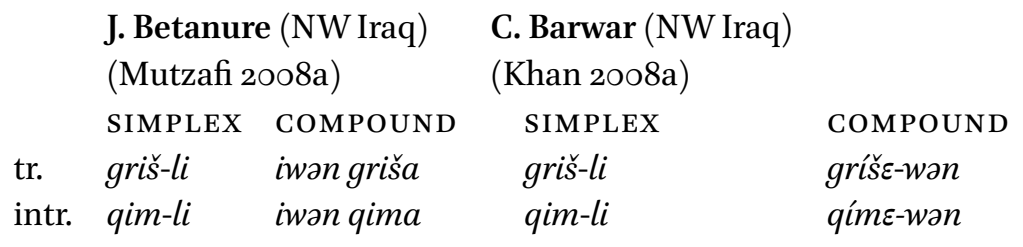

13 Similarly, the Turoyo 3sg. form -yo presumably arose in analogy to its past pendant -wo 'he/she/it was' < *hwo 'he was', a direct reflex of the 3ms. suffix-conjugation of $h w y$. 
The deictic and relative copula never cliticize, so that the compound verbal forms for C. Barwar in (10) above correspond to the following constructions using the deictic copula. The enclitic copula forms can also be phonetically reduced, ending up identical with the E-set, illustrated for C. Barwar below.

(12) C. Barwar (NW Iraq; Khan 20o8a)

$\begin{array}{llll} & \text { BASIC } & \text { SHORT } & \text { DEICTIC } \\ \text { tr. } & \text { gríš-wan } & \text { griš-ən } & \text { holigriša } \\ \text { intr. } & \text { qíme-wan } & \text { qim-ən } & \text { holiqima }\end{array}$

A discussion of the manifold ways whereby pronominal objects can be expressed in these compound verbal forms can be found in $\S 2.2 .5$. The fact that a NENA dialect uses one strategy in the compound verbal form, i.e. the compound perfect, does not entail that it uses the same strategy in the simplex verbal forms, i.e. the preterit, and vice versa. Thus in C. Marga, illustrated below, the compound verbal form combines with the 'all-series, but this is not attested for the simplex form.

(13) C. Marga (SE Turkey)

SIMPLEX COMPOUND

tr. griš-ux-le 'He pulled us.' hole griš-allan 'He has pulled us.' intr. qam-le 'He rose.' hole qima 'He has risen.'

The deictic copula can also be combined with forms based on qtil- and develop into the expression of the perfect, similarly to the compound verbal forms based on the resultative participle. Thus Western, Eastern and Southeastern Christian dialects as well as Jewish Barzani and Western Trans-Zab Jewish dialects use a preverbal TAM-marker to indicate a distinction between preterit and perfect, such as hule in C. Hașanan ${ }^{14}$ and gi- in C. Sanandaj below. Forms like hule go back to a fossilized third person form of the deictic copula. ${ }^{15}$

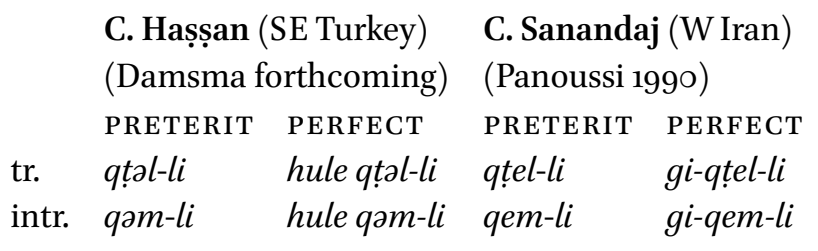

143 fs. and 3pl. can still optionally show agreement, e.g. hule $\sim$ huna grəš-na 'They have pulled' (Damsma forthcoming).

15 Similarly to $l \bar{a}$ in J. Arbel, Ruwanduz and Rustaqa, and $n \bar{a}$ in J. Dobe, see $§ 3 \cdot 4 \cdot 2-3 \cdot 4 \cdot 3$. 
The majority of dialects patterns like the above, where simplex and compound verbal forms, i.e. preterit and realis perfect, are neatly symmetric in $\mathrm{S}$ and A-marking.

\subsubsection{Prepositional Marking of Agents}

Another important contrast with the Trans-Zab Jewish varieties is that a few dialects in Northwest Iraq and Southeast Turkey can employ the preposition ('al)l- and its allomorphs to introduce the agent. This can be used only when the agent is not additionally expressed by the L-suffixes in the preterit or the copula in the compound perfect. By way of illustration, the following alternation in (15) shows the correspondence of A in (15a) expressed by the L-suffix to the agent expressed by the preposition 'all-in $(15 b)$.

\section{(15) C. Azakh (NW Iraq) \\ a. dewa $\begin{array}{llll} & -i & -l e\end{array}$ wolf:MS- eat ${ }_{\mathrm{PFV}}-\mathrm{P}: 3 \mathrm{PL}-\mathrm{A}: 3 \mathrm{MS}$ \\ 'The wolf ate them.'}

b. 'arwe xil $-i \quad$ 'all-ew

sheep:PL eat ${ }_{\mathrm{PFV}}-3$ PL DAT-3MS

'The sheep have been eaten by $i_{M}$ (i.e. the wolf).'

Constructions like $(15 \mathrm{~b})$, which betray relics of a former historical relationship between the L-suffixes and the preposition $l$-, are not common to all NENA dialects. As far as we can tell from the dialects thus far documented, those NENA dialects that have constructions like $(15 \mathrm{~b})$ in their repertoire always mark $s$ and A by means of L-suffixes. On the other hand, constructions like (15b) do not occur in the Trans-Zab Jewish varieties of NENA.

Some dialects may allow the same alternation only in a compound verbal form, e.g.

(16) C. Mar Yaqo (NW Iraq)

'arwa haydo-le xila l-dewa

sheep:Ms DEIX-3MS eaten:MS DAT-wolf:Ms

'The sheep has been eaten by the wolf.'

This obviously raises questions about the status of the patient and agent in these constructions and their relationship to the passive voice, to which we turn in the following section. 


\subsection{Ergative or Passive? Agents in and out of Focus}

Doron and Khan (2012) argue that the dialects that group S and A by means of the L-suffixes still manifest a type of ergativity called 'extended ergative.' ${ }^{16}$ Their main argumentation is that the syntactic and morphological markedness of the L-set point to traces of an earlier ergative type, similarly to the Southeastern Trans-Zab Jewish varieties.

An agentless preterit or qțil-form ${ }^{17}$ occurs sporadically in dialects in Northwest Iraq and Southeast Turkey, which is reminiscent of the passive, e.g.

(1) a. xabuše xil-i-le

apple:PL eat ${ }_{\mathrm{PFV}}-\mathrm{P}: 3 \mathrm{PL}-\mathrm{A}: 3 \mathrm{MS}$

'He ate the apples.'

b. xabuše $x i l-i(-\varnothing)$

apple:P L eat ${ }_{\mathrm{PFv}}-3 \mathrm{PL}$

'The apples were eaten.'

Moreover, third person enclitic copulas may also be omitted entirely, so that the participial inflection is the only remaining agent or subject coding in compound perfects (Khan 2008a, 669-671), for example:

(2) C. Barwar (NW Iraq; Khan 2008a, A31:4)

qtil-a xá-neriye

killed:RPP-Ms a-goat:Ms

'The male goat has been killed.'

lit. ' $\mathrm{X}$ (is) killed a goat'

In addition, the agent can be introduced by the dative preposition ('al)l- 'to, for', which is comparable to agent complements in passives. The same kind of predicate in (2), for instance, is compatible with agent complements, such as

(3) C. Barwar (NW Iraq; Khan 2008a, A23:15)

xmare ho-la xil-e l-dewe

donkey:PL DEIX-A:3FS eaten-A:PL DAT-wolf:PL

'The asses have been eaten by wolves.' (ibid. A23:15)

16 Cf. Mengozzi (2002b, 45, fn. 144), Barotto (2015) and Khan (2017).

17 See Gutman (2008). 
After a study of the morphological markedness of these constructions in such dialects, we examine the possible omission of the L-set and copula. We will discuss these agentless verbal forms in relation to ergativity and the passive voice along a continuum (Comrie 1988) and in the light of passive and anticausative voice constructions in NENA. In leaving the agent unexpressed, the question arises whether the construction is morphosyntactically still transitive or not. ${ }^{18}$ Is the patient-like argument in (1) and (2) an instance of $S$ or P? After having decided on that, we can address the question whether this should be analyzed as either ergative or passive, and in case we cannot decide, this phenomenon might not be classifiable using these categories.

\subsubsection{The Importance of Zero}

\subsubsection{Typological Markedness}

In linguistic typology, alignment patterns are further distinguished by overt vs. zero marking. ${ }^{19}$ Various scholars ${ }^{20}$ have argued that the ergative and accusative alignment systems each have their own unmarked case, which often has no overt nominal marking.

Functional typologists presuppose symmetric or asymmetric functional relationships between form and function. When at least one of the arguments in the transitive counterpart, i.e. $\mathrm{A} / \mathrm{P}$, is treated similarly to $\mathrm{S}$, the relation between form and function is symmetric for an alignment system, where the morphologically and functionally unmarked properties of the form associated with $\mathrm{s}$ also apply to the argument, i.e. $\mathrm{A} / \mathrm{P}$, with which it is morphosyntactically grouped. ${ }^{21}$ There are, however, also divergent patterns that lead to asymmetry, which are considered 'marked'.

The unmarked case is expected to be the nominative $(\mathrm{s}=\mathrm{A})$ for an accusative case system and the absolutive $(\mathrm{s}=\mathrm{P})$ for the ergative counterpart. Functionally, the unmarked case, i.e. nominative/absolutive, is used as the citation form, is more likely to be obligatory and express the topic of equational sentences, while the marked case, i.e. accusative/ergative, is more likely to be optional and have various additional functions, such as temporal or locative expressions or marking of goals or instruments (Dixon 1994; cf. Handschuh 2015). Formally, if an argument involves zero nominal coding, i.e. $\varnothing$, this is most likely the one grouped with s, i.e. nominative/absolutive, since it is more economical to overtly mark the isolated role (Comrie 1978).

\footnotetext{
18 Cf. Keenan and Dryer $(2007,330)$.

19 See Dixon (1979, 1994), Croft (1988, 2001, 138-146).

$20 \quad$ See inter alia Tsunoda (1981), Comrie (1989), Lazard (1998).

21 This does not apply to tripartite $(S \neq A \neq P)$ or horizontal alignment $(S \neq A=P)$.
} 
TABLE 22 Zero vs. overt case coding in the accusative type

\begin{tabular}{|c|c|c|c|}
\hline & $\begin{array}{l}\text { Nominative } \\
(\mathrm{S}=\mathrm{A})\end{array}$ & $\begin{array}{l}\text { Accusative } \\
(\neq \mathbf{P})\end{array}$ & Gloss \\
\hline Classical Arabic & bayt-un & bayt-an & 'a house' \\
\hline Gə`əz & bet- $\varnothing$ & bet- $a$ & 'house' \\
\hline Harar Oromo & sárée-n & sáréé- $\varnothing$ & ‘dog’ \\
\hline
\end{tabular}

SOURCE: FOLLOWING TABLE 4.3 IN CROFT $(2001,139)$. HARAR OROMO DATA FROM COMRIE $(2005,398$, ORIGINAL SOURCE CITED THEREIN)

TABLE 23 Distribution of zero vs. overt case coding in the ergative type

\begin{tabular}{|c|c|c|c|}
\hline & $\begin{array}{l}\text { Absolutive } \\
(\mathrm{s}=\mathbf{P})\end{array}$ & $\begin{array}{l}\text { Ergative } \\
(\neq \mathbf{A})\end{array}$ & Gloss \\
\hline Tongan & 'a he talavou & 'e ha talavou & 'a young man' \\
\hline Yup'ik & nuna- $\varnothing$ & nuna-m & 'land' \\
\hline Nias & n-asu & $\varnothing$-asu & ‘dog’ \\
\hline
\end{tabular}

SOURCE: TABLE FROM CROFT (2OO1, 140), SLIGHTLY ADAPTED, AND NIAS DATA FROM HANDSCHUH $(2015,31$, EMPHASIS MINE, ORIGINAL SOURCES CITED THEREIN)

Table 22 offers examples from Classical Arabic and Gəəəz, i.e. Classical Ethiopic, which both have an accusative case system. The nominative and accusative may be equally unmarked formally, as displayed for Classical Arabic. The formally unmarked case in Gə`əz is the expected nominative. The reverse situation would be a marked nominative, a distinct subtype of accusative alignment, where P lacks overt coding and is used in citation. Comrie (2005, 398) offers an example from Harar Oromo, i.e. Cushitic, Ethiopia, represented schematically in the last row of Table 22.

This would be exactly the reverse in an ergative case system, illustrated by Tongan (Polynesian, Tonga) and Yup'ik (Eskimo, Alaska) in Table 23. The accusative and ergative alignment types are mirror each other in terms of markedness. Marked absolutive is thus far only found in Nias (Malayo-Polynesian, Indonesia), illustrated by the last row in Table 23, where it is the A that lacks overt coding and is used in citation (Handschuh 2015, 31). 
TABLE 24 Marked intransitive/transitive alignment types

\begin{tabular}{l|cc|c|cc|c}
\hline \multirow{2}{*}{} & \multicolumn{3}{|c|}{$\begin{array}{c}\text { MARKED } \\
\text { NOMINATIVE }\end{array}$} & \multicolumn{3}{c}{$\begin{array}{c}\text { MARKED } \\
\text { ABSOLUTIVE }\end{array}$} \\
\cline { 2 - 6 } & S & A & P & P & S & A \\
\cline { 2 - 5 } NOMINAL MARKING & $\mathrm{m}$ & $\mathrm{m}$ & $\mathrm{O}$ & $\mathrm{m}$ & $\mathrm{m}$ & $\mathrm{O}$ \\
VERBAL PERSON MARKING & $\mathrm{O}$ & $\mathrm{O}$ & $\mathrm{m}$ & $\mathrm{O}$ & $\mathrm{O}$ & $\mathrm{m}$ \\
\hline
\end{tabular}

Markedness in verbal person marking is defined in terms of trigger potential and possible zero realization. ${ }^{22}$ It is the presence of a person marker that correlates with the least marked argument. $P$ is not overtly expressed in accusative verbal person marking, while A is not overtly expressed in ergative verbal person marking. In Classical Arabic, for example, full nominal ps do not trigger cross-indexing. In Gəcəz, indexing of full nominal ps is conditioned, i.e. differential, while indexing of $S$ and $A$ is obligatory.

Conversely, obligatory indexing of A, but optional verbal person marking of $\mathrm{P}$ and $s$ would be marked in an ergative agreement system. In phonological form, the set of indexes that more likely includes zero morphemes is $\mathrm{S}$ and $\mathrm{A}$ in the accusative type and $\mathrm{S}$ and $\mathrm{P}$ in the ergative type. Thus if indexing of $\mathrm{P}$ does occur, zero morphemes would be marked for the accusative grouping, while zero morphemes in the set of agent indexes would be marked in the ergative counterpart.

The marked patterns are given in Table 24 above, where 'o' represent the absence and ' $m$ ' the presence of overt marking (following Haspelmath $2005 \mathrm{~b}$ ).

It is the argument that is not grouped with s in marked systems that has zero nominal marking, but greater trigger potential for verbal person marking. One can observe how, strictly in terms of markedness, the P of the marked nominative exhibits the same properties as the $\mathrm{P}$ of the ergative and the $\mathrm{A}$ of the marked absolutive the same as the A of the accusative (both are outside of the gray area). In this sense, the marked alignment types are neither typically accusative nor typically ergative. The groupings, however, are clearly identifiable, and, for this reason, one tends to subsume 'marked nominative' as

22 See Dixon (1994, 67-68), Croft (1988, 2001, 140-141). 
a subtype under accusative alignment $(\mathrm{A}=\mathrm{S} \neq \mathrm{P})$ and 'marked absolutive' under ergative alignment $(\mathrm{A} \neq \mathrm{S}=\mathrm{P})$.

\subsubsection{Ergative-Like Markedness in NENA?}

In line with Dixon (1979), Doron and Khan (2012, 231-233) analyze the verbal person marking as given for dialects such as Jewish Challa and 'Amedia as 'extended ergative'. Relative markedness plays an important role in Dixon's $(1979,1994)$ approach to ergativity. In his view, P is ideally most marked in accusative systems, and A in ergative systems. Dixon (1979) introduced the term "extended ergative" to describe a case system, where the case-marker of a may be extended to all instances of $s$ against $P$ that is functionally and morphologically the default form. ${ }^{23}$

(4) J. Challa (SE Turkey; Fassberg 2010)

a. nšiq $\quad-a \quad-l e$

(transitive)

see $_{\mathrm{PFV}}-\mathrm{P}: 3 \mathrm{FS}-\mathrm{A}: 3 \mathrm{MS}$

'He saw her.' (lit. Him saw she)

b. $d \max \quad-l e$

(intransitive)

sleep $_{\mathrm{PFV}}-\mathrm{S}: 3 \mathrm{MS}$

'He went to sleep.' (lit. Him slept)

Here P (i.e. the E-set) is less marked, while $\mathrm{S}$ is more marked like A (L-set). Similarly, Mengozzi (2002b, 45, fn. 144) refers to this pattern as theoretically "post-ergative", although he admits "it cannot be regarded as ergative in itself". Thus, the notions of 'post-ergative' or 'extended ergative' are mainly diachronically motivated and presumes that these dialects were once ergative, but have extended the L-suffixes that mark the agent to all intransitive verbs, thereby aligning A with s. Barotto (2015) suggests that we could also consider the type of inflection in these dialects a kind of 'marked nominative'.

Later on, Dixon (1994, 64) preferred the less confusing label "marked nominative" over "extended ergative", because the morphological distinction between $\mathrm{S}$ and $\mathrm{P}$ is clearly not typical of an ergative type. Moreover, $\mathrm{P}$ need not be unmarked, even when a formally ergative case-marker of A extends to s. For example, in the upper dialect of Waxi, an Iranian Pamir language described by Payne (1980, 180-181), the special marker of A not only extends to s, but P also has developed a dedicated case marker.

23 Cf. Payne (1980) for parallels in Eastern Iranian. 
Synchronically, anything related to 'nominative-accusative' is preferable to 'extended ergative' or 'post-ergative' to characterize this system. The obvious reason for this is that the defining characteristic of an ergative system, namely that $\mathrm{S}$ and $\mathrm{P}$ are somehow treated alike, is not observed. ${ }^{24}$ Adopting the term 'ergative', then, is rather misleading, at least from a synchronic perspective.

Moreover, it is often overlooked that Dixon (1994, 67-68) first and foremost applies these markedness principles to nominal marking and is reluctant to extend this to verbal person marking. For, as explained in the previous subsection, if $\mathrm{P}$ has less or no trigger potential for overt agreement as opposed to $\mathrm{s}$ and $\mathrm{A}$, this is considered typical of accusative agreement. The reverse holds for a 'marked nominative' agreement system where $\mathrm{S}$ and $\mathrm{A}$ are not overtly indexed, but only P is. It is clear that these NENA dialects are typically accusative in this respect, since they exhibit differential object indexing $(A=S \neq P)$. It is the indexing of $P$ that is more restricted and context-dependent against the indexing of A and $\mathrm{s}$, which is also morphosyntactically grouped by means of the same set. These dialects, then, cannot be considered 'marked nominative' in this sense.

There is only one respect they could be: at the same time, Dixon $(1994,68)$ considers the paradigm that has most zero realizations an unmarked instance of the expression of s. Cross-linguistically, it is third person (singular) agreement marking that tends to be zero, especially in $\mathrm{S}$ and A role (Siewierska 2004, 24,2005 ). This would be the $3 \mathrm{~ms}$. form of the E-set in NENA, which expresses $P$ in the preterit in these dialects. Remarkably, the phonologically identical form is used for the inflection of intransitive verbs. Thus, this agreement system is only arguably 'marked nominative' in terms of possible zero realizations, since the L-set has no equivalent zero morpheme, e.g. J. Challa (SE Turkey; Fassberg 2010)

grəš- $\varnothing$-le 'He pulled him.' : dmax-le 'He slept.' $x z e-\varnothing-l e \quad$ 'He saw him.' : se-le 'He came.'

What is clear, however, is that ergativity in the strict sense of argument groupings $(\mathrm{A} \neq \mathrm{S}=\mathrm{P})$ does not characterize the pattern in (4) above.

24 Cf. Hoberman (1989, 91, fn. 2). See also Coghill (2016, 61-62) who arrives at a similar point of view. 
Prototypical passive Prototypical ergative

a) Subject properties The patient has all or at least The patient has no or at least of the patient more behavioral properties of $\mathrm{s}$ than the agent

b) Integration of the The agent is indexed by the verb agent in clausal or obligatorily expressed to no, a syntax minimal or at least lesser extent

c) Relative marked- Non-basic voice: less frequent, ness less productive, more complex, and more restricted. fewer behavioral properties of $s$ than the agent

The agent is indexed by the verb or obligatorily expressed to a maximal or at least greater extent Basic voice: more frequent, more productive, less complex, and less or not restricted.

BASED ON COMRIE (1988)

\subsubsection{On Agent (De)focusing and Passive Typology}

\subsubsection{Passive-Ergative Continuum}

Constructions can be characterized in terms of a continuum and considered passive-like or ergative-like. Comrie's (1988) criteria for the passive-ergative continuum are paraphrased in Table 25 above. The criteria allow for intermediate cases. Which criterion has greater weight, must be weighed on languageinternal grounds. ${ }^{25}$ Moreover, they are not sufficient conditions for considering a construction passive- or ergative-like, but rather constitute a continuum. That is, we do not always have to decide whether a construction is ultimately either passive or ergative; it could just as well be somewhere in between. The criteria are treated briefly below in the reverse order c)-a).

Generally speaking, a voice opposition is a requirement for a passive, as entailed by criterion c). In terms of voice, the passive is "less frequent, functionally specialized, not fully productive" vis-à-vis the active counterpart (Haspelmath 1990, 27). An ergative construction, being transitive, functions similarly to the active voice of an accusative type. ${ }^{26}$

25 From a diachronic point of view, the criteria may be ambiguous as well. For example, if the ergative transitive construction is ultimately passive in origin, there may well have been a point where c) the markedness opposition was lost.

26 s-like behavioral properties, such as equi-NP deletion of P in languages like Dyirbal, are rather passive-like, but irrelevant to languages where ergativity is only manifested morphologically and not in syntactic behavior. See Keenan and Comrie (1977), Comrie (1988, 
The passive voice itself has not been uncontroversial, but it is generally characterized in terms of prototypicality, i.e. a relative degree of passive-likeness, ${ }^{27}$ which includes a special intransitive verbal form (Keenan and Dryer 2007). The main pragmatic function is said to be to defocus the agent (Shibatani $1985,2004,2006,248$ ) as a result of inactivization (Haspelmath 1990). Crosslinguistically, the passive is a rather infrequent phenomenon (Siewierska 1984, 23), and its functional distribution differs widely across languages.

Nevertheless, interestingly, from a purely constructional perspective, passives are a rather uniform phenomenon. The subdued agent shifts in argument status from a core argument (A) to a peripheral one (OBL) or complete omission, while the patient is the $S$ of the passive (Haspelmath 199o, 27). ${ }^{28}$ Thus typically, in a passive construction, the $P$ argument of the transitive construction is expressed as $\mathrm{S}$ in the intransitive construction, and $\mathrm{A}$ of the corresponding transitive construction, if expressed at all, is realized as oblique. The passive voice, therefore, is semantically transitive, but morphosyntactically intransitive.

It is the second criterion, however, that allows for most ambiguity. To what extent is the agent dispensable in languages like an oblique argument? The omission of A can still yield well-formed sentences where languages otherwise exhibit an ergative pattern. ${ }^{29}$ Samoan, for instance, allows the absence of agent coding for most transitive verbs, such as 'hit' in (5) below (Mosel and Hovdhaugen 1992,104). The agent of the corresponding active transitive clause is omitted in $(5 \mathrm{~b})$, and the resulting construction is similar to the passive in that an impersonal agent may still be implied. The agent is thereby more loosely integrated in the clause and can be freely omitted and unspecified, much like oblique agents in the passive, but there is no special verbal morphology indicating a voice shift.

(5) Samoan (Polynesian, Samoa; Mosel and Hovdhaugen 1992, 416, 421; glossing adapted)

[V] [ERG $\rightarrow \mathrm{A}][\mathrm{P}]$
a. Sā sasa e le teine $\varnothing$ le le maile.
PST hit ERG the girl ABS the dog
'The girl hit the dog.' (specified agent)

12-15), Givón (1995, 256-267). Cf. Section 2.3. on syntactic ergativity and syntactic behavioral properties.

27 E.g. Givón $(1984,164)$, Shibatani $(1985,2004)$, Payne $(1997,204)$.

28 Cf. Siewierska $(1984,256)$, Dixon $(1994,146)$.

29 Cf. Keenan $(1976,313)$, Comrie (1988, 18-19). 
$[\mathrm{v}] \quad[\mathrm{s} / \mathrm{P} ?]$

b. $S \bar{a}$ sasa $\varnothing$ le le maile.

PST hit ABS the dog

'The dog was hit.' / 'Someone hit the dog.' (unspecified agent)

(lit. Dog hit)

Naturally, the coding is indistinct from the $s$ in intransitive constructions, such as 'fall' in (5c), because of ergative alignment:
[V]
[s]
c. $S \bar{a}$ pa'u $\varnothing$ le teine
PST fall ABs the girl
'The girl fell.' (Mosel and Hovdhaugen 1992, 108)

Alternations of the kind in $\left(5^{a}\right)$ and $\left(5^{b}\right)$ would be a type of referential reduction of the agent, i.e. unspecified agent deletion, where possibly some impersonalization of the agent is intended.

Some properties of the transitive counterpart, however, are retained in intransitivization. This is generally true for impersonal subject or unspecified agent constructions that are similar to passives. Languages may employ a nonreferential dummy subject, such as German man or French on, instead of a passive. Alternatively, the active verbal form and the coding of the agent and patient do not change, but the referentiality of A is reduced to a third person morpheme.

Complete omission of the agent (or subject) is also possible, while retaining some of the transitive coding (Givón 1990, 581-583). The unspecified agent is simply omitted or expressed as dummy NP or third person morphology. Ute, a Uto-Aztecan language, allows the agent/subject of any verb to be omitted (Givón 1990, 583). This is distinct from the passive prototype in that $\mathrm{P}$ retains object coding, and the agent cannot be expressed as oblique, for example:

(6) Ute (Uto-Aztecan, United States, Colorado; Givón 1990, 581, glossing slightly modified)

$[\mathrm{A}] \quad[\mathrm{P}] \quad[\mathrm{v}]$

a. ta'wá-ci sivąątu-ci pax̂́á-puga

(active)

man-SUBJ goat-OBJ kill-TENSE

'The man killed the goat.' 

$[\mathrm{A}] \quad[\mathrm{P}] \quad[\mathrm{V}-\mathrm{PASS}]$
b. $\varnothing$ sivąątu-ci pax̂á-ta-puga
(passive) goat-OBJ kill-PASS-TENSE
'Someone killed the goat.' / 'The goat was killed (by someone).'

Givón (1990, 581) shows that (third person) plural agreement of the agent can still be retained in the agentless construction. Some residual reference to the agent is maintained, so that $(5 \mathrm{~d})$ effectively means 'Some persons killed the goat'.
$[\mathrm{A}]$
[P]
$[\mathrm{v}-\mathrm{A}]$

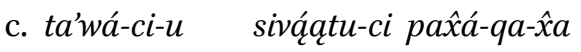
man-SUBJ-PL goat-OBJ kill-PL-TENSE
'The men killed the goat.'
[A] [P] [V-A-PAss]
d. $\varnothing$ sivąátu-ci pax̂á-qa-ta-puga
PL goat-OBJ kill-PL-PASS-TENSE
(passive)
'Some persons killed the goat.'/ 'The goat was killed (by some persons).'

A transitive interpretation with implied third person plural reference is also possible in past tense constructions in Badini Kurdish (Haig 2008, 262-268). In Northern Kurdish, a special so-called 'oblique' case expresses A in the past tense, while the verb agrees with P. In the Badini dialect A can also be omitted, but is contextually recoverable, yielding clauses that are still interpretable as transitive:

(7) Badini (Northern Kurdish, Northwest Iranian; MacKenzie 1962, 320; Haig 2008, 267; glossing modified)

(Ø) $\quad s \bar{e}$ paz kušt-in

(A:PL) three sheep killed-3PL

'They killed the sheep.' / 'Three sheep were killed.'

The possible omission of the agent, therefore, is not a decisive criterion for the distinction between active ergative constructions from passives. Nevertheless, if a language employs ergative agreement, it is the patient that is marked with s-like agreement in both the passive and ergative (Givón 199o, 597-599). When the agent manifests itself in agreement, we more clearly diverge from the passive prototype. Agreement, if obligatory, unifies $\mathrm{S}$ and $\mathrm{A}$, and sets $\mathrm{S}$ and $\mathrm{A}$ apart from other grammatical functions $(\mathrm{P}, \mathrm{T}, \mathrm{R}, \mathrm{OBL})$, where agreement is usually 
optional and sensitive to definiteness, animacy, and other factors relating to prominence.

Thus in both the ergative and passive prototypes, the full nominal agent may be left unexpressed without agreement on the verb. In the passive prototype, the agent typically does not trigger agreement nor is the coding of the patient expected to be sensitive to differential object-like factors. Nevertheless, there are cases where some referential properties of the agent may be retained in impersonal/unspecified agent constructions, which, though defocusing the agent, treat the patient like an object.

\subsubsection{Optional Focal Agent Marking}

Overt nominal marking can also have pragmatic conditions that are the very opposite of the passive, namely agent focalization. Overt and zero nominal marking of A can alternate in a type of optional ergative case marking. Overt nominal marking of A serves to contextualize unexpected arguments pragmatically and tends to be grammaticalized for agent focus and/or inanimate arguments. ${ }^{30}$

Several languages, especially of Australian languages, show special A-marking that is conditioned by role discrimination, animacy and focus. Overt nominal marking is employed to express the unexpectedness of the agent. Thus, the ergative alignment $(\mathrm{A} \neq \mathrm{S}=\mathrm{P})$ is optional and found for the focal counterpart only.

Moreover, Siewierska (2004, 16o-162) observes that some languages may omit verbal person marking of A when A is focal. The Australian language Konjo, for example, employs dependent person markers for A only when it is not in focus, while the focalized A lacks agreement. The indexing of $A$ is absent when A is focalized by means of fronting to preverbal position, and A may be additionally marked ergatively by $i$ - (Friberg 1996, 142-147), for example:

(8) Konjo (Austronesian, South Sulawesi; glossing adapted to Siewierska 2004, 160)

$\left[\begin{array}{llll}\mathrm{A}-\mathrm{V} & -\mathrm{P}] & {[\mathrm{A}]} & {[\mathrm{P}]}\end{array}\right.$

a. Na-kanre - $i \quad$ Amir loka-ku

(unmarked)

$3 \mathrm{~A}^{-}$eat -3s/P Amir banana-1

'Amir ate my banana.' (Friberg 1996, 141)

30 See Givón (1985a), McGregor (2006, 2010), Fauconnier (2011a, 2012), Fauconnier and Verstraete (2014). This can also extend beyond a TAM-based split (Verbeke 2013a). 


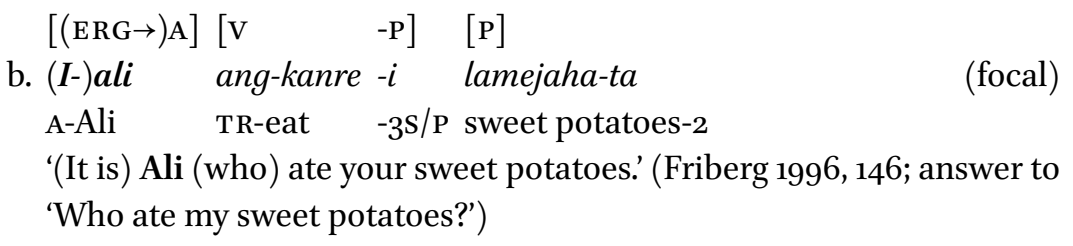

When we turn to NENA, it will become apparent that the passive-intransitive, unspecified agent constructions and optional agent marking are all connected with the agentless preterit, the omission of verbal person marking for A licensing different interpretations and construction types.

\subsubsection{Passive-Like Properties and Anticausatives}

In some languages where ergative morphosyntax predominates (such as Lezgian, Haspelmath 1993a), there is no distinction in verbal morphology between verbs that freely omit the agent and spontaneous events. This also applies to the SE Trans-Zab Jewish varieties of NENA for several weak verbs, but for most verbs a special verbal base is used in the intransitive valence pattern against the transitive, e.g. palt- $a$-le 'He took her out' vs. plit-a 'She went out'. As shown in Section 3.5, these verbal constructions with the E-suffix should be analyzed as inchoative, the E-suffix expressing $\mathrm{S}$, whereas A is expressed by the L-set in the causative counterpart.

In the dialects concerned in this chapter, $\mathrm{s}$ and $\mathrm{A}$ arguments are always treated alike. Verbs generally alternate in valency by means of causativization. The transitive verb is modified by means of a distinct stem derivation of the verbal root, such as $p l t$ 'move out' (stem II against I):

(9) C. Upper Ṭiyari (SE Turkey; Talay 20o9, 6.25)

a. plat-le

(stem I, inchoative)

go.out $_{\mathrm{PFV}}-\mathrm{S}: 3 \mathrm{MS}$

'He went out, left.'

b. mpolt-a-le

(stem II, causative)

II:take.out ${ }_{\mathrm{PFV}}-\mathrm{P}: 3 \mathrm{FS}-\mathrm{A}: 3 \mathrm{MS}$

'He took it ${ }_{\mathrm{F}}$ out.'

A few verbs, such as 'break' and 'open', which are well-known to be labile in languages of the world are also so in NENA (Mengozzi 1998). ${ }^{31}$ The coding of $s$ and A does not diverge for labile verbs, such as 'open', e.g.

Cf. Göransson (2015) and Khan (2016 $: 397-402)$. 
(10) C. Urmi (NW Iran; Khan 2016)

$[\mathrm{s}] \quad[\mathrm{v} \quad-\mathrm{s}]$

a. ${ }^{+}$tarra plax - le

(inchoative)

door:Ms open PFV $-\mathrm{S}: 3 \mathrm{MS}$

'The door opened.'

$[\mathrm{P}] \quad[\mathrm{V} \quad-\mathrm{P} \quad-\mathrm{A}]$

b. ${ }^{+}$tarra plax $\quad-\varnothing \quad-l e$

(causative)

door:MS open ${ }_{\mathrm{PFV}}-\mathrm{P}: 3 \mathrm{MS}-\mathrm{A}: 3 \mathrm{MS}$

'He opened the door.'

A sentence like (10) is thus ambiguous.

Object indexing can serve a discriminatory function in valency alternations for verbs. ${ }^{32}$ The cross-referencing of $\mathrm{P}$ definitively distinguishes between an intransitive or transitive valence pattern. ${ }^{33}$

(11) C. Marga (SE Turkey)

$\left[\begin{array}{lll}\mathrm{v} & -\mathrm{s}\end{array}\right] \quad[\mathrm{s}]$

a. qte $\quad$ la šas-ew

(inchoative)

cut $_{\mathrm{PFv}}$-S:3Fs fever:Fs-his

'His fever stopped.'

$\begin{array}{llll}{\left[\begin{array}{lll}\mathrm{V} & -\mathrm{P} & -\mathrm{A}\end{array}\right]} & {[\mathrm{P}]} \\ \text { b. } q \partial t y & -a & -l e & \check{s} a s-i \\ \text { cut }_{\mathrm{PFV}} & -\mathrm{P}: 3 \mathrm{FS} & -\mathrm{A}: 3 \mathrm{MS} & \text { fever:F S-my }\end{array}$

(causative)

'He stopped my fever.'

If no patient index is present and the gender and number of the patient and agent are identical, only the word order potentially discriminates between the transitive and intransitive valence pattern. In the intransitive valence pattern in (12a) below, the verb follows $\mathrm{s}$. In the transitive valence pattern in (12b), the verb precedes $P$.

(12) C. Barwar (NW Iraq; Khan 2008a, 756)

$[\mathrm{s}] \quad[\mathrm{v} \quad-\mathrm{s}]$

a. bsta tlix -le (inchoative, s-v order)

house:MS destroy ${ }_{\mathrm{PFV}}-\mathrm{S}: 3 \mathrm{MS}$

'The house collapsed.' (lit. The house destroyed)

32 Cf. Mengozzi (2006).

33 Cf. Givón $(1976,168)$. 

$\left[\begin{array}{llll}\mathrm{V} & -\mathrm{P} & -\mathrm{A}\end{array}\right] \quad[\mathrm{P}]$
$\begin{array}{llll}\text { b. tlix } & -\varnothing \quad-l e \quad \text { beta }\end{array}$
destroy $_{\mathrm{PFV}}$-P:3MS -A:3MS house:Ms
(causative, V-P order)
'He destroyed the house.'

A causal phrase may also be added to the inchoative/anticausative verbs and is introduced by the source preposition man- 'from', such as man 'ilāha 'by/because of God' in (13) expressing the cause of lqy 'get punished', intransitive counterpart to transitive stem II lqy 'punish' (Mutzafi 2008a, 36o):

(13) J. Betanure (NW Iraq; Mutzafi 20o8a, 314.571)

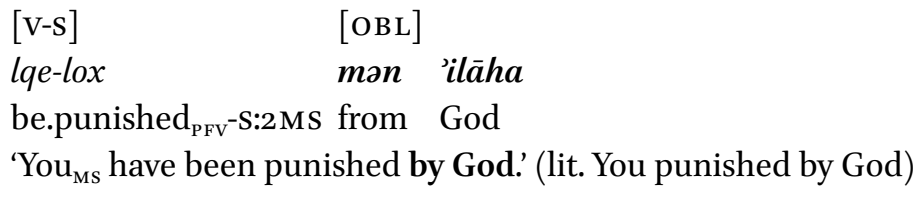

To some extent, rearranging the word order of transitive valence patterns is sufficient to obtain an agent defocusing effect similar to a passive. Thus, postverbal position reduces the salience of the agent, while the preverbal definite patient controls agreement on the verb, e.g.

(14) C. Shaqlawa (NE Iraq)

$[\mathrm{P}] \quad\left[\begin{array}{lll}\mathrm{V}- & -\mathrm{P} & -\mathrm{A}\end{array}\right] \quad[\mathrm{A}]$

urba xil- $-a$-lu dewe

sheep:Fs eat $\mathrm{PFV}_{\mathrm{PF}}-\mathrm{A}: 3 \mathrm{FS}$-P:3PL wolf:PL

'The sheep was eaten by wolves.' (lit. The sheep the wolves ate)

The passive voice is more typically expressed by various dedicated passive voice constructions in NENA dialects. These include:

a) Impersonal 'they' passive

b) Auxiliary 'come' and infinitive ${ }^{34}$

c) Auxiliary 'become' and resultative participle

d) Auxiliary 'be'/copula and resultative participle

Dialects may employ multiple passive voice constructions. Overt expression of the agent is rare, especially in type b) based on the infinitive. If the agent is

34 This is a pattern replication from Northern Kurdish (Badini). In Kurdish, the infinitive is based on a past stem (like Aramaic qțil-) and can have an inherently passive meaning. 
overt, it tends to be expressed by means of several prepositions, particularly ('al)l- which otherwise also marks the recipient, and man 'from', for example:

(15) C. Baghdeda (Qaraqosh, NW Iraq; Khan 20o2a, 383)

[s] [AUX-S RPP-S] [OBL]

pasra pašle xil-a l-kalwa

meat:Ms become $\mathrm{PFV}-\mathrm{S}: 3 \mathrm{MS}$ eaten-MS DAT-dogs

'The meat was (lit. became) eaten by dogs.'

(16) C. Aradhin (NW Iraq; Krotkoff 1982, 106.118)

\begin{tabular}{|c|c|c|c|}
\hline [AUX-S & $\mathrm{v}-\mathrm{s}]$ & [OBL & \\
\hline 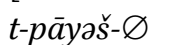 & $d i \bar{s}-a$ & man & anne \\
\hline
\end{tabular}

(17) C. Baz (Maha xtaya, SE Turkey; Mutzafi 200o, 311)

$\begin{array}{llll}{[\mathrm{s}]} & {[\mathrm{RPP}-\mathrm{s}} & -\mathrm{s}] & {[\mathrm{OBL}]} \\ \text { kawdənta } & \text { mxé-ta } & -l a & \mathbf{l}-\boldsymbol{m a} \mathbf{a}-\boldsymbol{a} \boldsymbol{w}\end{array}$

she-mule:FS hit:RPP-S:FS -S:COP:3FS DAT-master:Ms-her

'The she-mule has been (lit. is) beaten by its master.'

The resultative participle agrees with the subject in gender and number. Type d), the copula with resultative participle, is not productive in every dialect, as it has also grammaticalized into a compound perfect. Thus, such forms can have only an agent orientation, ${ }^{35}$ e.g. C. Shaqlawa (NE Iraq),

pașra xil-ele ${ }^{36}$ 'He has eaten meat', not **'The meat has been eaten' (lit. He is eaten meat)

There can be morphological overlap between the prepositional object of the compound perfect and the agent complement of type d) passives. Forms like

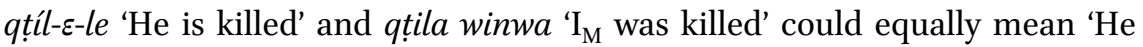
has killed' and ' $\mathrm{I}_{\mathrm{M}}$ had killed' when they combine with a nominal object, for example in C. Ashitha (NW Iraq; Borghero 2006, 176), illustrated below. The orientation of the participle is distinguished morphologically. In the patientoriented, i.e. passive, construction, the copula follows the participle, and the

35 Cf. Khan (2016:403) on C. Urmi.

36 xíl-ele < *xila-ile. 
'all-series denoting the agent remain separate. In the agent-oriented, i.e. active, construction, the 'all-series attaches immediately to the participle, denoting $P$.

(18) C. Ashitha (SE Turkey; Borghero 2005, 334-336)

ACTIVE

[V-P-A]

a. qtíl-alla-le

killed:MS-DAT:3F S-COP:3MS

'He has killed her.'

[V-P]

b. qțil-alle

[A]

killed:MS-DAT:3MS PST:COP:1MS

'I $\mathrm{I}_{\mathrm{M}}$ had killed him.'
PASSIVE

[v-s]

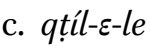

[OBL]

killed-MS-COP:3MS DAT:3FS

'He was killed by her.'

$$
\text { [v-s] [s] }
$$

d. qțil-a winwa

[OBL]

killed-MS PST:COP:1MS DAT:3MS

' $\mathrm{I}_{\mathrm{M}}$ had been killed by him.'

Remarkably, in several other NENA dialects, a construction similar in morphology to (18d) would correspond to the active (see $§ 2.2 .5 .2$ ), e.g. C. Harbole (SE Turkey; Khan personal communication)

holi qțila ’alle 'I have killed him'

The most common type of passive in NENA, however, is the impersonal/unspecified agent construction based on the non-referential third plural. The coding does not change with respect to the active voice, but the referentiality of the agent is reduced by using the $3 p l$. The patient is highly topical. An example is given below from the Christian dialect of Aradhin (NW Iraq). Here the demonstrative āwa refers back to berzara 'seed', and the verbal form šawq-i-le is indistinct from the active, but the referential reduction of the agent indicates a type of passivization. The higher topicality of the patient also manifests itself in the differential indexing.

(19) C. Aradhin (NW Iraq; Krotkoff 1982, 76.27, transcription adapted) pāyiš- $\varnothing \quad$ berzara dax +barzare š-šišme daqīqa $u$ remain $_{\text {IPFV }}-3 \mathrm{MS}$ seed:MS like seed:MS LK-sesame tiny:MS and šawq-īle àwa man čéri hul baher

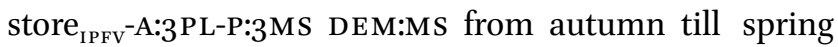
'The seed remains small like sesame seed, and it is stored (lit. they store $\mathrm{it}_{\mathrm{M}}$ that one) from fall to spring.' 
Such agentless constructions can parallel the constructions above, but they are not typically intransitive. Unlike Trans-Zab Jewish varieties, a spontaneous reading is only available for verbs that inflects like $\mathrm{A}$. This is illustrated by the following examples from Jewish Betanure for the verb $p q$ ' 'burst'. Both the specified agent acting on a patient in the transitive valence pattern in (20a), and the subject of the intransitive valence pattern of the spontaneous event in (2ob) are expressed by means of the L-set. When the agent is unspecified, however, the patient in (20c), may also be encoded by means of the E-set, exactly like P in (20a).

(20) J. Betanure (NW Iraq; Mutzafi 20o8a)

a. $p q i-a-l u$ (causative, specified agent) burst $_{\mathrm{PFV}}-\mathrm{P}: 3 \mathrm{FS}-\mathrm{A}: 3 \mathrm{PL}$ 'They burst it $\mathrm{F}_{\mathrm{F}}$.'

b. $p q e^{3}-l a$ (inchoative, spontaneous) burst $_{\mathrm{PFv}}-\mathrm{S}: 3 \mathrm{FS}$ 'It ${ }_{\mathrm{F}}$ burst.'

c. $p q i-a$ (impersonal, unspecified agent) burst $_{\mathrm{PFv}}-3 \mathrm{FS}$ 'It $\mathrm{F}_{\mathrm{F}}$ was burst (by sb.).'

Although it involves no special verbal morphology, the agentless construction resembles a passive. The patient is topicalized to preverbal position like $\mathrm{s}$, and the agent is postverbal and prepositional, compare:

(21) J. Betanure (NW Iraq; Mutzafi 20o8a, 274.450, 286.487)

a. hambašāya xil $\quad-\bar{a} \quad$-le 'e-’ozza ogre:MS eat PFV $_{\mathrm{PF}}$-P:3FS -A:3MS DEM:FS-goat:FS 'The ogre ate that goat.'

b. 'arwe xil $-i \quad$ l-dewe sheep:PL eat ${ }_{\mathrm{PFV}}-3 \mathrm{PL}$ DAT-wolf:PL 'The sheep were eaten by wolves.'

In Jewish 'Amedia, the patient NP, if made explicit, is regularly put before the verb like s (Hoberman 1989, 111-112). Unlike example (21b) above, when a topical patient occurs in preverbal position, no overt expression of the agent is possible. 
The referentiality of the patient can also be reduced. In C. Barwar, the agentless preterit can lack indexing of the patient altogether, and the preverbal position of the patient is typical of the $\mathrm{s}$ of inchoatives (Khan 2008a, 750), compare:

(22) C. Barwar (NW Iraq; Khan 2008a, 749-75o; cf. Doron and Khan 2012, 231) $[\mathrm{s}] \quad[\mathrm{v}]$

a. 'o-bsta tlix-le

(inchoative, agreement)

the-house destroy $_{\mathrm{PFv}}-\mathrm{S}: 3 \mathrm{MS}$

'The house collapsed.'

b. baxta qțil(-Ø)

(agentless, no agreement)

woman kill $\mathrm{PFv}_{(-3 \mathrm{MS})}$

'A/the woman was killed.'

Thus the patient-like subject of the inchoatives (e.g. tlix-le 'it collapsed', $p q e^{\text {'- }}$ le 'it exploded') is treated as more agent-like than the patient of the agentless construction. At first glance, this may seem rather unexpected, since subjects of inchoatives are by definition least agent-like. The degree of saliency on the part of the patient could be expected to be higher for an anticausative intransitive type than for a passive, since the agent is not in view even implicitly in a spontaneous event (Croft 2001, 317). While this seems to hold for the Southeastern Trans-Zab Jewish varieties, e.g. paqy-a 'it $t_{\mathrm{F}}$ exploded', this principle is not reflected in the person indexes in the dialects discussed here, e.g. paqe-la ' $i t_{\mathrm{F}}$ exploded'.

On closer examination, however, agentless constructions can have certain properties that set them apart from passives.

\subsubsection{Ergative-Like Properties}

There are a number of reasons to analyze agentless preterits as truncated $q t i l-a$ le forms, rather different from the seemingly identical intransitive verbal forms in SE Trans-Zab Jewish dialects of NENA. The patient retains certain object properties that set it apart from s. What we do not find is overt verbal and overt nominal marking of the agent ${ }^{37}$ or independent prepositional agents and dependent L-suffixes, e.g.

$$
\begin{array}{lll}
\text { **I-kalwe } & x i l-a-l u & \text { 'Dogs ate } i_{\mathrm{F}} . \\
\text { **ali } & x i l-a-l i & \text { 'I ate } \mathrm{it}_{\mathrm{F}} \text {. }
\end{array}
$$


The absence of overt A agreement on transitive qțil-a-le forms is permitted in the case of a strong implication of the agent in the immediate context. This absence is apparently obligatory to facilitate a particular focal status of the agent nominal, reminiscent of optional ergative marking. At the same time, not all agents are always compatible with agentless verbal person marking, which resembles the impersonal/unspecified agent constructions. This, as we have already observed, ${ }^{38}$ is where passive and ergative can be difficult to tell apart. The special treatment of $\mathrm{A}$ in the preterit may be considered a type of ergative grouping $(\mathrm{S} \neq \mathrm{A})$ with respect to trigger potential of agreement. When we examine the full expression of $\mathrm{A}$, this will provide further evidence for treating at least some of such agentless clauses as active-transitive and thus ergative rather than (impersonal) passive.

\subsubsection{Referential Continuity}

Agentless qțil-forms can be analyzed as truncated transitive constructions. In J. Zakho, this construction can entail an implicit reference to a third person (especially plural) agent just like the overt counterpart (Gutman 2008). Similarly in other literary varieties of NENA, lack of indexing of A is confined to the third person plural, ${ }^{39}$ as illustrated in the following examples, where the agent reference is clear from the immediate context:

(23) C. Ashitha (Literary, SE Turkey; Polotsky 1996, 17, transcription mine)

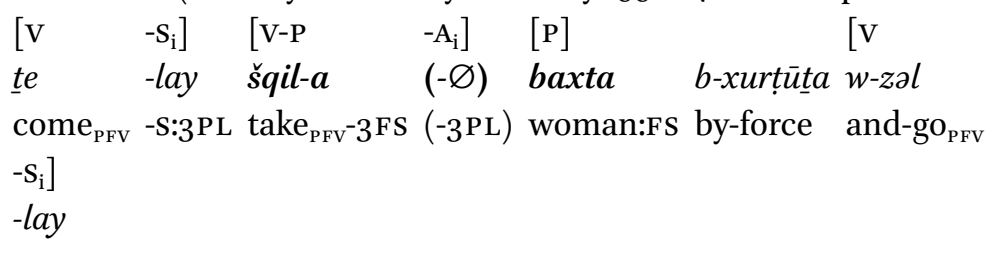

-S:3PL

'They came, took the woman by force and went.'

This also occurs in the recently documented dialect of Marga (SE Turkey). Two constructions alternate in the same story one after the other in the immediate context. In (24a), there is no indexing of A in the second verb, while it is expressed in (24b). In theory, one could interpret both as impersonal passives, i.e. They put/took her $=$ She was put/taken.

$38 \quad$ See $§$ 4.1.2.

39 Polotsky (1996, 17-18). All of his examples, are also confined to third person patients. 
(24) C. Marga (SE Turkey)

a. mot -a -wa -ney l-xaș-ət dăware 'u-nubl-a put $_{\mathrm{PFV}}-\mathrm{P}: 3 \mathrm{FS}$-PST -A:3PL on-back-of mule:PL took $\mathrm{PFV}_{\mathrm{PF}}-3 \mathrm{FS}$ $-w a(-\varnothing)$ $-\mathrm{PST}(-3 \mathrm{PL})$

b. mot -a -ney l-xaș-ət dăware 'u-nubl-a -ney put $_{\mathrm{PFV}}-\mathrm{P}: 3 \mathrm{FS}$-A:3PL on-back-of mule:PL took $\mathrm{PFV}_{\mathrm{P}}-\mathrm{P}: 3 \mathrm{FS}-\mathrm{A}: 3 \mathrm{PL}$ 'They put her on the back of a mule and took her along.'

Sabar (1976, $48 \mathrm{fn}$. 101) considers such constructions a stacking of preterit forms in which only one of them takes L-suffixes, much like a serial verb construction. Nevertheless, the null marked agent can also be co-referential with qatalconstructions (Polotsky 1996, 18), as illustrated in (25) below for J. 'Amedia.

\section{(25) J. 'Amedia (NW Iraq; Hoberman 1989, 111; glossing adapted)}

min 'id-i šlip-a(- $\boldsymbol{i}) \quad \boldsymbol{g}$-əmr-i raḅt-ela

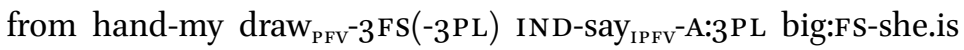
'(There was also a ring ${ }_{F}$ on my hand; ) they drew it from my hand, they said (lit. say): It $_{\mathrm{F}}$ 's big.'

A similar phenomenon is recorded for the enclitic copula. ${ }^{40}$ It is not uncommon for the third person enclitic copula to be absent in transitive compound perfects, so that only participial agreement expresses A. The binding of the object pronominal in forms like qtalt-alle and qtalt-abbe denoting 'She has killed him' gives sufficient clarity to omit the agent copula. In general, a verbal form in the immediate vicinity takes the argument coding to introduce the referent, as for instance in the following example. It is not clear whether it is also possible for the first and second person copulas to be omitted. The /1/-based copula of the third person thus behaves similarly to the L-suffixes.

(26) C. Lewen (SE Turkey; Talay 2009, 102.28)

qím -ele awa šqil-u $\quad(-\varnothing) \quad$ o-naša risen -S:COP:3MS DEM:MS taken-P:MS (-A:3MS) DEM:MS-man:MS $\begin{array}{lllll}\text { mann-u } & \text { o-tarjumman } & \text { tiw-a } & (-\varnothing) & \text { go ... }\end{array}$ with-him DEM:Ms-translator:Ms and seated-s:Ms (-s:3Ms) in 'He rose (and) took that man with him, that translator, and sat down in (his car).'

40 Cf. Khan (2008a, 670). 
Unlike the compound perfect, however, the agentless preterit is always transitive. Thus one does not find truncated intransitive preterit counterparts to tiwa above, i.e. ** tiw- $\varnothing$ for 'They sat'. The trigger potential for $\mathrm{s}$ and $\mathrm{A}$ is thus the same for the copula in the compound perfect, but not for the L-suffix in the preterit.

\subsubsection{Full Expression of the Agent}

The overt expression of agent NPS can be indistinct from the transitive counterpart. An example from Gutman's (2008) discussion of such forms in J. Zakho is given below. A zero-marked full nominal agent $x \bar{u}$ rāse 'his friends' is present, but the verb $\mathrm{fhm}$ 'understand' expresses agreement only with the patient:

(27) J. Zakho (NW Iraq; Gutman 20o8, 74)

$\begin{array}{llll}{[\mathrm{A}]_{i}} & {[\mathrm{~V}-\mathrm{P}]} & {[\mathrm{P}]} & {[\mathrm{V}-\mathrm{A}]_{i}} \\ \text { xürās-e } & \text { fhìm-a-(-Ø) } & \text { zāya } & \bar{u} \text {-ngaz-lu ... }\end{array}$

friend:PL-his understand $\mathrm{PFv}-3 \mathrm{FS}(-3 \mathrm{PL})$ matter:FS and-bite $\mathrm{PFv}_{\mathrm{PF}}-\mathrm{A}: 3 \mathrm{PL}$

'His friends understood the matter, and bit (their lips).'

Remarkably, the word order is A-V-P, as expected for a transitive clause.

In the following example from C. Marga, the full expression of the agent qaša 'priest' for mburxan ' $\mathrm{I}_{\mathrm{F}}$ was wedded' is postponed to the next clause, even when it is clear from the context that this is also the agent of the preceding event denoted by the agentless construction. The construction, then, seems similar to the English gerund, i.e. ' $\varnothing_{i}$ Having wedded me, the priest $_{i}$ went off.'

(28) C. Marga (SE Turkey)

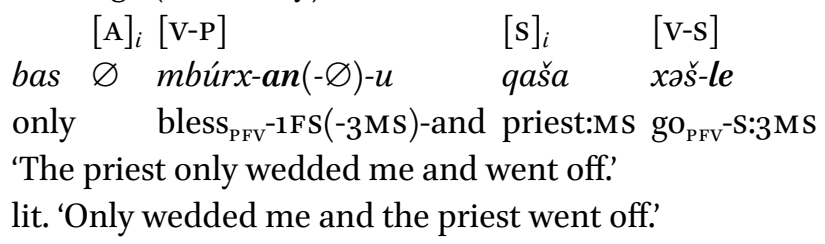

Thus while the intransitive verb $x ə s ̌$-le 'went off', as shown in (28), obligatorily shows a subject index from the L-set, an agent index can be absent on the preceding transitive verb with referential continuity, where the E-set expresses the patient. While $\mathrm{S}$ and $\mathrm{P}$ are evidently not grouped in phonological form, i.e. Lset vs. E-set, one could argue that this is an ergative grouping $(\mathrm{A} \neq \mathrm{S}=\mathrm{P})$ in terms of trigger potential: $\mathrm{S}$ and $\mathrm{P}$ trigger overt agreement, but $\mathrm{A}$ does not. 


\subsubsection{Focal Marking of the Agent}

The restriction to third person (plural) agents does not appear to apply absolutely in contrastive focus (Gutman 2008, 75). In C. Artun (Hertevin, SE Turkey), independent personal pronouns appear to be compatible with truncated qțilforms, e.g.

(29) C. Artun (Hertevin, SE Turkey)

[A] [V-P] [P]

a. man gniw-a čanț-i?

who steal ${ }_{\mathrm{PFv}}-3 \mathrm{FS}$ bag:FS-my

'Who has stolen my bag?'
[A] $[\mathrm{V}-\mathrm{P}] \quad[\mathrm{P}]$
b. ahat gniw-a čanț-i?
you:SG steal $_{\mathrm{PFv}}-3 \mathrm{FS}$ bag:FS-my
'Have you $_{\mathrm{sG}}$ stolen my bag?'

The more common forms would obviously be gniw-a-le and gniw-a-loh, respectively. Lack of overt agreement, however, is compatible with focal agents that are non-prepositional, which clearly indicates that the agentless form is not typically passive.

Movement of the object and agent to preverbal position can also express focalization. Thus in the following example from J. Zakho, the agent NP kalwe is non-prepositional, yet the verb agrees only with the fronted object:

(30) J. Zakho (NW Iraq; Sabar 2002, 193)

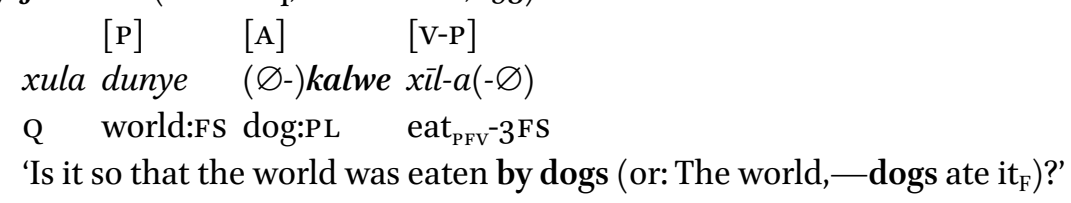

Agent verbal person marking is necessarily absent in NENA dialects that mark the agent by the preposition ('al)l- in order to focalize it. Synchronically, the Lsuffix is a verbal person marker, yet, diachronically, it is derived from the same preposition that introduces NPs and independent prepositional pronouns. Earlier grammatical treatments of mainly literary Neo-Aramaic ${ }^{41}$ mention the use of this preposition, and, on its function, Rhétoré $(1912,220)$ already remarked

41 E.g. Rhétoré (1912, 220), Goldenberg (1992, 120-121), Pennacchietti (1994, 278, fn. 71). 
that such prepositional marking is used to express the agent more assertively in the dialects of the Nineveh Plains and conveys agent focalization, e.g.

läli qțilā 'It is I who killed her', lit. 'Me she was killed'

Jastrow $(1988,152.432,156.499)$ records several examples in the C. Artun dialect (Hertevin, SE Turkey), where the agent is marked by $l$, e.g.

(31) C. Artun (Hertevin, SE Turkey; Jastrow 1988, 152.432, 156.499)

l-êt'-ah l-dewe hellek l-naše qțellek

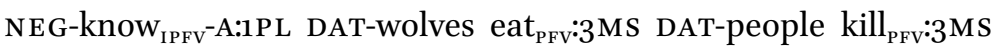

l-debbabe hellek

DAT-bears eat ${ }_{\mathrm{PFv}}: 3 \mathrm{MS}$

'We do not know whether (it was) wolves (who) ate him (i.e.Joseph), people (who) killed him or bears (who) ate him.'

An equivalent construction where A is both prepositional and indexed on the verb is so far unattested for NENA. The absence of the L-suffix licenses its prepositional expression and its focalization. To illustrate, in C. Marga, the prepositional agent, such as 'alli 'by me' in (32b), can be contrasted with the L-suffix, such as -li in (32a). Only a form with overt agent agreement, such as griš-a-li, however, may freely combine with an independent non-prepositional personal pronoun 'ana, cp. (32d).

(32) C. Marga (NW Iraq)

a. ('ana) griš $\quad-a \quad-l i$

(I) pulled $_{\mathrm{PFV}}-\mathrm{P}: 3 \mathrm{FS}$-A:ISG

'I pulled her.'

b. ’alli griš $\quad-a$

me pulled PFv $-3 \mathrm{FS}$

'(It was) I (who) pulled her.' / '(It was) By me she was pulled.'

c. ${ }^{* *}$ ana griš $\quad-a$

${ }^{* *} \mathrm{I} \quad$ pulled $_{\mathrm{PFV}}-3 \mathrm{FS}$

Intended: 'I pulled her.'

d. **alli griš $\quad-a \quad-l i$

**me pulled ${ }_{\mathrm{PFV}}-\mathrm{P}: 3 \mathrm{FS}$-A:ISG

Intended: 'I pulled her.' 
The speakers of C. Marga favor the prepositional agent in preverbal position. In fact, in the rare occurrence of two full NPs, the patient precedes the agent, i.e. xmarta 'alli qțil-a '(It was) I (who) killed the she-ass', rather than 'allixmarta qțil-a or xmarta qțil-a alli.

These prepositional agents can alternate with L-suffixes, while the remaining verbal predicate is not interpretable as intransitive. Thus, $l \bar{a} x z \bar{e}-\varnothing l-n \bar{a} s \bar{a} \overline{i n}$ (33) below taken from early NENA poetry is not interpretable as intransitive i.e. 'What did not appear to anybody' but only transitive like the following $x z \bar{e}-\varnothing-l \bar{e}$ 'He saw', which does have agreement.

\section{(33) Early C. Alqosh (Literary, NW Iraq; Mengozzi 2002a, I2 28.31c) $m \bar{a} \quad d-l \bar{a} \quad x z \bar{e}-\varnothing \quad l-n \bar{a} \bar{s} \bar{a} \quad x z \bar{e}-\varnothing-l \bar{e}$ what SUBR-NEG Saw $_{\mathrm{PFv}}-3 \mathrm{MS}$ DAT-anyone saw $_{\mathrm{PFV}} \mathrm{P}$ :3MS-A:3MS 'He saw what nobody saw / was not seen by anybody.'}

The agentless form can imply a certain degree of subordination to or interdependency with another verb that does take overt agreement. Mengozzi $(2002 \mathrm{~b}$, 36) mentions several examples, where an active interpretation is also favored for prepositional agents. In the example below, the L-suffixes continue the same reference of the prepositional agent. They all belong to the third person plural:

(34) Early C. Alqosh (Literary, NW Iraq; Mengozzi 2002a, J6 142.79d)

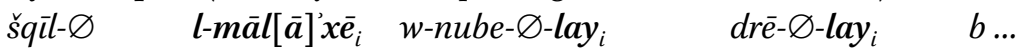
take $_{\mathrm{PFV}}-3 \mathrm{MS}$ DAT-angel:PL and-carry ${ }_{\mathrm{PFV}}-3 \mathrm{MS}-3 \mathrm{PL}^{\mathrm{PL}}$ put $_{\mathrm{PFv}}-3 \mathrm{MS}-3 \mathrm{PL}$ in ' $\mathrm{He}_{\mathrm{j}}$ was taken by angels ${ }_{\mathrm{i}}$ (or: Angels took him $\left._{\mathrm{j}}\right)$ and $\left(\right.$ they $_{\mathrm{i}}{ }^{\text {*** he }} \mathrm{j}_{\mathrm{j}}$ ) carried him and put him in (Gehenna).'

While the position of the prepositional agent is not completely fixed, its typical preverbal position signifies an increase in prominence of the $l$-marked argument. Its association with the agent function is peculiar to its combination with qțil-based morphology. At the same time, a full nominal patient typically precedes it, so that the favored order for this construction is P-A-V.

A similar phenomenon is found in compound verbal forms, where preverbal focalization usually occurs via a pseudo-cleft sentence. As mentioned elsewhere, the prepositional object and agent complement are expressed by the same preposition. The argument orientation is neutralized for the Christian dialect of Aradhin (NW Iraq; Krotkoff 1982). Binding of $l$-marked pronominals to the participle is only possible in their object function, e.g. 
(35) C. Aradhin (NW Iraq; Krotkoff 1982)

A-ORIENTATION

a. ile

COP:3Ms killed-MS DAT:3FS

'He has killed her.'

b. iwan qtíl-alla

COP:1Ms killed:Ms-DAT:3Fs

'I have killed her.'
P-ORIENTATION

c. qțil-a alla killed-MS DAT:3Fs

'He was killed by her.'

When the agent is prepositional, as shown in (35c), the copula has to be omitted (Krotkoff 1982, 34, 39), and the patient has to be third person, so that constructions of the following type do not occur:

$$
\begin{array}{llll}
\text { d. **ile } & \text { qțila } & \text { alla } & \text { 'He was killed by her.' } \\
\text { **iwan } & \text { qțila } & \text { alla } & \text { 'I } \text { was killed by her.' }
\end{array}
$$

When, however, the agent is in focus, such as alli in (35e) below, the third person masculine singular copula is present as a focus marker and denotes an expletive subject only ('It is $\mathrm{X}$ who ...'):

$$
\begin{aligned}
& \text { e. álli-le wid-a } \\
& \text { DAT:1SG-COP.3Ms done-MS } \\
& \text { 'It is I (who) did it }{ }_{\mathrm{M}} \text { '. }
\end{aligned}
$$

Krotkoff $(1982,34)$ states that his informants' interpretation fluctuates between active and passive. The first interpretation readily applies to independent person markers with agent focus occurring in preverbal position. This would otherwise be reserved for the unmarked independent person markers, i.e.

$$
\text { anna iwan wid-alle 'I (am the one who) did } \mathrm{it}_{\mathrm{M}} \text { ' }
$$

For the agent to be prepositional and focal, then, the copula must be omitted and the object cannot be prepositional.

Similarly in C. Barwar, the agent is expressed by the preposition ('al)l-, such as $l$-dabba 'by the bear' below. In terms of word order, the agent may be put before the verb, but will not precede the topical patient: 
(36) C. Barwar (NW Iraq)

a. xabuša šmoqa l-dább-zle xil-a apple:MS red:MS DAT-bear:Ms-COP:3Ms eaten-MS

b. **-dábba xabuša šmóq-zle xil-a DAT-bear:Ms apple:Ms red:MS-COP:3Ms eaten-MS

'The red apple has been eaten by the bear.' (Khan 2008a, D2:65)

There is, however, an unusual feature in the marking of the agent in this type of construction. When it is fronted to preverbal position, the preposition $l$ - may be absent (Khan 2008a, 752). The remaining agreement, therefore, is controlled by the patient, while the agent remains unmarked, such as babi 'my father' in (36c) below.

c. 'ayya yaloxta (Ø-)babi-la zqir-ta

DEM:FS handskerchief:FS father:MS:my-COP:3FS woven-FS

'This handkerchief has been woven (by) my father.' (Khan 2008a, A37:

12)

All else being equal, then, none of these features are typical of agents in NENA in general, and yet neither is it typical of prepositional arguments. These prepositional agents are restricted to constructions, where the remaining agreement is controlled by the patient. The fact that the agent is focalized and not obligatorily prepositional makes it less like passive and more like ergative morphosyntax.

\subsubsection{Differential Object Marking}

Finally, the same sensitivity to definiteness for objects may also be found for the patient in the agentless qțil-form. This is for instance found in Christian Barwar. The indexing of the patient is conditioned by definiteness; contrast (37a) and (37b) below, compared with (37c) and (37d).

(37) C. Barwar (NW Iraq; Khan 2008a, 749-75o; cf. Doron and Khan 2012, 231)

a. baxta qțil-a woman kill $_{\mathrm{PFv}}-3 \mathrm{FS}$

(definite patient)

'The woman was killed.'

b. baxta qțil

(indefinite/definite patient)

woman kill ${ }_{\mathrm{PFV}}$

'A/the woman was killed.' 
$\begin{array}{ll}\text { c. qtil-a-le baxta } & \\ \text { kill }_{\mathrm{PFV}}-\mathrm{P}: 3 \mathrm{FS}-\mathrm{A}: 3 \mathrm{MS} \text { woman }\end{array}$

(definite patient)

'He killed the woman.'

d. qtil-le baxta

kill $_{\mathrm{PFv}}$-A:3Ms woman

(indefinite patient)

'He killed a woman.'

Similarly, the truncated transitive form may be person-restricted like the corresponding full transitive ${ }^{42}$ in dialects such as C. Barwar (Doron and Khan 2012, 232-233) and possibly also J. Zakho (Gutman 2008). This resembles the object indexes, compare:

(38) C. Barwar (NW Iraq; cf. Khan 20o8a, 749-75o)

**griš- $\boldsymbol{a x}$ - $\varnothing$ 'They pulled us.' / 'We were pulled.' (non-third person)

**griš-ax-le 'They pulled us.'

griš- $\boldsymbol{a}-\varnothing \quad$ 'They pulled her. / 'She was pulled.' (third person)

griš-a-le 'They pulled her.'

C. Barwar thus treats the patient in the truncated $q$ țil-construction like $P$ rather than s (Khan 2008a, 750). This does not apply to all dialects; in J. Betanure, a town in the Barwar region, the truncated form is compatible with first/second person patients, whereas the full form is not:

(39) J. Betanure (NW Iraq; Mutzafi 20o8a, 68)

griš-ax- $\varnothing \quad$ 'We were pulled.'

**griš-ax-lu 'They pulled us.'

(non-third person)

griš-a- $\varnothing \quad$ 'She was pulled.'

griš-a-lu 'They pulled her.'

(third person)

In conclusion, while the agentless form may in itself be a rather marked construction in these dialects, it can be used as a truncated transitive construction. The verbal person marking can essentially only be treated as ergative in terms of trigger potential for a limited set of arguments (third person, definite NPS).

42 This does not apply to all dialects, for example J. Betanure griš-ax 'We were pulled (= Somebody pulled us)' (NW Iraq; Mutzafi 2008a, 68). The restriction also does not apply to Trans-Zab Jewish varieties in general, compare J. Sulemaniya griš-ax 'We got pulled' (NE Iraq; Khan 2004a), where the construction is intransitive. 
Ergative verbal person marking $(\mathrm{A} \neq \mathrm{S}=\mathrm{P})$ is not identifiable on the basis of other criteria (affix order, morphological marking).

\subsection{Verb-Related Factors: Grammaticalization of Resultatives}

Southeastern Trans-Zab Jewish varieties of NENA are the only dialects that have grammaticalized the original resultative-stative construction of qtil- combined with E-suffixes to the expression of the perfective past. ${ }^{43} \mathrm{~A}$ few Christian dialects of NENA as well as Jewish varieties other than Southeastern Trans-Zab have maintained this construction in the resultative or perfect. Novel compound perfects have largely replaced such simplex constructions in yet other dialects. These compound perfects, though originally resultative, have fully grammaticalized transitive coding; the respective outcome differs from dialect to dialect, however. There is a noteworthy tendency to harmonize the transitive verbal person marking of such compound verbal forms with that of qatal-.

\subsubsection{Tense-Aspect Associated Person Marking: $s$ and $A$}

Christian varieties in general and Jewish dialects in the West exhibit relics of a former distinction between the resultative or perfect and preterit in the inflection of qtil-. Mengozzi (2002b, 38-39, 2005, 249-250; 2012), for instance, shows that the usage of E-suffixes to mark the subject co-existed alongside L-suffixes in the earliest Christian NENA textual witnesses in North Iraq (17th century), illustrated below.

\section{(1) su-li 'I became old' siw-en 'I have become old'}

The earliest Jewish NENA texts also retain examples of this type, e.g.

$$
\begin{array}{lll}
\text { 'əty-a sā' } \partial d & \text { 'The hour has come.' } & \text { (Sabar 1976, fn. 56) } \\
\text { la snīq- } \varnothing & \text { 'It isn't needed.' } & \text { (Sabar 2002, 242a) }
\end{array}
$$

Indeed, there are traces of such dynamic-stative subject marking in the spoken dialects as well. Typically in lishana deni dialects like J. Betanure, for instance, only the intransitive verb pyš 'remain' retains an $\mathrm{s}_{\mathrm{P}}$ form expressing a perfect, e.g. (Mutzafi 2008a, 68).

43 See $§ 6.1 .2$. for a discussion. 
šop-ad kepe lá-piš- $\varnothing \quad$ 'No trace of stone has remained.'

The same formation of the verb ' $z$ l 'go', e.g. zil-a 'She is gone', has grammaticalized into a proximative auxiliary 'be about to' in the Christian dialects of the Nineveh Plains from its resultative sense 'be gone to.44 In Jewish Barzani (Mutzafi 2002a), such forms are found for the modal auxiliary $m s y$ 'be able', e.g.
(2) mṣe-li
'I was able'
mșil-ən hmil-ən ' 'I $\mathrm{I}_{\mathrm{M}}$ am able'

(preterit)

(present)

In Christian dialects, such active-stative s-marking is still productively found in the western periphery, such as C. Artun (Hertevin, SE Turkey; Jastrow 1988):
(3) dmah-li 'I fell asleep'
dmih-en 'I have fallen asleep'

(preterit)

(perfect)

In C. Artun, the transitive counterparts are essentially differentiated by a preverbal TAM-marker (hole), optionally added to intransitives: ${ }^{45}$

(4) C. Artun (Hertevin, SE Turkey)

$$
\text { PRETERIT PERFECT }
$$

tr. qțal-li holiqțal-li

intr. qam-li (holi) qim-an

On closer examination, the E-suffixes are, to some extent, compatible with transitive verbs and transitive coding in C. Artun (Jastrow 1988, 58). In elicitation, speakers find the E-suffixes acceptable for certain transitive verbs, but not all of them, e.g. susarkiw-ən ' $\mathrm{I}_{\mathrm{M}}$ have mounted a horse', la mir-an ' $\mathrm{I}_{\mathrm{M}}$ haven't said', la hil-ən 'I haven't eaten', but not * "ptih-ən 'I $\mathrm{I}_{\mathrm{M}}$ have opened'. Further research is required to examine their distribution and to assess whether this is merely contextually restricted or whether there is a categorical lexical restriction. In addition, C. Artun speakers also employ compound verbal forms, where the deictic copula is inflected and the participle agrees with s/A as opposed to the invariant 3ms. form hole used to express the perfect with qtalle or the progressive with qațal-, e.g.

44 See Borghero (2008, 85), Coghill (2010, 375), Noorlander (2017). Cf. Rhétoré (1912, 156).

45 This is comparable to J. Rustaqa (NE Iraq), see $\S 3 \cdot 4 \cdot 3$. 
$\begin{array}{lll}\text { hol-ən } & \text { šatya } & \text { 'I } \mathrm{M} \text { have drunk' } \\ \text { hole } & \text { šte-li } & \text { 'I have drunk' } \\ \text { hole } & \text { šat-ən } & \text { 'I } \mathrm{I}_{\mathrm{M}} \text { am drinking' }\end{array}$

A similar opposition exists further west in the Bohtan region (Fox 2009). The difference between preterit and perfect is entirely based on the set of person indexes attached to qțil-. The L-set marks the preterit against the E-set for the perfect, both marking $\mathrm{s}$ and $\mathrm{A}$ :

(5) C. Borb-Ruma (Bohtan, SE Turkey)

PRETERIT PERFECT

\begin{tabular}{ll|l} 
tr. & qtal-li & qtil-an \\
intr. & qam-li & qim-an
\end{tabular}

Thus the default expression of $\mathrm{s}$ is identical to $\mathrm{A}$ in at least the preterit. An active-stative or rather dynamic perfective-stative resultative opposition in at least subject indexes exists throughout the NENA dialectal landscape. ${ }^{46}$ Even the earliest documents from Iraq (Mengozzi 2002b, 38, 2005) bear witness to active-stative subject marking, whereby qțil-could be used as a base for either L-suffixes expressing the dynamic perfective past or E-suffixes expressing a resultative-stative that eventually developed into a perfect. The difference lies solely in the set of person markers to express $\mathrm{s}$. It is plausible that this co-existed in all dialects, ${ }^{47}$ but was gradually lost and replaced by either preverbal TAMmarking, i.e. hole qam-li, or a compound verbal form based on the resultative participle, i.e. qime-wan.

\subsubsection{Transitivization of Compound Verbal Constructions}

The compound perfect based on the resultative participle goes back to a resultative construction. A resultative is a verbal construction typically derived from telic verbs that expresses an acquired state: a state that implicitly results from a previous event and directly or indirectly affects a subject (Nedjalkov 1988, 2001;

46 This includes the Trans-Zab Jewish varieties discussed in the previous chapter. See § 6.1.2. and Noorlander (forthcoming) for further argumentation.

47 See § 6.1.2. Noorlander (forthcoming; cf. Goldenberg 1992) considers the verbal systems in SE Trans-Zab Jewish varieties to be innovative and also originating in such active-stative subject-marking. That is, originally resultative intransitive qim-ən 'I am arisen' existed alongside qam-li 'I rose' from the beginning. The former grammaticalized into a preterit qim-ən 'I rose' and replaced qam-li in these dialects, possibly due to convergence with local Iranian languages. 
Haspelmath 1994). Resultatives are, strictly speaking, voice-neutral (Nedjalkov and Jaxontov 1988, 16) and can be patient-oriented, subject-oriented and agentoriented. Subject orientations for result states are found for intransitive verbs, e.g. J. Dohok

$\begin{array}{lll}\text { wan tiwa } & \text { 'I } \mathrm{I}_{\mathrm{M}} \text { am seated' } & \text { (lit. 'am sat') } \\ \text { wan skanta } & \text { ' } \mathrm{I}_{\mathrm{F}} \text { live' } & \text { (lit. 'am settled') }\end{array}$

The predication of a result state is also found for transitive telic verbs that typically form agent orientations in resultative constructions, such as $d w q$ 'hold', šql 'take', lwš 'wear, put on', t' $n$ 'carry', lyp 'learn' (Noorlander forthcoming). ${ }^{48}$ In J. Dohok, for instance, the resultative participle is mostly entirely confined to such possessive-like transitive verbs in this usage alongside intransitive verbs, e.g. 'ana heš wan dwiqa laxma bat-'idi 'I am still holding (lit. held) bread in my hand'.

In several NENA dialects, the agent orientation is available for virtually all transitive verbs in the expression of the perfect and perfective past. The possible connotation of an anterior change of state in the implied event leading to the result restate in resultatives is made explicit in the perfect, compare English resultative He is gone and perfect He has gone, and the resultant state in the present is absent in the perfective past. The aspectual opposition between the intransitive stative-resultative and transitive perfect also correlates with their integration into the verbal system. ${ }^{49}$ Thus for example, in C. Shaqlawa (NE Iraq), pașra xíl-ele (< *xila-ile) can have only a dynamic agent orientation denoting 'He has eaten meat', not ${ }^{* * *}$ The meat has been eaten'.

Certain typical change-of-state verbs belonging to stem I, however, are essentially voice-neutral in their resultative construction in several NENA dialects. Virtually any telic transitive verb is ambivalent, expressing both a dynamic-transitive perfect and stative-intransitive resultative. The orientation (subject/agent/patient) has to be contextualized. This is illustrated in the following examples from Christian Barwar.

48 See also Kapeliuk (2008). Cf. Nöldeke (1868, 308, §150).

49 See Kapeliuk (2008). Cf. Mutzafi (2004a, 105-109), Khan (20o8a, 653-659). 
(6) C. Barwar (NW Iraq; Khan 20o8a)

BASIC

qtíl $\quad-\varepsilon \quad-l e^{50}$

killed -Ms -COP:3Ms
DEICTIC

ho-le

DEIX:COP-3Ms killed-MS
a. 'He has killed.'
c. 'He has killed.'
(A, dynamic)
b. 'He is killed.'
d. 'He is killed.'
(s, stative)

The basic copula is generally enclitic, following the participle. It may also alternate with an independent deictic copula. The forms with the deictic copula are mainly used to express the perfect and pluperfect (Khan 2008a, 673-675). What applies to the construction based on the deictic copula, as illustrated in (6c) and (6d), generally also applies to other tense and modal categories based on the auxiliary hwy 'be'.

Speakers use different strategies as to how to resolve the ambiguity in orientation, namely the relative position of the copula, preverbal marking, the presence of an object and, finally, a greater degree of integration into the verbal system through adaptation of the unmarked transitive coding of qațl-; each of these will be examined in turn below.

\subsubsection{Copula Position}

Some dialects, mainly those in NW Iraq, can differentiate between a dynamictransitive perfect and stative-intransitive resultative by the relative position of the basic copula. If the copula precedes the participle, the orientation is ambiguous, but when it follows, the construction is always intransitive. Thus in Jewish Betanure, for example,,$^{51}$ postverbal position of the copula is impossible for the agent orientation:
(7) J. Betanure (NW Iraq; Mutzafi 20o8a)
COP PRED
PRED-COP
'ile šqil-a
šqil-a-yle
COP:3Ms taken-Ms
taken-MS-COP:3Ms
a. 'He has taken.'
c. **'He has taken'
b. 'He is taken.'
d. 'He is taken.' (only)

(dynamic)

(stative)

$50 \quad q t ̦ i l-\varepsilon-l e=q t i l-a+-i l e$.

$5^{1}$ Cf. J. Challa (Fassberg 2010, 117). 


\subsubsection{Preverbal Marking}

By contrast, dialects like C. Koy Sanjaq (NE Iraq) make a distinction by adding an invariant preverbal modifier $(l \bar{a})$ to the stative-intransitive resultative, where in the case of the third person the copula is absent:
C. Koy Sanjaq (NE Iraq; Mutzafi 2004b)
(stative)
(dynamic)
lā PRED(-COP)
PRED-COP
a. $l \bar{a}$ skar-ta $(-\varnothing)$
PVB lost-Fs
c. skár-t-ela
'She has lost.'
lost-F S-COP:3F S
'She is lost.'
b. lā skar-t-ewan
PVB lost-FS-COP:1Fs
'I $\mathrm{F}_{\mathrm{F}}$ am lost.'
d. skár-t-ewan
lost-FS-COP:1Fs
'I $\mathrm{F}_{\mathrm{F}}$ have lost.'

\subsubsection{Object Marking}

The ambiguity in orientation can also be remedied by the presence of an object. When the object is pronominal, it is expressed by attaching a pronoun of the 'all-series. This is given for Christian Barwar below. The enclitic copula denoting $\mathrm{A}$ is attached to the preceding participle, and the 'all-set denoting $\mathrm{P}$ is attached to the copula. If the copula is deictic and precedes the participle, the patient person form attaches immediately to the participle itself:

(9) C. Barwar (NW Iraq; Khan 20o8a) BASIC

a. qțil $-e \quad-l \quad$-alle killed -A:PL -A:COP:3 -P:3MS 'They have killed him.' (lit. They is killed him)

\section{DEICTIC}

b. ho-la qtil-alle

DEIX-A:3PL killed:NONFS-P:3MS 'They have killed him.'

The agent-marking enclitic copula is completely mobile and can move to the front, e.g. ku-t-ile qțil-alle 'Each that has killed him' (Khan 2008a, A24:43). The 'all-series regularly attaches to the participle when the copula precedes it. Only when the copula is third person, and thus in form similar to the L-suffixes, it may also follow this series or be omitted entirely (Khan 2008a, 285, 782-783) A $3 \mathrm{~ms}$. form can therefore occur in the following forms (see further next subsection): 


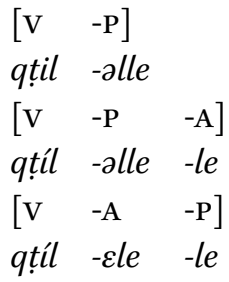

When the clause contains two full NPs, the A function of the noun is typically indicated by agreement. When the gender and number differs between the arguments, the verbal construction always agrees with $\mathrm{A}$ as it does with $\mathrm{s}$, and the respective roles are clear, for example:
[A]
$[\mathrm{COP}-\mathrm{A}]$
[RPP-A]
$[\mathrm{P}]$
c. 'aw-naša
ho-le
dwiq-a
baxta
DEM-Man:MS DEIX-A:3MS seized-A:MS woman:MS
'The man has seized the woman.' (Khan 2008a, 657)

When the patient is differentially marked, this will automatically disambiguate between the roles of the arguments. Differential object marking can be via indexing, i.e. the 'all-series, or via prepositional marking, e.g. the dative preposition țla-, for example:
[A]-[COP:A] [RPP:A-P]
$[\mathrm{P}]$
d. 'at-it qțil-alle xuwwe
you-A:2MS killed:A:MS-P:3MS snake:MS

'Are you (the one who) has killed (lit. him) the snake?' (Khan 2008a, A24:45)
$[\mathrm{A}]$
[BE:A]
[RPP-A]
e. awwa
xuwwe
$t$-awe- $\varnothing-w a$
qțil-a
DEM:MS snake:MS FUT-be ${ }_{\text {IPFv }}{ }^{-A: 3 M S-P S T ~ k i l l e d-A: M S ~}$
$[\mathrm{DOM} \rightarrow \mathrm{P}]$
tla-bron-i
DOM-son:MS-my
'The snake would have killed my son.' (Khan 2008a, Ag:6)

The coding of either role may be completely absent, in which case the roles have to be inferred from the context. This applies when the two referents belong to the same gender and number and when the patient is not differentially marked. In (12a) below, the status of the argument bron- $i$ is ambiguous, 
since no object is present, while, in (12b), an object is present. Both arguments are morphologically unmarked (ms.), but it is pragmatically obvious what their respective role is, i.e. a human agent as opposed to a fruit.

$$
\begin{aligned}
& \text { C. Barwar (NW Iraq) } \\
& \begin{array}{ll}
{[\mathrm{S} / \mathrm{A}]} & {[\mathrm{COP}]} \\
{[\mathrm{RPP}]}
\end{array}
\end{aligned}
$$

a. bron-i ho-le xil-a

(ambiguous)

son:MS-my DEIX-3MS eat:RPP-MS

'My son has eaten'

'My son is/has been eaten (by sth.)' (Khan 2008a, A18:2)
$[\mathrm{A}]$
[COP]
[RPP]
$[\mathrm{P}]$
b. xon-ux
ho-le
xil-a
xabuša
brother:MS-your:MS DEIX-A:3MS eat:RPP-MS apple:MS
'Your ${ }_{\mathrm{MS}}$ brother has eaten an apple.' (Khan 2008a, 678)

(active)

The A argument regularly precedes the verb. The $\mathrm{P}$ argument, however, may be fronted, yielding the reverse word order:
$[\mathrm{P}]-[\mathrm{COP}]$
$[\mathrm{RPP}]$
$[\mathrm{A}]$
c. la xawx-zle
xil-a
xon- $i$
(fronted object)
NEG peach:MS-COP:3Ms eaten-Ms brother:Ms-my
'No, a peach my brother has eaten.' (Khan 2008a, 678)

Word order, then, may be an important clue, but it is not definitive. Without the presence of an agent in (12c), the clause la xawxe-le xila could mean 'A peach is/has been eaten' or, in theory, 'A peach has eaten'.

\subsubsection{Adaption to Transitive qațal-}

Across NENA dialects, contracted forms may alternate with uncontracted forms that are indistinct from the E-set. The contracted past perfect qtil-in-wa $\mathrm{I}_{\mathrm{M}}$ had killed' of the uncontracted qtila win-wa ' $\mathrm{I}_{\mathrm{M}}$ had killed' in C. Ashitha, for instance, parallels the E-suffix with anteriority affix -in-wa in the past habitual qaț-in-wa ' $\mathrm{I}_{\mathrm{M}}$ used to kill' (Borghero 2005, 332). The structural cohesion between the verb and the enclitic copula is virtually on the same level as that of the core verbal system.

The effects of cross-system harmony are evident in the inflection of compound verbal forms. The transitive qatal-construction serves as the unmarked model. The convergence of compound and simple verbal constructions is motivated by the morphological identity that results for reduced forms of the orig- 
inally enclitic copula and 'all-series. The latter merge with the E-set and L-set of the qatal-constructions, but the convergence is only partial. The incidental outcome is a special treatment of transitive verbal clauses.

The transitive realis perfect and progressive is regularly formed by the copula and 'all-series in NENA dialects. The coding of $\mathrm{A}$ and $\mathrm{P}$ by means of reduced variants, however, is partially merged with the E-suffixes and L-suffixes, for example in C. Barwar. The resultative participle expresses agreement with the agent like the subject, whereas reduced variants of the copula that are virtually identical to the E-set denote the agent. The patient can be expressed by L-suffixes or 'all-series, markers attached to these reduced variants. Forms like *qtíla-iwat 'alle ' $\mathrm{You}_{\mathrm{MS}}$ have killed him' have evolved through contracted forms like qțíl-at-alle into qțíl-at-le. ${ }^{52}$ The reduced enclitic copula is morphologically near-identical to the E-set and could hardly be considered a separate set, for example:

(11) Perfect with reduced copula (C. Barwar, NW Iraq; Khan 2008a, 18o, 28o281, 284)

\begin{tabular}{|c|c|c|c|c|}
\hline & PERFECT & & COPULA & E-SET \\
\hline $2 \mathrm{~ms}$. & $q t ̦ i l-\partial t-l e$ & 'You ${ }_{\mathrm{MS}}$ killed him' & $-i w a t$ & $-\partial t$ \\
\hline & qțilt-at-le & 'You ${ }_{\mathrm{FS}}$ have killed him' & -iwat, -iwat & $-a t$ \\
\hline & qțile-tu-le & etc. & -iwstu, -iwitu & -itu \\
\hline is. & qțil-ən-ne & & $-i w a n$ & $-\partial n$ \\
\hline & qțilt-ən-ne & & $-i w a n,-i w a n$ & $-a n$ \\
\hline & $q t ̦ i l-\partial x-x e$ & & $-i w \partial x$ & $-\partial x$ \\
\hline
\end{tabular}

As seen in (11), the forms of the reduced copula are virtually identical to the E-set except for the third person. The third person copula can follow the 'allseries, precede the L-set denoting the object or be omitted altogether. Their forms are identical to the L-suffixes, but when the affix order shifts to that of the present, $\mathrm{P}$ is expressed by means of L-suffixes as in the present.

$\begin{array}{lllllll} & {[\mathrm{v}} & -\mathrm{P} & -\mathrm{A}] & & \text { COPULA } & \text { L-SET } \\ \text { 3ms } & \text { qțil } & - \text {-llle } & -l e & \text { 'He has killed him' } & -i l e & -l e \\ \text { 3fs. } & \text { qțilt } & - \text {-alle } & -l a & \text { 'She has killed him' } & -i l a & -l a \\ \text { 3pl. } & \text { qțil } & - \text {-alle } & -l a & \text { 'They have killed him' } & -i l a,-i l \varepsilon & -l a,-l \varepsilon\end{array}$




\begin{tabular}{|c|c|c|c|c|c|}
\hline$[\mathrm{v}$ & $-\mathrm{A}$ & $-\mathrm{P}]$ & & COPULA & L-SET \\
\hline qțíle & $-l e$ & $-l e$ & 'He has killed him' & -ile & $-l e$ \\
\hline qțilte & $-l a$ & $-l e$ & 'She has killed him' & -ila & $-l a$ \\
\hline qțile & $-l a$ & $-l e$ & 'They have killed him' & -ila, -ile & $-l a,-$ \\
\hline
\end{tabular}

Non-reduced variants of the copula are used when no coalescence occurs, for example in the present and past tense:

(12) $\mathbf{E}_{2}$-set and copula alternations (Khan 2008a, 189-19o) ${ }^{53}$

$\mathrm{E}_{2}$-SET COPULA

priqt-an $\sim$ príqte-wan ' $\mathrm{I}_{\mathrm{F}}$ have finished'

príxt-ən-wa $\sim$ príxte-wanwa 'I $\mathrm{F}_{\mathrm{F}}$ had flown'

Where the copula is independent, such as the negative copula or deictic copula, the reduced variants are not used:

(13) C. Barwar (NW Iraq; Khan 20o8a, 284, 286)

l-en qțil-alle ' $\mathrm{I}_{\mathrm{M}}$ have not killed him'

(negative)

ho-n qțil-alle ' $\mathrm{I}_{\mathrm{M}}$ have killed him'

(deictic)

The enclitic copula and the ('al)l- series are hardly distinguishable from the Eset and L-set. Their inflection strongly resembles that of qatal-. Compare the following transitive forms based on qțila and qațal-:

(14) C. Barwar perfect and imperfective (NW Iraq; Khan 2008a, 28o-281, 284) PERFECT

: IMPERFECTIVE

2ms. qțil-at-le ' $\mathrm{You}_{\mathrm{Ms}}$ killed him.' qaț-ot-le 'You ${ }_{\mathrm{MS}}$ kill him.' 2fs. qțilt-at-le ' $\mathrm{You}_{\mathrm{FS}}$ have killed him.' qațla-t-le 'You ${ }_{\mathrm{FS}}$ kill him.' 2pl. qtíle-tu-le etc. qațli-tu-le etc. ims. qțil-an-ne qațl-an-ne ifs. qțilt-on-ne qațla-n-ne ipl. qțil-əx-xe qațl-ax-xe

Presumably, originally uncontracted forms like *qtíla-iwat 'alle 'You ${ }_{\mathrm{MS}}$ have killed him' evolved via contracted forms like qțil-at-alle into qțíl-at-le in analogy to the qațal-in Christian dialects like Barwar. ${ }^{54}$ If we consider the E-suffixes

53 Third person forms do not show this same alternation, e.g. príqte-la 'She has finished' and príxta-wawa alongside príxte-yawa and prixtz-wa 'She had flown'.

54 The same holds for C. Ashitha (SE Turkey), see Borghero (2005). 
$-a$ and $-i$ as expressions of gender in qatal-, then they pattern exactly like the gender agreement of the resultative participle $q t i^{\prime} a,{ }^{55}$ so that we obtain the following parallel:

$\begin{array}{llll} & \text { qțila } & & \text { qațal- } \\ \text { MS } & \text { qțil- } \varnothing- & : & \text { qațl- } \varnothing \\ \text { FS } & \text { qțil-t- } & : & \text { qațl-a- } \\ \text { PL } & \text { qțil-e- } & & \text { qațl-i- }\end{array}$

The same is true for the past tense with -wa-, compare:

\section{PERFECT}

(15) qțil-t-an-wa-le 'I $\mathrm{F}_{\mathrm{F}}$ had killed him.
IMPERFECTIVE

: qațl-á-n-wa-le

'I $\mathrm{F}_{\mathrm{F}}$ would kill him.'

The stress pattern between the two forms is still distinct in C. Barwar. The participle $q$ țila still carries the main stress, treating the affixes like clitics. ${ }^{56}$

The processes of analogy and phonetic erosion can lead to considerable mixing. Khan $(2008 \mathrm{a}, 284)$ shows that the reduced variants of the $\mathrm{E}_{2}$-series, for instance, can combine with either the 'all-series or L-suffixes, i.e. qțil-ən-alle or qțil-an-ne for ' $\mathrm{I}_{\mathrm{M}}$ have killed him'. Even the third person copula set, namely fs. -ila, ms. -ile, pl. -ile, may be, though rarely is, fully expressed before the $\mathrm{L}_{1}{ }^{-}$ suffixes e.g. qțilte-la-le (< * qtilta + -ila + -le) 'She has killed him'. The resulting third person indexes are morphologically identical, leading to a phonologically non-distinct verbal person marking pattern identical to the L-suffixes:

$\begin{array}{llll} & \mathrm{A} / \mathrm{s} \text { (PARTICIPLE) } & \mathrm{A} / \mathrm{s}\left(<{ }^{*} \text { COPULA }\right) & \mathrm{P}\left(<{ }^{*} \text { วll- }\right) \\ \mathrm{ms} . & \text { qtile- } & -l e & -l e \\ \mathrm{fs} . & \text { qțilte- } & -l a & -l a \\ \text { pl. } & \text { qtile- } & -l \varepsilon,-l a & -l \varepsilon,-l a\end{array}$

The third person forms derived from 3ms. -ile, 3fs. -ila and 3pl. -ile are different, but also follow the V-A-P affix order of qațal-. They are reduced to al-before object suffixes in the transitive present perfect and also found in the past, with

55 Note that this agreement is absent in the corresponding analytical progressive based on an indeclinable verbal noun qțala (Khan 2008a, 287), e.g. qțal-ət-le 'You ${ }_{\mathrm{Fs}}$ are killing him'.

56 Complete convergence between the compound perfect and progressive with qața- occurs in Jewish Urmi, see § 3.1.3.3. 
-wa- between A and $\mathrm{P}$, thereby merging the transitive coding partly with qațal-, for example:

\section{PERFECT}

(16) qțil-tal-le

'She has killed him.'

qțil-tal-wa-le

'She had killed him.'

\section{IMPERFECTIVE}

: qațl-a-le

'She kills him.'

: qatl-á-wa-le

'She used to kill him.'

Furthermore, the analogy between qațal- and the compound verbal constructions creates an interesting split between transitive and intransitive constructions. This is illustrated by the pluperfect in C. Barwar below. Every verb without object indexes can freely use the full form of the past copula, but a verb with object indexes adapts to the past qațal-,, 57 for example:

(18) Split in transitivity coding (Khan 2008a, 190, 284-286)
a. $[-\mathrm{P}] \quad$ príxa-wat-wa $\sim$ príx-at-wa 'You ${ }_{\mathrm{MS}}$ had flown'
[P: fNP] ptíxa-wat-wa (tăra) 'You ${ }_{\mathrm{MS}}$ had opened (a door)'
$\sim p t \underline{t} x$-st-wa (tăra)
[P: PRO ] ptíx-st-wa-le ' $\mathrm{You}_{\mathrm{MS}}$ had opened it ${ }_{\mathrm{M}}$ '

These constructions therefore make a subtle difference between clauses with only full nominals and independent pronouns and clauses with dependent person markers. There is a fundamental distinction between $\mathrm{A}$ with and $\mathrm{A}$ without a $\mathrm{P}$ index. The omission or independent expression of $\mathrm{P}$ favors a different construction. The verb adapts morphologically to the inflection of qațal- particularly when $P$ is a dependent person form.

Moreover, the difference between intransitive and transitive coding is even stronger for third person referents, where A can display special properties distinct from s. They are as follows:
b. $[-\mathrm{P}]$ príxta-wawa ${ }^{58} \sim$ prixte-wa
'She had flown'
[P: fNP] qțilt-ol-wa (gawra)
[P: PRO] qțilt-al-wa-le
'She had killed (a man)'
'She had killed him'

\footnotetext{
57 Only an intransitive verb can take a reduced form of the past copula, cf. príxzwa 'He had flown', príxətwa 'You ${ }_{\mathrm{MS}}$ had flown' (Khan 2008a, 190).

$5^{8} \quad$ Also prixte-yawa.
} 
While, third person copula forms are reduced to -al- before - wa- and/or an L-suffix, this the same agent marking -al-is analogically restored for transitive verbs without an object index. Hence, one obtains the form qtílt-al-wa instead of qțilta-wawa on the basis of qțilt-al-wa-le for qțilta-wawa 'alle. Such object indexes are absent, for example, in contexts, where $P$ is an indefinite full nominal:

\section{(19) 'ay šwíq -t -al -wa majma tama \\ she left:RPP -A:FS -A:3 -PST tray there \\ 'She had left a tray there.' (Khan 2008a, A4:53)}

And nevertheless, we do not find this morphology on an intransitive verb, so that forms like ** prixt-al-wa for 'She had flown' are impossible. Here, s is treated differently from both A and P.

In conclusion, A is treated remarkably different from $\mathrm{s}$, and while this is exactly what we would expect for an ergative pattern (see § 4.4.1.1.), namely a higher degree of morphosyntactic transitivity triggering marking of A distinct from s, we do not observe morphological ergativity. Gender and number participial agreement always groups $\mathrm{S}$ and $\mathrm{A}$. In phonological form, indexing is also accusative for first/second persons but varies for the third person: S, A and P can be either identical to each other or distinct from each other. Verbal person marking involving both $\mathrm{A}$ and $\mathrm{P}$ is prone to approximate that of the more frequent, unmarked transitive qațal-forms due to cross-system harmony, and, consequently, only transitive clauses are treated differently. This cross-system harmonization is also observed in transitive perfective past clauses, which is the topic of the next section.

\subsection{Argument-Related Factors: Harmonizing the Object}

In the majority of dialects, NENA speakers have multiple strategies for transitive verbal person marking (Pennacchietti 1994) ${ }^{59}$ The inverted perfective past construction qțil-a-le is generally person-restricted. Several constructions listed in (1) below serve as alternatives for qtill-a-le, which will be discussed one by one in the subsequent sections.

59 See Mengozzi (2012) for the distribution of these forms in early Christian poetry written in the NENA of Iraq, dated from 17 th to 20 th century. 


\begin{tabular}{lll}
\hline $\begin{array}{l}\text { Alternative I: prepositional object } \\
\text { Alternative II: L-suffix + L-suffix }\end{array}$ & e.g. 'You saw me' & $\begin{array}{l}\text { grəš-lox ’alli } \\
\text { gráš-lux-li }\end{array}$ \\
$\begin{array}{l}\text { Alternative III: L-E-suffix + L-suffix } \\
\text { Alternative IV: qam- + qațal- }\end{array}$ & $\begin{array}{l}\text { grəš-l-ət-ti } \\
\text { qam-garš-ət-ti }\end{array}$ \\
qațal & e.g. 'You see me' & $k$-garš-at-ti
\end{tabular}

Dialects can use more than one of these strategies. Ditransitive constructions presumably served as a model for alternatives I-II, since this is to what they are confined in several other dialects. Alternatives II-IV, and presumably to some extent also Alternative I, are attempts to harmonize at least the object marking in analogy to qațal-. The absence or presence of an additional object index, therefore, is central to our discussion, and its presence may even affect the marking of A. The differences in coding strategies incidentally result in person splits, often third vs. first/second, as well as splits between clauses containing full nominal objects and pronominal objects.

\subsubsection{Person-Role Constraints}

4.4.1.1 Ergativity, Co-argument Sensitivity and Person-Role Associations The relative ranking of $\mathrm{A}$ and $\mathrm{P}$ on a prominence scale can be a determining factor for alignment splits, also known as "hierarchical alignment" (Siewierska $2003,2004,55)$. Not merely one argument type, but both a particular argument type, i.e. 1st/2nd vs. 3 rd person or pronoun vs. full NP, and associated role, i.e. A vs. P or R vs. T, are higher or lower in ranking. Such hierarchy effects show crosslinguistic tendencies for treating clauses differently when either A or P is higher in prominence (and balanced rankings as possibilities in between).

Person role inverse constructions are, among others, a typical trait of Native American languages and a few Tibeto-Burman languages (e.g. DeLancey 1981). The construction where A outranks $P$ along the prominence hierarchy is called 'direct', while constructions that deviate from this are called 'inverse', and this is highlighted by special verbal morphology. DeLancey $(1981,642)$ offers the following example from Jyarong, a Tibetan language, spoken in the Sichuan Province of China, where ergative case morphology and verbal person marking are conditioned by the highest person reference. The ergative postposition, $-k a$ in ( $1 \mathrm{~b})$, occurs only when A is of lower ranking in person than P. The third person does not trigger agreement, only the non-third person (-ng). At the same time, the verb indexes the highest ranking person and takes a special, so-called 
inverse form $(u-)$ to indicate that the patient is associated with the highest ranking person instead of the expected agent, i.e. P outranks A in person.

(1) Jyarong (Tibeto-Burman, Sichuan, China; DeLancey 1981, 642)

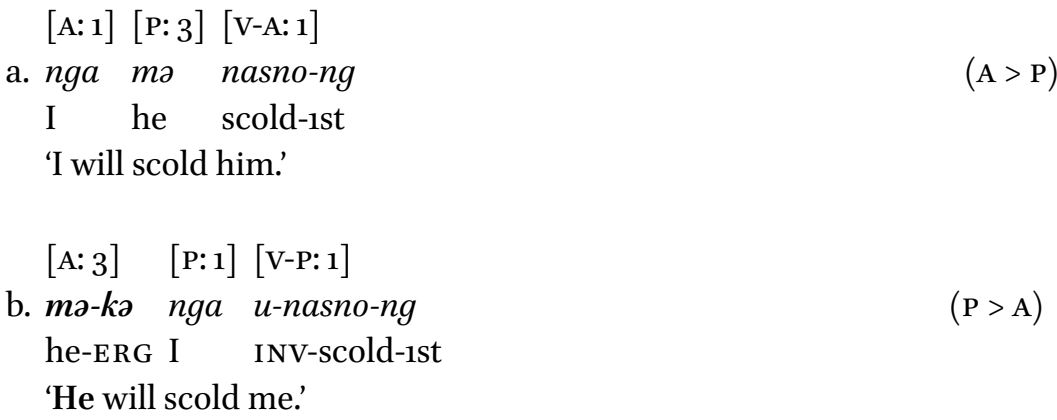

Witzlack-Makarevich et al. (2016) argue that what has been called hierarchical alignment does not represent a single special alignment type, but represents two basic alignment types conditioned by particular referential properties. Following previous literature, they distinguish between hierarchical agreement and co-argument sensitivity. In co-argument sensitivity, the properties of another argument determine the marking of a particular grammatical function. Importantly, this is first and foremost a construction-specific property and not necessarily the morphosyntax nor alignment pattern as a whole. ${ }^{60}$ In this different approach, the system above is not a hierarchical type, but one that can be characterized as either ergative or non-ergative depending on the properties of either or both arguments. Thus in the example of Jyarong above A is only overtly marked ergatively when P is first/second person; otherwise the marking is neutral. They also mention that P can be marked accusatively only if A has certain properties, for example only when A is third person in Ik, a Kuliak language (Nilo-Saharan, Uganda); otherwise it is marked in the nominative. In Finnish, P is only overtly marked accusatively when A is a full nominal; otherwise the marking is neutral. Comrie (1975) argues that nominal marking in languages like Finnish serves to discriminate arguments, distinguishing a from $\mathrm{P}$. It is the presence of full nominal As that trigger distinct coding of $\mathrm{P}$, in order to distinguish $\mathrm{P}$ from $\mathrm{A}$.

Languages with ergative alignment can also show differences in the morphosyntax of clauses where the referentiality of the patient is reduced. The

6o Compound verbal forms also show these effects of co-argument sensitivity with respect to person in J. Koy Sanjaq, see Subsection 3.4.4., and gender in J. Sulemaniyya, see Subsection 3.4.6. 
antipassive is a case in point, which expresses the agent distinctly from the ergative and is typically used when the object is less individuated (Hopper and Thompson 1980). ${ }^{61}$ Similarly, Dalabon, an Australian language (Northern Territory), is reported to manifest only overt (ergative) case-marking of A when $A$ and $P$ are of equal ranking in animacy (Silverstein 1976, 129; Comrie 1978, $386-387$ ). A few languages with ergative morphosyntax employ the ergative case only when a full nominal object is expressed (Woolford 2015, 509-513). In fact, several languages that exhibit ergative morphology only mark the agent distinctly when a definite object is present. When the object is indefinite, the verbal person marking is distinct from intransitive clauses. In Selayarese, an Austronesian language of the Selayar Islands in Indonesia, for instance, a special set of agent prefixes is used only when the object is definite, while A is marked indistinctly from $s$ by means of suffixes in the corresponding clause with an indefinite object; contrast $k u$ - in (2c) below with $-a$ in (2b) and $-i$ in (2a) and (2c).

(2) Selayarese (Austronesian, Indonesia; Mithun 1991, 171, 175, glossing modified)

$$
[\mathrm{v}-\mathrm{s}] \quad[\mathrm{v}]
$$

a. máye-i n-río

(s of intransitive)

go-3:s INTR-bathe

'He went to take a bath.'

$$
[\mathrm{V}-\mathrm{A}] \quad[\mathrm{P}]
$$

b. m-máli-a sápo

( $\mathrm{P}$ is indefinite, $\mathrm{A}=\mathrm{S}$ )

INTR-buy-1A house

'I bought a house.'

$[\mathrm{A}-\mathrm{V}-\mathrm{P}] \quad[\mathrm{P}]$

c. ku-hálli-i sapó-ñjo

( $\mathrm{P}$ is definite, $\mathrm{P}=\mathrm{S}$ )

1:A-buy-3:P house-the

'I bought the house.'

The properties associated with A and $\mathrm{P}$, therefore, are pertinent to such alignment splits. Haspelmath (2007), following Zúñiga (2002), distinguishes the following four major possible combinations of person and associated A or P role rankings:

$61 \quad$ See Subsection 3.5.2. 
a) canonical: $\mathrm{A}>\mathrm{P}$.

b) clustering I: both A and $\mathrm{P}$ are high;

c) clustering II: both $\mathrm{A}$ and $\mathrm{P}$ are low;

d) crossing: $\quad P>A$.

Such person-role associations for $\mathrm{A}$ and $\mathrm{P}$ are partly inspired by corresponding phenomena in ditransitive constructions with the theme $(\mathrm{T})$ and recipient $(\mathrm{R})$. It is well known from studies of ditransitive constructions that combinations of two independent pronouns expressing both $\mathrm{T}$ and $\mathrm{R}$ are cross-linguistically rare and that first/second person favors independent expression in the combination of two dependent pronouns. ${ }^{62}$ Such independent pronouns typically only express $\mathrm{R}$ when dependent person markers are not available. This is consistent with the relative argument salience. The recipient is typically highly animate and definite and independent pronouns by themselves are generally confined to human and definite referents, while the opposite applies to themes. A ditransitive person-role constraint thus typically applies to clauses, where $\mathrm{T}$ outranks $\mathrm{R}$ in person.

This tendency also holds for NENA dialects that allow for two object indexes to occur in verbal person marking, such as (3a) in J. Dohok. When the theme is non-third person, the verb cannot take more than two L-suffixes, i.e. two object person indexes, as intended in ( $3 \mathrm{~b})$ and it is the recipient that is expressed independently by means of an independent prepositional pronoun as given in (3c).

\section{(3) J. Dohok}

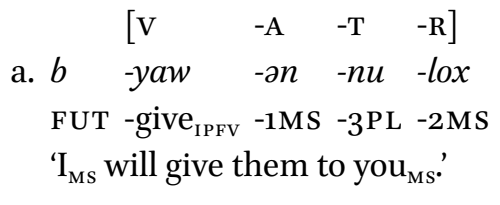

b. * ${ }^{*} b$-yaw -an - nox $-l u$

FUT - give $_{\text {IPFV }}-1 \mathrm{MS}-2 \mathrm{FS}-3 \mathrm{PL}$

(Intended) 'I will give you $_{\mathrm{MS}}$ to them.'

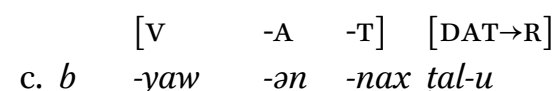

$$
\begin{aligned}
& \text { FUT -give }{ }_{\text {IPFV }}-1 \mathrm{MS}-2 \mathrm{FS} \text { to-3PL } \\
& \text { 'I } \mathrm{MS}_{\mathrm{S}} \text { will give } \text { you }_{\mathrm{FS}} \text { to them.' }
\end{aligned}
$$

62 See Siewierska (2004, 6o-61) and Malchukov et al. (2010) 
Similarly, (4c) is not necessary when $\mathrm{T}$ is a full nominal, such as zuze 'money' in (4d) below. The L-suffix on the verb expresses $\mathrm{R}$, as the dependent person marker becomes available:
d. $b \quad-y a w \quad-a n \quad-n a x$ zuze
FUT -give IPFV $^{-1 M S}-2$ FS money
'I $\mathrm{MS}_{\mathrm{MS}}$ will give you $_{\mathrm{FS}}$ money.'
$\left[\begin{array}{lll}\mathrm{V} & -\mathrm{A} & -\mathrm{R}\end{array}\right] \quad[\mathrm{T}]$

Languages naturally differ in this respect: first/second dependent person markers are, for instance, impossible to cluster in French $\left({ }^{* *}\right.$ Elle te me donne), while Spanish allows, but disfavors such clusters. ${ }^{63}$ But where T outranks $\mathrm{R}$ in person, both languages favor a prepositional $\mathrm{R}$, like J. Dohok above. We could expect the same to apply to languages where person-role constraints occur in monotransitive clauses such as the NENA varieties, which we discuss in the next section. An important difference, though, is that the co-occurrence of first/second person themes and recipients in ditransitive clauses is generally pragmatically restricted, but this is much less the case in monotransitive clauses. While ditransitive clauses, like He showed me to you, may well be restricted or impossible in a language, there is no reason this should equally apply to equivalent monotransitive clauses, like I saw you. Nevertheless, there are languages where such combinations of dependent person markers cause the same restrictions.

Thus, Haspelmath (2007) argues that when P outranks A on the prominence hierarchy and thereby a crossing association of role and argument ranking applies, a more complex construction tends to be used. The so-called canonical pattern represents a harmonic person-role association. Clustering associations are balanced, but not 'canonical'. They are considered less harmonic, while the crossing association, i.e. $\mathrm{P}>\mathrm{A}$, is completely disharmonic, and therefore the more disharmonic a person-role association, the more likely the construction will involve special verbal morphology, overt marking of the A function and/or independent person markers (Haspelmath 2007).

\subsubsection{Person-Role Constraints in Transitive Verbal Forms}

The transitive perfective past constructions express various person splits in NENA. The E-suffixes used to express $P$ in qțil-constructions are restricted in the vast majority of dialects. There seems to be at least a patient-related person scale peculiar to the verbal person marking of $q t ̦ i l-$, and the restriction on

63 See Haspelmath (2004b) and Bonet (2008) for a discussion. 
patient-marking appears to follow a hierarchy from 1,2 $\supset$ 3ms. $\supset 3 \mathrm{pl} . \supset 3 \mathrm{fs}$. There are indications we are dealing with a gradual loss of a particular paradigm. ${ }^{64}$

Complete marking of all persons is found only in a few Christian and Jewish dialects in NW Iraq, such as C. Umra d-Shish, C. Bebede, J. 'Amedia, J. Aradhin and J. Barzan, as well as SE Turkey, such as J. Challa, C. Ashitha, C. Harbole, C. Marga, C. Billin and C. Bne-Matha, and Christian varieties of Hawdiyan (NE Iraq), Urmi and Salmas (NW Iran). ${ }^{65}$ It is also documented in the earliest NENA literature, such as Jewish texts from Nerwa (15th-16th c. NW Iraq; Sabar 1976). Except for J. Nerwa and Challa, speakers of these NENA dialects, especially the younger generation, have alternatives to express transitive perfective past clauses. The further southeast, the more likely a dialect will not have a full paradigm and, if it all, only a person-restricted form.

We should take into account that, when a particular paradigm can or cannot be elicited, this does not always indicate whether a speaker uses this or not. A linguist may well not be able to elicit a particular form of qțil-, but then stumble upon it in a text (see below). Moreover, when speakers become puzzled during elicitation, this does not always mean they cannot deal with such forms in a clear context and more routine-driven usage. Another factor to take into account is that language attrition may also affect production and simplification of forms.

Constructions like qtil-a-le are thus confined to the third person in the vast majority of dialects, so that forms like ** $q t i l-a x$-lu 'They killed us' do not occur. This does not necessarily mean all these dialects once had a full paradigm, though. It does indicate that a particular combination of dependent person markers is disfavored or categorically disallowed. ${ }^{66}$ There is no such constraint in the same sequence of morphemes attached to qatal-, where these roles follow the unmarked affix order (e.g. 'našq-at-te ' $\mathrm{You}_{\mathrm{FS}}$ kiss him'). The restriction minimally targets the first and second person in their $\mathrm{P}$ function. Thus, if $\mathrm{P}$ references the highest ranking person, it cannot be marked by means of the E-series and must be marked differently, for instance independently of the verb, yielding a split in the marking of persons.

Generally speaking, while the ranking of the A role, which is expressed by means of the L-set, is not relevant in all dialects, relative ranking of persons

64 For the gradual loss of these forms in early Christian poetry, see Mengozzi (2012).

65 Maclean $\left(1895,135^{-139)}\right.$ also mentions the Christian dialects of Tkhuma, Upper Tyari and Shemsdin in SE Turkey and Alqosh in NE Iraq.

66 For a generativist perspective on this person-role constraint in NENA, see Doron and Khan (2012). 
does seem to play a role. In her description of the NENA (Judi) Christian dialect of Beșpen (SE Turkey), Sinha (2000, 142) mentions that, apart from the third person markers, only the first masculine singular is attested in the $\mathrm{P}$ function. In her text sample, she records the following forms with a ims. E-suffix marking the object.

(4) C. Beșpen (SE Turkey; Sinha 200o, 182.10, 192.65)

a. ala hiw-ən-ne-̌̌ danye

God:MS give ${ }_{\mathrm{PFV}}-\mathrm{P}: 1 \mathrm{MS}-\mathrm{A}: 3 \mathrm{MS}-\mathrm{ADD}$ world

'God gave $\mathbf{m e}_{\mathbf{M}}$ the world (i.e. I was born).'

b. qam-le matt-an-nehen b-gawad tarzyuta rise $_{\mathrm{PFV}}-\mathrm{S}: 3 \mathrm{PL}$ put ${ }_{\mathrm{PFV}}-\mathrm{P}: 1 \mathrm{MS}-\mathrm{A}: 3 \mathrm{PL}$ in-inside.of tailoring 'Then they put $\mathbf{m e}_{\mathrm{M}}$ inside the tailor's workplace.'

c. lá- mšoder-an-nehen l-nawba plax-li tama

NEG II:send ${ }_{\mathrm{PFV}}-\mathrm{P}: 1 \mathrm{MS}-\mathrm{A}: 3 \mathrm{PL}$ to-patrol work ${ }_{\mathrm{PFV}}$-S:1SG there 'They didn't send $\mathbf{m e}_{\mathrm{M}}$ on patrol. I worked there.'

Similarly, the first plural E-suffix is used sporadically in a Lower Tyari dialect (SE Turkey). Talay (2008a, 317-318) does not mention this, but it is undoubtedly also an exceptional case in an otherwise person-restricted construction, for example:

(5) C. Sarspido (Lower Tyari, SE Turkey; Talay 2009, 142.29)

a. siq-la axni šqil-ix-la man tama

go.up $_{\mathrm{PFv}}-\mathrm{S}: 3 \mathrm{FS}$ we take $_{\mathrm{PFV}}-\mathrm{P}: 1 \mathrm{PL}-\mathrm{A}: 3 \mathrm{FS}$ from there

'She came (and) took us away from there.'

b. mot-ix-la l-qașra diyy-a

bring $_{\text {PFv }}-\mathrm{P}: 1 \mathrm{PL}-\mathrm{A}: 3 \mathrm{FS}$ DAT-castle POSS-3FS

'She brought us to her castle.'

Interestingly, what these sporadic exceptions have in common-and what I believe is not incidental, but possibly could be-is the fact that P outranks A, i.e. the person-role association is crossed. One possibility to consider here is obviously that third person will be more common in narrative texts in any case and the inverted qțil-construction serves particular discourse functions in narrative chains of events. Nevertheless, there are reasons to think such examples are not incidental. Elicitation from a Christian speaker from Bne-Matha (SE 
Turkey) revealed that he accepted such clauses with lower ranking As, but not with higher ranking As. e.g.

$$
\begin{array}{llll}
x ә z y & -a n & -n a & \text { 'She saw } \mathrm{me}_{\mathrm{F}} \\
\text { **xazy } & - \text { at } & -t i & \text { 'I saw you }{ }_{\mathrm{FS}}
\end{array}
$$

Recently, Khan $\left(2016_{\mathrm{II}}: 248-249\right)$ came to the same conclusion regarding C. Urmi (NW Iran), given that most of his informants more readily accept third person agents rather than first and/or second person ones, e.g.

$$
\begin{array}{llll}
x ә z y & -\partial n & -n ә & \text { 'He saw me } \\
\left({ }^{* *}\right) x \partial z y & -\partial n & -n u x & \text { 'You saw me } \\
&
\end{array}
$$

Informants for C. Marga (SE Turkey) similarly become puzzled by higher ranking persons in both $\mathrm{A}$ and $\mathrm{P}$ function, but the crossing situation $(\mathrm{P}>\mathrm{A})$ is perfectly acceptable in narrative texts.

These observations indicate that when P outranks A in person, qțil-a-le seems to be more acceptable in several dialects, whereas when both A and P are nonthird person, the construction is avoided altogether. If this is correct, the reference of A is significant, and the relative ranking may have contributed to the conventionalization of the person split in NENA dialects. The prominence scale, however, does not account for this, as it is the crossing situation that is more acceptable than the clustering II situation where both arguments rank high on the person scale. After all, when both A and P rank low and are thus equally potentially ambiguous, the qtil-a-le is generally available, e.g. C. Urmi:

xәzy -a -la 'He saw her'

Moreover, one would expect that when P outranks A in topicworthiness, verbal morphology other than the canonical ranking, i.e. A > P, would be favored, but this is not the case, the harmonic and disharmonc person-role associations have the same coding strategies e.g. C. Urmi

$x ә z y-a \quad-l i \quad$ 'I saw her'

Be that as it may, another conceivable reason why the inverted forms are disfavored could be the V-P-A affix order that stands out with respect to the dominant morphosyntax of qatal-. While affix order is likely to be involved in the cross-harmonization, V-P-A order per se does not seem to be a problem for speakers. It is the inversion between qațal- and qțil- in particular that is dis- 
favored by speakers, not V-P-A order per se. Evidence for this comes from the compound verbal forms. In C. Shaqlawa, for instance, the V-P-A order is available for all persons in both the compound progressive and compound perfect, e.g.

(6) C. Shaqlawa (NE Iraq)

$\left[\begin{array}{lll}\mathrm{V} & -\mathrm{P} & -\mathrm{A}\end{array}\right]$

a. b-gráš $\quad-u x \quad-i w a n$

in-pulling -2MS -COP:1FS

'I $\mathrm{F}_{\mathrm{F}}$ am pulling you $_{\mathrm{MS}}$ '

b. gráš-t -ux -iwan

pulled-FS -2MS -COP:3FS

'I $\mathrm{F}_{\mathrm{F}}$ have pulled $\mathrm{you}_{\mathrm{MS}}$ '

The inverted qtill-form, however, is limited to third person feminine singular objects, e.g.
$\left[\begin{array}{lll}\mathrm{V} & -\mathrm{P} & -\mathrm{A}\end{array}\right]$
c. griš $\quad-a \quad-l e$
pull $_{\mathrm{PFV}}-3 \mathrm{FS}-3 \mathrm{MS}$
'He pulled her'
d. * ${ }^{*}$ griš $\quad-\partial t \quad-t i$
${ }^{* *}$ pull $_{\mathrm{PFV}}-2 \mathrm{MS}-1 \mathrm{SG}$
Intended: 'I pulled you $\mathrm{ms}^{\text {' }}$

In addition, the 'all-series may cliticize to the preceding form of the infinitive or resultative participle, occurring before the copula. The resulting relative V-A$\mathrm{P}$ order of dependent markers mimics that of qatal-and is distinct form that of the equivalent compound verbal constructions, e.g. C. Ashitha qțil-allan-ile 'He killed us', that follow the same pattern as that of qtil-ax-le 'He killed us' (Borgero 2005, 197).

The rather unrestricted usage of qtill-a-le occurs only when s and A are grouped systematically in some way (e.g. dmax-lan 'We slept': nšiq-ax-lu 'They kissed us'). ${ }^{67}$ There is thus far not a single dialect where forms like qțil-an-nux are common within coherently ergative verbal person marking, while it does

67 Cf. Golbenberg $(1992,125)$. 
occur in coherently accusative ones like Jewish Challa. Nevertheless, there is no direct connection between its restricted usage and ergativity. The person-role constraint occurs in all dialects irrespective of alignment. ${ }^{68}$ Indeed, as we will see, it is not ergativity in itself that is being avoided, but rather the parallelism with the unmarked qatal-constructions that is favored for transitive clauses in general.

\subsubsection{Alternative I: Independent Object Pronouns}

Dialects differ in the way and the extent to which they express pronominal objects independently. There are several dialects that, like the Trans-Zab Jewish varieties of NENA (see § 3.1.2.2.), use independent prepositional pronominal objects as an alternative to the dependent E-set. Hence, although the independent object person markers are optional in other clauses, they are necessary in qtili-constructions to refer to at least the first and second person in personrestricted contexts. This suggests that the wide array of object sets does not have the same status for each inflectional system. The independent object person markers are mainly acceptable in qțil-based morphosyntax and are favored as an alternative to the E-suffixes dialects with person-restricted constructions. Finally, if pronominal objects are based on a preposition, this need not necessarily but sometimes may also entail that definite nominal objects are also differentially marked by means of this preposition. The nominal marking, therefore, is similarly accusative or otherwise neutral, i.e. flagging is absent altogether.

\subsubsection{Another Series of Person Markers}

While unmarked independent personal pronouns are generally used to express $\mathrm{S}$ and $\mathrm{A}$, they are not 'subject' pronouns in the strict sense (see § 2.3.1.2.), as they can express other grammatical functions as well, namely $\mathrm{P}$. If they do so, they generally require additional person marking on the verb, such as (8a) in C. Barwar. It is rarely the case, however, that both A and P are expressed by such unmarked pronouns, and in my interaction with speakers in northern Iraq this has never been accepted upon elicitation. Example (8b) below from C. Barwar is a notable exception.

68 It is always found in Trans-Zab Jewish varieties, and it is also found in compound verbal constructions that pattern accusatively, cf. $\S 3 \cdot 3.1$ and $\S 3 \cdot 3 \cdot 2$. 
（7） C. Barwar (NW Iraq; Khan 2008a, 881, transcription slightly modified) [V-A-P]

a. qa-t-nabl-an-ne $[\mathrm{P}]$ to-SUBR-take ${ }_{\text {IPFV }}$-A:1MS-P:3MS ADD-he 'so that I take also him.' (lit. I take him also he)

[A] $[\mathrm{P}] \quad[\mathrm{V}-\mathrm{A}]$

b. 'ana 'ati bay-zn

I you:SG want $_{\mathrm{IPFV}}-\mathrm{A}: 1 \mathrm{MS}$

'I want you.'

Such independent pronouns can also serve to mark P in qțil-based constructions:

(8) C. Hawdiyan (NE Iraq)

'ana $x z \quad$-an $\quad$-nux $\quad f u$-bazar

I $\quad$ see $_{\mathrm{PFV}}-\mathrm{P}: 1 \mathrm{MS}$-A:2MS in-market

'You saw me at the market.' (lit. Your saw I at the market)

Nevertheless, it is more common for speakers to resort to prepositional object pronouns, like the 'all-series, especially when other means to express a pronominal object are unavailable, e.g.

(9) C. Ashitha (SE Turkey; Borghero 2006, 192)

xze-li 'all $-\boldsymbol{a x}$

see $_{\text {PFV }}$-A:ISG OBJ -2 FS

'I saw you $_{\mathrm{Fs}}$ ' (lit. Me saw to-you $\mathrm{FS}$ )

(10) C. Sardarid (NW Iran; Younansardaroud 2001, 205, 232.4, transcription modified)

a. ${ }^{+}$avva puraq-la qa yala mon mota DEM:MS II:rescue ${ }_{\mathrm{PFV}}-\mathrm{A}: 3 \mathrm{MS}$ DOM boy:MS from death:MS

'He saved the boy from death.' (lit. Him saved to-boy)

b. may xzi-la $\quad \mathbf{q a}^{-} \mathbf{d i y}^{+} \boldsymbol{}{ }^{+} \boldsymbol{u}$ fu palxana?

who see $_{\mathrm{PFV}}-\mathrm{A}: 3 \mathrm{MS}$ OBJ- LK-2MS in work

'Who saw you MS $_{\text {during work?' (lit. Him saw to-you }}$ ) 
Several NENA dialects employ prepositional pronominal objects ${ }^{69}$ as an alternative to the dependent E-set or as the only means to express pronominal objects in the preterit. The areal distribution of this is presented in Map 4 at the end of this chapter, including the Trans-Zab Jewish dialects, discussed in Chapter 3. Prepositional objects are thus not only found in the Trans-Zab Jewish varieties of NENA, but also in Jewish Barzan, C. 'Ankawa, Western Christian varieties in SE Turkey and Northern Christian varieties in NW Iran. The use of the inverted preterit alongside this strategy becomes less common towards the east. In C. Sardarid (NW Iran; Younansardaroud 2001), the preposition $q a$ - is the only means to express pronominal objects in the preterit. Contrasting with the Trans-Zab Jewish dialects, however, such prepositional objects are only common for the perfective past, and not readily available for qaț $l-$, where L-suffixes are used instead. ${ }^{70}$

\subsubsection{Splits in Ditransitive Clauses}

The independent pronominal objects are ultimately derived from goal markers. In lishana deni dialects like J. 'Amedia, where independent pronominal objects are avoided, a prepositional object is used with certain verbs as an alternative to qțil-a-le to express the goal or recipient, such as the addressee of ' $m r$ 'say':

(11) J. 'Amedia (person-unrestricted, NW Iraq; Greenblatt 2011, 336.8, 336.5)
a. mir- at $-t i$
b. mar -ri tat $\underline{\text { tux }}$
say $_{\mathrm{PFV}}$-A:1SG R:to-2MS
'I told you $_{\mathrm{Ms}}$ '

The same pattern is found for qațal- where tat- is an alternative to the L-suffixes, respectively

$\begin{array}{ll}\text { g-emar- } \varnothing & \text {-re } \\ \text { g-emar- } \varnothing & \text { tat-u } u\end{array} \quad$ 'He tells him'

$69 \quad$ See $\S$ 4.1.1.2.

70 An extreme opposite case are the Jewish dialects in Iranian Azerbaijan that freely express the pronominal object independently for all verbal constructions treating them like full nominal objects, e.g. all-án dah-i-wa 'They would beat us', all-í ambal-lu 'They took me' (Khan 20o8b, 300, 445); see Subsection 3.1.2. 
Generally speaking, it would seem that if a dialect tolerates, uses or favors independent pronominal objects, it will tend to avoid this for qațal-constructions, the Trans-Zab Jewish dialects being a noteworthy exception. ${ }^{71}$ This can even lead to the differential treatment of the theme-object in ditransitive constructions. Khan $\left(2016_{11}: 385\right)$, for instance, observes for C. Urmi that the person markers based on the preposition qa-mark the recipient throughout the system, but they only mark the patient in qțil-based constructions and, importantly, they can never mark the theme of ditransitive verbs.

This can be contrasted with C. Ashitha. Consider the following examples in (12). The prepositional argument in (13a-c) does not express the theme, but the recipient irrespective of person, NP type or TAM.

(12) C. Ashitha (SE Turkey; Borghero 2006, 200-202)

$\left[\begin{array}{lll}\mathrm{V}-\mathrm{A} & -\mathrm{T}\end{array}\right] \quad\left[{ }^{\mathrm{a}} \mathrm{ll} \rightarrow \mathrm{R}\right]$

a. yawal- $\varnothing \quad-$ lux $\quad$ all-a

give $_{\text {IPFV }}-\mathrm{A}: 3 \mathrm{MS}$-T:2MS OBJ-3FS

'He gives you $_{\mathrm{MS}}$ to her.'

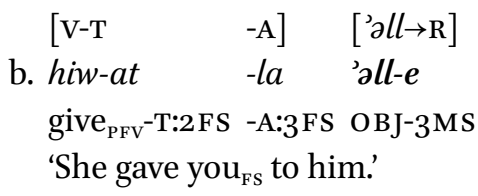

$[\mathrm{V}-\mathrm{A}] \quad[\mathrm{o} l l \rightarrow \mathrm{R}][\mathrm{T}]$

c. hiw-le 'all-i mexulta

give $_{\mathrm{PFv}}-\mathrm{A}: 3 \mathrm{MS}$ OBJ-1SG food:FS

'He gave me food.'

Nevertheless, 'all-is not the only preposition used to indicate recipients. The preposition dedicated to the recipient can vary freely within a single dialect. When one of these prepositions is also dedicated to the patient (and possibly the theme), another preposition țla lends itself to further differentiation in C. Ashitha:
[V-T
-A] $[t+l a \rightarrow \mathrm{R}]$
d. hiw-a
-li țlal-sxu
give $_{\mathrm{PFv}}-\mathrm{T}: 2 \mathrm{FS}-\mathrm{A}: 3 \mathrm{FS}$ to-2PL
'I gave $\mathrm{it}_{\mathrm{F}}$ to you $_{\mathrm{PL}}$ ' 
When the 'all-series is combined with a qțil-form, it can also mark the theme in C. Ashitha. The recipient is marked differently by another preposition, in this case țla-:
[V-A ] ['all $\rightarrow \mathrm{T}][t+l a \rightarrow \mathrm{R}]$
e. hiw-le 'all-a thlal-ux
give $_{\mathrm{PFV}}-\mathrm{A}: 3 \mathrm{SG}$ OBJ-3FS to-2MS
'He gave it to $_{\mathrm{F}} \mathrm{you}_{\mathrm{MS}}$ '

What we do not seem to observe in C. Ashitha are examples like the following, where the theme and recipient are marked by the same preposition:

$$
\begin{array}{lll}
\text { f. } & \text { **all } \rightarrow \mathrm{T}] & {[\text { 'all } \rightarrow \mathrm{R}]} \\
\text { give }_{\mathrm{PFv}}-\mathrm{A}: 3 \mathrm{SG} & \text { овJ-3Fs } \\
\text { 'He gave } \text { it }_{\mathrm{F}} & \text { you }_{\mathrm{Ms}} \text { '. }
\end{array}
$$

Such a double object construction with two identical independent object person markers is avoided. This differentiation in the coding of the recipient seems to be a feature peculiar to the preterit. Indeed, qațal-forms do not seem to combine with the 'all-series in such constructions at all, so that

\section{**yawal- $\varnothing$ all-a țlal-ux 'He gives her to you ${ }_{\mathrm{ms}}$ '}

is not possible. The following diverging patterns unfold for ditransitive constructions based on qațal- against those based on qți- in C. Ashitha:

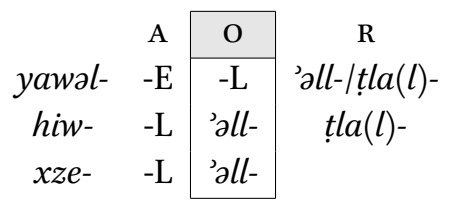

The perfective past is therefore characterized by a type of differential marking of R. In C. Van (Hawshesur, SE Turkey), the same preposition tla- dedicated to $\mathrm{R}$ in Ashitha is used to express $\mathrm{P}$ in the preterit, like $\mathrm{R}$. This can even be used to express $\mathrm{T}$, though the latter is rarely expressed as pronoun, but if it is, $\mathrm{R}$ must be marked differently, e.g. 
(13) C. Van (Hawshesur, SE Turkey; Noorlander field notes)

$$
[\mathrm{V}-\mathrm{A}] \quad[t \operatorname{la} \rightarrow \mathrm{P}]
$$

a. $\dot{g} z i-l \quad t a l-o x$

see $_{\mathrm{PFv}}$-A:3MS OBJ-2MS

'He saw .ou $_{\text {мs.' }}$

$$
[\mathrm{V}-\mathrm{A}] \quad[t+a \rightarrow \mathrm{R}] \quad[\mathrm{T}]
$$

b. maǵgi-l tal $-i \quad k t a v a$

show $_{\mathrm{PFV}}-\mathrm{A}: 3 \mathrm{MS}$ OBJ-1SG book:MS

'He showed me the book.'

$$
\begin{aligned}
& \text { [V-A ] [țla } \rightarrow \mathrm{T}]\left[{ }^{\prime} a l \rightarrow \mathrm{R}\right] \\
& \text { c. magzi-l țal-i 'all-ox } \\
& \text { show }_{\mathrm{PFv}}-\mathrm{A}: 3 \mathrm{MS} \text { OBJ-1SG on-2MS } \\
& \text { 'He showed me to you }{ }_{\mathrm{Ms}} \text { '. }
\end{aligned}
$$

All of this points to a constructional split between qațal- and qțil- in the treatment of independent pronominal objects. The L-suffixes are still favored as object indexes in qatal-and the independent prepositional pronouns as recipient markers, whereas independent prepositional pronominal objects are more readily available in qțil-and tend to be blocked from the recipient function in clauses with two pronominal arguments.

\subsubsection{Alternative II: Stacking of L-suffixes}

Stacking of L-suffixes in constructions like $x z e ́$-le-la 'He saw her' is attested in several NENA dialects, presented on Map 5 at the end of this chapter, which are the Jewish dialects of Azerbaijan, ${ }^{72}$ such as J. Urmi, and Christian dialects in Turkey, including the so-called h-dialects Umṛa (Hobrack 200o), Jinnet (Noorlander field notes) and Artun (Hertevin, Jastrow 1988) as well as BorbRuma (Bohtan; Fox 2009), Hașșan (Hassane, Jastrow 1997), Beșpen (Sinha 20o1), Harbole (Khan field notes) and dialects in the Khabur valley originating in Turkey (Talay 2011, 63) ${ }^{73}$ It is arguably analogical to the same use of Lsuffixes in qațal-, ${ }^{74}$ and the basis for this analogical extension would have been

$72 \quad$ See $\$ 3 \cdot 3 \cdot 2 \cdot 1$.

73 The third person objects can have distinct morphemes in some dialects, resulting in an accusative pattern, see $\S$ 4.1.1.3. It also occurs further to the west in Țuroyo and Mlahsó, discussed in Chapter 5 .

74 Cf. Pennacchietti (1994). 
ditransitive constructions, presumably in order to neutralize object marking across qțil-/qațal-.

Coghill $(2016,64-65)$ subsumes patterns with constructions like qtál-la-le 'She killed him' in NENA under accusative alignment because of the fixed vA-P affix order and because the second L-suffix occupies a slot distinct from the first. There are nevertheless a number of reasons to still consider the stacking of L-suffixes to be a type distinct from the rest and not simply accusative. I would be reluctant to consider a potentially English pattern like Her saw her and Her slept to be simply the same as She saw her and She slept? Though the fixed word order would contribute to argument discrimination, clearly not the identical morphological marking. Thus, although the fixed affix order in this construction in NENA helps distinguish A from $\mathrm{P},{ }^{75}$ it should not be subsumed under accusative alignment in terms of morphological marking.

Other viewpoints found in the literature are ambiguous. Barotto $(2015,242-$ 243), for instance, considers this a system that "tends towards accusative alignment", since the L-suffixes "function as accusative markers" alongside "a marked ergative subject". Similarly, Khan $(2017,891)$ speaks in terms of "ergative verbs", where the pronominal object is expressed "by attaching a second L-suffix after the L-suffix that expresses the ergative subject". Both point to the fact that the inverted preterit is generally limited to the third person, as would be predicted for the ergative type according to the prominence hierarchy. The person restrictions on the inverted preterit, however, should not be considered evidence of ergative alignment in accordance with the prominence hierarchy. The second L-suffix is conditioned by the higher ranking properties of the object, while the L-suffixes denoting $\mathrm{S}$ and $\mathrm{A}$ are obligatory for agreement in general. This point has been raised repeatedly: due to differential object marking, the trigger potential is primarily accusative in all Neo-Aramaic dialects, even for the inverted preterit, albeit limited to the third person.

\subsubsection{From Ditransitive to Monotransitive Verbs?}

As will be shown, the properties of the second L-suffix are indeed similar to those of the L-suffix added to the qatal-base.

Constructions like $x z e ́-l e-l a$ 'He saw you' are restricted to recipient-like arguments in several Jewish and Christian varieties ${ }^{76}$ also indicated on Map 5, e.g.

75 See $§$ 2.3.2.3. for why affix order is not considered a determinant of argument grouping in this approach.

76 See Noorlander (2021). 
hú -li -lax 'I gave to $\mathrm{you}_{\mathrm{FS}}$ '

One finds such stacking also in qațal- at least in the Jewish lishana deni varieties, e.g. Zakho (NW Iraq; cf. Cohen 2012, 163-165) and Dohok (Molin 2021) as well as in the Christian dialects in Turkey, such as Artun (Hertevin, SE Turkey; Jastrow 1988, 63), Marga (SE Turkey) and the Khabur valley (Talay 2008, 316). They regularly allow such stacking of L-suffixes in a double object construction for the themes that refer to the third person. The first L-suffixes always denote the theme, the second one always the recipient:

(14) J. Dohok (NW Iraq)

$$
\begin{aligned}
& {\left[\begin{array}{lll}
-\mathrm{A} & -\mathrm{T} & -\mathrm{R}
\end{array}\right]} \\
& \text { bว-yāw -án -nu -lox } \\
& \text { FUT-give }_{\text {IPFV }}-1 \mathrm{MS}-3 \mathrm{PL}-2 \mathrm{MS} \\
& \text { ' } \mathrm{I}_{\mathrm{M}} \text { will give them to } \text { you }_{\mathrm{MS}} \text { ' }
\end{aligned}
$$

Christian dialects like Marga and Jewish lishana deni dialects, such as Dohok, Zakho and 'Amedia, can also avail themselves of a similar construction, where the qtil-form of the ditransitive verb takes two L-suffixes. The supplementary L-suffix can be used to encode only R. It can never encode T or P; compare:

(15) Stacked L-suffixes (J. Dohok, NW Iraq; cf. Hoberman 1989, 108-109)
a. hu-le -li
give $_{\mathrm{PFV}}-\mathrm{A}: 3 \mathrm{MS}-\mathrm{R}: 1 \mathrm{SG}$
'He gave to me $(\mathrm{R})$.'
b. ${ }^{* *} h u ́-l e \quad-l u$
give $_{\mathrm{PFV}}-\mathrm{A}: 3 \mathrm{MS}-\mathrm{T}: 3 \mathrm{PL}$
'He gave them $(\mathrm{T})$ (to sb.)'
c. ${ }^{* *}$ šme $-l u \quad-l i$
hear $_{\mathrm{PFV}}-\mathrm{A}: 3 \mathrm{PL}$-P:1SG
'They heard me (P).'

In person-unrestricted constructions, as those found in J. 'Amedia, the stacked L-suffixes are used with ditransitive verbs as an alternative to qtil-a-le, to express the goal or recipient, such as the addressee of ' $m r$ 'say': 
(16) J. 'Amedia (person-unrestricted, NW Iraq; Greenblatt 2o11, 336.8, 336.5)
$\left[\begin{array}{lll}\mathrm{V} & -\mathrm{R} & -\mathrm{A}\end{array}\right]$
a. mir $-a t \quad-t i$
say $_{P F V}-R: 2 M S$-A:1SG
$\left[\begin{array}{lll}\mathrm{V} & -\mathrm{A} & -\mathrm{R}\end{array}\right]$
b. már -ri -lux
say $_{\mathrm{PFV}}-\mathrm{A}: 1 \mathrm{SG}-\mathrm{R}: 2 \mathrm{MS}$
'I told you $_{\mathrm{MS}}$ '

The second L-suffix is specified for $\mathrm{R}$ as well as $\mathrm{R}$-like participants (Noorlander 2021). ${ }^{77}$ Adding an L-suffix to a qtal-le verbal form is constrained by its recipientlike function, as other kinds of objects cannot be marked in this way. A, s, and $\mathrm{R}$ may thus be marked by the L-set, so that it is not $\mathrm{P}$ or $\mathrm{T}$ that aligns with $\mathrm{A}$ and S, but R.

The L-suffix, therefore, marks recipients consistently throughout the inflectional systems in these dialects. Verbal inflection based on qațal- can take one object L-suffix that refer to either T or R, e.g. $b$-yawal- $\varnothing$-le 'He gives him' conveys 'He gives him (something)' or 'He gives him (to somebody)'. The object L-suffix in qtil- may refer only to $\mathrm{R}$, e.g. hú-le-le 'He gives him (something)'.

Object L-suffixes are generally used for $\mathrm{P}$ in several NENA dialects in SE Turkey and NW Iran, however. An additional L-set that encodes only $\mathrm{R}$ in the aforementioned dialects also expresses $\mathrm{P}$ and $\mathrm{T}$ by means of the same set as that for $\mathrm{S}$ and $\mathrm{A}$. If the second L-suffix expresses $\mathrm{T}, \mathrm{R}$ is prepositional, e.g. lal-an 'to us' in $(17 \mathrm{C})$.

(17) C. Hașșan (SE Turkey; Damsma forthcoming)

a. dmax -la

(intransitive)

sleep $_{\mathrm{PFV}}-\mathrm{S}: 3 \mathrm{FS}$

'She went to bed.' (lit. Her went to bed)

b. $x z e ́ \quad-l e \quad-l a$

(monotransitive)

see $_{\mathrm{PFV}}-\mathrm{A}: 3 \mathrm{MS}-\mathrm{P}: 3 \mathrm{FS}$

'He saw her (P).' (lit. Him saw her) the earliest texts (16th-17th c.), e.g. mar-ri--lu 'I told them (R)' (Sabar 1976, xxxix, 53.10:16). 
TABLE 27 Imperfective-perfective parallelism of object marking L-suffixes

\begin{tabular}{|c|c|c|c|c|c|}
\hline & A & $\mathbf{R}$ & & A & $\mathbf{P}$ \\
\hline qațal- & $\begin{array}{c}\mathrm{E} \\
y a w-a \\
\text { 'She gives }\end{array}$ & $\begin{array}{c}L \\
-l u x \\
\text { (to) } \text { you }_{\mathrm{ms}}\end{array}$ & $::$ & $\begin{array}{c}\mathrm{E} \\
\text { qațl-a } \\
\text { 'She kills }\end{array}$ & $\begin{array}{c}L \\
-l u x \\
\text { you }_{\mathrm{Ms}}\end{array}$, \\
\hline qțil- & $\begin{array}{c}\mathrm{L} \\
\text { wál-la } \\
\text { 'She gave }\end{array}$ & $\begin{array}{c}L \\
-l u x \\
\text { to } \mathrm{you}_{\mathrm{MS}}\end{array}$ & $\begin{array}{l}:: \\
::\end{array}$ & $\begin{array}{c}\mathrm{L} \\
\text { qtál-la } \\
\text { 'She killed }\end{array}$ & $\begin{array}{c}L \\
-l u x \\
\text { you }_{\mathrm{MS}}\end{array}$, \\
\hline
\end{tabular}

DATA BASED ON DAMSMA (FORTHCOMING)

$\begin{array}{llll}\text { c. már } & -r e & - \text { la } & \text { lal-an } \\ \text { say }_{\mathrm{PFV}}-\mathrm{A}: 3 \mathrm{MS} & -\mathrm{T}: 3 \mathrm{FS} & \mathrm{R}: \mathrm{to}-1 \mathrm{PL}\end{array}$

(ditransitive)

'He told it $_{\mathrm{F}}$ to us.' (lit. Him said her to-us)

S, A, P, T and R are therefore morphologically neutralized in systems like the one exemplified for C. Hașsan above. The object-marking L-suffixes neatly align with each other across the qațal-and qțil-constructions. Compare the forms in Table 27 above. The arrow indicates the direction of the analogy from qatal- to $q t$ til-. The parallel would have been first available in the person indexes denoting the recipient and then extended to all objects.

It seems plausible, therefore, that $x z e$-le-la 'He saw her' at least partly developed in analogy to the qatal-forms, where the L-suffixes specifically mark objects and spread from ditransitives to monotransitives.

\subsubsection{Agent Marking Sensitive to Aspect}

When we turn to Christian dialect of Borb-Ruma (Bohtan, SE Turkey; Fox 2009), marking $S$ and $A$ by means of the same set as $P$ is part of an additional tense-aspect sensitive constructional split. The E-set is used to mark the realis perfect for both intransitive and transitive verbs, for example:

(18) C. Borb-Ruma (Bohtan, SE Turkey; Fox 2002, 72, 73.3, 2009)
a. qam-li
'I got up, rose.'
b. qim-on
' $\mathrm{I}_{\mathrm{M}}$ am up, have risen.'
c. ġze-Ø-wa xa xalma 'He had seen a dream.' 
The L-set is used as object indexes in the perfect:

d. $\dot{g} z-\partial n-n a(<-\partial n+-l a) \quad$ 'I $\mathrm{I}_{\mathrm{M}}$ have seen her.'

e. mutw-ax-la 'We have put her.'

Objects are regularly marked by the L-set in both qațal-and qțil-based verbal forms in the Borb-Ruma dialect, e.g.

f. $x o z-\partial n-n a(<-2 n+-l a)$ 'I see her.'

(present)

Indeed, the E-set never marks the object; it only expresses S and A. Even the third person forms that would express the object in the majority of NENA denote the agent (Fox 2009, 52-54):

g. ptix-i-le 'They have opened $\mathrm{it}_{\mathrm{M}}$ '. $\left({ }^{* * *}\right.$ He has opened them')

Christian Borb-Ruma is unique in this respect: the person-role inversion is totally absent and the choice of inflection for subject agreement is completely tense-aspect-sensitive, treating both intransitive and transitive verbs alike. No person-role split exists, because there is no role inversion: the qți-perfect patterns exactly like qațal-.

The object marking is stable throughout. The two subsystems are represented in (19) and (20) below.

(19) Preterit: Neutral morphological marking

a. qam-li

(intransitive)

rise $_{\mathrm{PFV}}-\mathrm{S}: 1 \mathrm{SG}$

'I rose.'

b. $\dot{g} z e ́-l i-l a$

(transitive)

$\mathrm{see}_{\mathrm{PFv}}{ }^{-\mathrm{A}: 1 \mathrm{SG}-\mathrm{P}: 3 \mathrm{FS}}$

'I saw her.'

(20) Realis perfect: Accusative morphological marking

a. qim-en

(intransitive)

rise $_{\mathrm{PFV}}$-S:1MS

'I have risen.' 
b. $g z-\partial n-n \boldsymbol{a}$

(transitive)

see $_{\mathrm{PFV}}-\mathrm{A}: 1 \mathrm{MS}-\mathrm{P}: 3 \mathrm{FS}$

'I $\mathrm{I}_{\mathrm{M}}$ have seen her.'

Object marking has been levelled in C. Borb-Ruma, while maintaining the aspectual distinction in subject and agent indexes between qțil-ən-na 'I have killed her' and qtál-li-la 'I killed her'.

Therefore, while using the L-set for P throughout seems to be primary, this incidentally leads to the identical marking of $\mathrm{s}, \mathrm{A}$ and $\mathrm{P}$ by means of the same set in the perfective past, where only the affix order serves to discriminate grammatical functions.

\subsubsection{Alternative III: Mixing of L-and E-suffixes}

The stacking of L-suffixes in the preterit neutralizes grammatical distinctions, with S, A and P all being marked by means of the same L-suffixes. Some Christian dialects in SE Turkey, most notably Artun (Hertevin;Jastrow 1988), but also Umra (Hobrack 2000) and Jinnet, ${ }^{78}$ use a distinct set to mark A. Since this is modelled on the E-set in transitive qațal-based constructions, Coghill (2016, 64-65) subsumes this under accusative alignment, while Barotto $(2015,224-$ $245)$ and Khan $(2017,891)$ argue for partial adaptation to accusative alignment for the first and second person. In fact, observing that "ergative" L-suffixes mark s, Barotto $(2015,244)$ maintains the "3rd person shows the higher degree of ergativity", and, similarly, Khan $(2017,891)$ maintains the L-suffixes of the 3 rd person reflect the ergative subject. The special suffixes used for the first and second person are considered to reflect a tendency towards accusative alignment in accordance with the prominence hierarchy.

By contrast, I will demonstrate that this morphology cannot be simply regarded as an accusative type of verbal person marking. In fact, the partial convergence with the transitive qatal-model incidentally results in special marking of $\mathrm{A}$ and thus ergative alignment, albeit confined to the first and second person rather than the third, and conditioned by the presence of a co-argument, namely an object index; both contrary to the expectations of the prominence hierarchy. Finally, none of these varieties seem to have additional flagging of definite objects, so that the nominal marking pattern is neutral.

78 See Pennacchietti $(1991 ; 1994,274-275)$ and Mengozzi $(2012,31)$ for examples throughout literary texts from NW Iraq, which suggest that this construction is not necessarily a recent development and used to be more common. 
TABLE 28 Three types of transitive perfective past constructions

\begin{tabular}{|c|c|c|c|}
\hline qtil- & $\mathbf{P}$ & $\mathbf{A}$ & \\
\hline E-SET + L-SET & $\begin{array}{c}{[-1,2 ; 3 \mathrm{Ms}]} \\
-\mathrm{E}\end{array}$ & $\begin{array}{c}{[1,2]} \\
-\mathrm{L}\end{array}$ & $\begin{array}{l}\text { baḥti hazy-a-li } \\
\text { 'I saw my wife.' }\end{array}$ \\
\hline qtil- & A & $\mathrm{P}$ & \\
\hline L-E-SET + L-SET & $\begin{array}{l}{[+1,2]} \\
-\mathrm{L}-\mathrm{E}\end{array}$ & $\begin{array}{c}{[1,2]} \\
-\mathrm{L}\end{array}$ & $\begin{array}{l}\text { hzé-l-án-na baḥtoh } \\
\text { 'I } \mathrm{I}_{\mathrm{M}} \text { saw your }{ }_{\mathrm{Ms}} \text { wife.' }\end{array}$ \\
\hline L-SET + L-SET & $\begin{array}{c}{[-1,2]} \\
-\mathrm{L}\end{array}$ & $\begin{array}{c}{[1,2]} \\
-\mathrm{L}\end{array}$ & $\begin{array}{l}\text { ḩzé-le-la bahtoh } \\
\text { 'He saw your }{ }_{\mathrm{Ms}} \text { wife.' }\end{array}$ \\
\hline
\end{tabular}

DATA BASED ON JASTROW (1988) AND NOORLANDER FIELD NOTES

\subsubsection{Multiple Transitive Constructions}

There are several constructions available and each of them person-restricted: a typical inverted qțil-construction confined to third person Ps (hazy-a-le 'He saw her'), stacking of L-suffixes confined to third person As (hzé-le-la 'He saw her') and a mixture of the two confined to first and second person As (see Table 28 above). The argument belongs to a particular person category and this absolute ranking determines the choice of construction. Only A and P are affected, while $s$ is not. In actual transitive clauses, different combinations of person markers are possible.

First of all, object indexes from the E-set are limited ${ }^{79}$ to $3 p l$. and ${ }_{3}$ fs. in C. Artun, for example:

$$
[\mathrm{V}(-\mathrm{P})-\mathrm{A}][\mathrm{P}]
$$

(21) hze-li bahta

'I saw a woman.'

(22) hazy-a-li bahti

'I saw my wife.'

79 They can also mark the subject in the realis perfect (e.g. dmihn-en 'I have slept'), see $§ 4.3 .1$. 
Forms like hze-le can mean only 'He saw', not * hze- $\varnothing$-le 'He saw him'. Jastrow $(1988,63)$ states that qțil-a-le is mainly used in differential object indexing in P-V word order; nevertheless, this form is certainly not excluded to this postverbal position. Clauses that omit $\mathrm{P}$ or include full indefinite nominal Ps are treated similarly to intransitive clauses. Definite NPs like bahti 'my wife' above may be indexed by means of the E-set, reflecting an accusative pattern.

Secondly, additional L-suffixes express P for all persons, e.g.

\section{(23) hazé-le-le 'He saw him.' \\ hzé-le-li 'He saw me.'}

Remarkably, the person restriction on stacking of L-suffixes in monotransitive verbs is also found ditransitive verbs. Two consecutive L-suffixes are also employed in ditransitive constructions other than qțil-. Thus, unlike the majority of NENA dialects, C. Artun allows stacking in qaț - as well as the imperative, e.g. hal-le-li 'Give them to me' (hal 'give!' + -lehan 'them' + li 'me'). This is limited to a third person theme index and parallels the restriction to third person agents immediately following qtil-. (24) offers a schema for comparison. ${ }^{80}$

(24) C. Artun (SE Turkey; Jastrow 1988, 63)

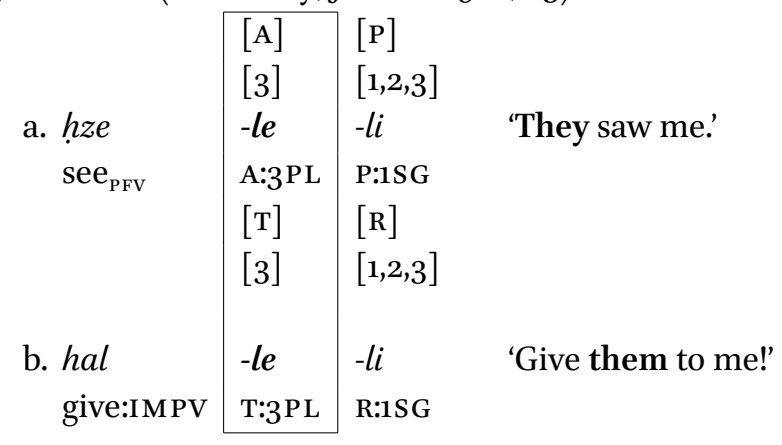

In light of this, it would seem that at least for C. Artun, stacking of L-suffixes is principally avoided depending on person reference and not a particular participant role by itself, since this is disfavored for both themes as well as agents in combinations of dependent person markers.

For first and second person agents, C. Artun blends the L- and E-suffixes to a separate set, which we shall refer to as the $L$-E-suffixes, for example:

8o In other contexts, $\mathrm{R}$ is expressed by means of the preposition (la)l- 'to, for', e.g. mat'en-nenna lal-ew ' $\mathrm{I}_{\mathrm{M}}$ loaded it for him' (Jastrow 1988, 112.59). 


\section{(25) hazé-l-áh-leḥon 'We saw you ${ }_{\mathrm{PL}}$ ' (**hze-lan-lehon $)$ ḩzé-l-át-ti 'You ${ }_{\mathrm{MS}}$ saw me' $\quad\left({ }^{* *} h\right.$ hee-loḥ-li)}

A closer examination reveals that the expression of a differs for the non-third person forms, but is partly identical to qatal-. The shape and order of the Esuffixes (such as -ən 1Ms) followed by L-suffixes (such as -lah $2 \mathrm{FS}$ ) are exactly the same (e.g. -ən-nah <-ən + -lah), but an /1/-element intrudes between the qtil- and person marking. We can schematize this as follows:

\begin{tabular}{|c|c|c|c|c|}
\hline ) haz & & $-\partial n$ & -lah & ḥаzənnah \\
\hline IPFV & & A & $P$ & \\
\hline BASE- & & E-SET & L-SET & \\
\hline $\begin{array}{l}\text { PFV- } \\
\text { hze- }\end{array}$ & $\begin{array}{l}\downarrow L \downarrow- \\
l-\end{array}$ & $\begin{array}{l}\mathrm{A} \\
\partial n\end{array}$ & $\begin{array}{l}\mathrm{P} \\
-l a h\end{array}$ & hzélánnah \\
\hline
\end{tabular}

This transitive perfective construction therefore shows a peculiar case of blending of both the E- and L-suffixes to what we could term 'L-E-suffixes'. These 'L-E-suffixes' are of a binary 'L-' and 'E-'nature; they can be treated either like Esuffixes or like L-suffixes. They generally align with the L-suffixes, where they pattern like stacked L-suffixes, where - wa is inserted before the L-suffixes to form the plupreterit, e.g.

(27) L-E suffixes after past convertor (Jastrow 1988, 61)

hze- -wa -le -la hzéwalela 'He had seen her'

BASE -PAST -L(-E) - -L

hre- $\quad-w a-\quad-l-a n \quad-l a \quad$ hzéwalənna ' $\mathrm{I}_{\mathrm{M}}$ had seen her'

Occasionally, however, they align with the E-suffixes in qața- where they precede -wa-:

(28) L-E suffixes before past convertor (Jastrow 1988, 62)

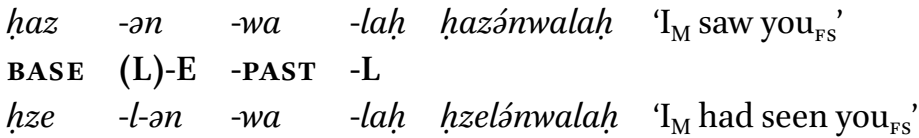

The L-E-series are possibly an attempt to harmonize argument encoding across transitive constructions. This also includes the predicative possessor, also marked by L-suffixes in NENA dialects. The same L-E-set is employed, if an Lsuffix indexing the object possessum follows, e.g. lat-la haye m-tu mandi 'She has no knowledge about anything', lát-l-áḥ-le (lát-lan +-le) haye 'We have no 
knowledge of that' (Jastrow 1988, 66-67). Similarly, intransitive verbs that take a B-series of affixes derived from the preposition $b$ - follow this pattern, e.g. nțár$\boldsymbol{r}$-án-be 'I $\mathrm{I}_{\mathrm{M}}$ looked at him'.

The same L-E-suffixes also occur in the deictic copula based on ho- to express an observable result state, e.g. ho-l-an tiwa ' $\mathrm{I}_{\mathrm{M}}$ am seated', corresponding to both ho-li tiwa and how-an tiwa in other NENA varieties. This is the only context where they can occur with the object affix.

\subsubsection{Ergativity and Split Agent-Marking}

Speakers of Artun thus make use of several constructions to express the perfective past. The three that include a pronominal object are sensitive person-role effects. The L-E-suffixes occur only together with object indexes. They cannot be used to encode s or A without an index of P. Constructions like ** dmah-l-an 'I $\mathrm{I}_{\mathrm{M}}$ slept' with subject coding instead of simply dmah-li are impossible. Agent coding without a patient index is not possible either: **hze-l-an (há)-bahta ${ }^{\prime} \mathbf{I}_{\mathrm{M}}$ saw a woman'. When there is no patient index, $\mathrm{s}$ and $\mathrm{A}$ are treated alike by means of the L-suffixes (dmah-li, hze-li). When P is indexed, however, the whole construction changes depending on the person of $\mathrm{P}$ and/or A.

Dialects like C. Artun, therefore, not only have a person-driven differential marking of $\mathrm{P}$ (gniw-a-li 'I stole it ' vs. hzé-la-li 'She saw me'), but also a persondriven differential marking of A (hzé-le-la 'He saw her' vs. hzé-l-án-na ' $\mathrm{I}_{\mathrm{M}}$ saw her'). The use of the E-set as patient indexes for third person forms (gniw-a-le I stole $\left.\mathbf{i t}_{\mathrm{F}}{ }^{\prime}\right)$ mirrors its incorporation as agent indexes in the L-E-set for first and second person forms (hzé-l-án-na ' $\mathrm{I}_{\mathrm{M}}$ saw her').

Consequently, while the convergence with the qatal-construction is evident, ${ }^{81}$ this leads to an unmistakably ergative alignment pattern due to the special marking of $\mathrm{A}$, to illustrate:

(29) Ergative pattern for non-third person reference in C. Artun (SE Turkey; Jastrow 1988)
a. dmáh-leḥon
(intransitive)
sleep ${ }_{\mathrm{PFv}}-\mathrm{S}: 2 \mathrm{PL}$
'You ${ }_{\mathrm{PL}}$ fell asleep.'
b. hazé-l-áh-leḥon
see $_{\text {PFv }}{ }^{-A: 1 P L-P: 2 P L}$
'We saw you $_{\mathrm{PL}}$ '.

81 See Pennacchietti (1994). Barotto (2015, 244-245) and Coghill (2016, 63, 65), subsume Artun (Hertevin) under dialects with accusative alignment. 
The L-series groups S and P ergatively, while the L-E-series only marks A. Neutral morphology would be found in most other contexts, where S, A and P are all marked by the L-set ( $h z e$-le-la 'He saw her'). ${ }^{82}$ In C. Artun, then, the ergative alignment in the preterit is sensitive to the person reference of $\mathrm{A},{ }^{83}$ which only incidentally emerges due to cross-system harmonization.

This cross-system harmonization is only partial in closely related dialects in Turkey, starting with the third feminine singular. One can already observe the convergence in C. Borb-Ruma, where a shift from $a$ to $o$ occurs in the 3 fs. Lsuffix, when another L-suffix marking P is added, i.e. $x z e$-la 'She saw' $\rightarrow x z e$-lo-le 'She saw him'. This shift incidentally also occurs in the corresponding qatalform, e.g. xazy-a 'She sees' $\rightarrow$ xazy-o-le 'She sees him'. This is because stressed á in an open syllable shifted to $o$ in C. Borb-Ruma. The same phenomenon exists in Jinnet, but, here, the second person singulars are harmonized, so that $h z i^{-}$ lo-le 'She saw him' occurs beside $h z i-l a t-t i$ 'You ${ }_{\mathrm{mS}}$ saw me'. The dialects of Umra did not undergo the vowel shift, but the second person singulars do have a special marker in the transitive preterit, e.g. hze-lat-ti ' $\mathrm{You}_{\mathrm{MS}}$ saw me', similarly to Jinnet. This could indicate that the harmonization was triggered by an analogy between the 3 fs. L-suffix - $l a$ and the 3 fs. E-suffix $-a$, the first could be analyzed as composed of an l-element and the E-suffix, i.e. xze-l-a-le 'She saw him'.

\subsubsection{Alternative IV: qam-qațal-construction}

The convergence with or analogy to the unmarked transitive qațal-inflection is complete in the so-called qam-qatal-formation, which is by far the most common cross-dialectally. ${ }^{84}$ Essentially, the qam-qatal-construction is an attempt to maintain the L-suffixes for the primary set for object indexes similarly to the alternatives II and III. Since this transitive verbal form is completely based on qațal-, Barotto $(2015,240-241)$ and Coghill $(2016,64-65)$ subsume this under accusative alignment, and, though not stated explicitly, Khan (2017, 891-892) mentions this in his discussion of a shift towards the accusative type. Chyet $(1995,245)$ adopts the term "pseudo-ergative" to refer to the dialects that use the qam-qatal-preterit. He prefers this term, because transitive and intransitive verbs are treated differently.

82 This is apart from the alternative pattern for 3 fs. and $3 p l$. where $\mathrm{P}$ may be marked by the E-set (hazy-a-le 'He saw her').

83 By contrast, the ergative alignment found for the preterit in Jewish Trans-Zab dialects is sensitive to the person reference of $P$; see $\S$ 3.3.1.1.

84 On the distribution of this construction in Christian poetry of Iraq, see Mengozzi (2012, $33)$. 
As we will see, however, the main distinction is not between transitive and intransitive verbs per se, but the presence or absence of two dependent person markers in transitive verbal person marking. Moreover, for similar reasons to the L-E-series discussed in the previous sections, one cannot regard this type as simply showing accusative morphology because its inflectional morphemes attach to qațl-. Alignment is identified primarily on the basis of a relationship between $s$ and another argument. The relationship between qamqațal-constructions and intransitives makes sense only when one considers it part of the system of the perfective past together with qțil-. Although the qamqatal-stem is based on the transitive morphosyntax of qațal-, it is confined to transitive perfective past clauses and functions as the equivalent to qtal-le with an object index. Thus, as we will see, pace the aforementioned authors, this relationship incidentally leads to an additional distinction between $\mathrm{s}$ and $\mathrm{A}$ but overlap between s and P. Consequently, this is best understood as a type of ergative verbal person marking, which, in turn, is conditioned by the presence of a co-argument, namely an object index.

\subsubsection{Two Basic Transitive Constructions}

The qam-qatal-construction (see $§$ 4.1.1.1.) is found in the majority of Jewish and Christian dialects, which otherwise group $\mathrm{s}$ and $\mathrm{A}$ in the preterit by means of the L-suffixes, and it serves to indicate the preterit of transitive clauses with an object index without inversion (qaţal-A-P). It alternates and competes with the inverted preterit based on qtil- (qțil-P-A). We can refer to the two types as qam-qațal-le and qțil-a-le, respectively. Map 6 at the end of this chapter shows the areal distribution of the relevant splits between qam-qatal-le for at least the first and second person and person-restricted or unrestricted qtil-a$l e$ in the various NENA dialects surveyed here. Whereas person-unrestricted constructions, as those found in J. 'Amedia, would seem to have two constructions that co-vary, qam-qațl-le is in complementary distribution with qțil-a-le in person-restricted constructions. The person restriction confines qtil-a-le to third person objects in, for instance, J. Zakho (NW Iraq; Cohen 2012), so that constructions like ** qtil-ax-lu 'They killed us' do not occur, but the qam-qațalformation is required instead, e.g. qam-qaț-i-lan.

Furthermore, qțl- $\varnothing$-le 'He killed him' cannot be interpreted as having a zero morpheme expression for the $3 \mathrm{~ms}$. object in several dialects, such as C. Baghdeda (Qaraqosh, NW Iraq; Khan 2002a, 140) and C. Aradhin (NW Iraq; Krotkoff 1982, 28). The qam-qațal-preterit is the only means to express a $3 \mathrm{~ms}$. object, which marginalizes qțil-a-le even further, for example C. Aradhin 


$$
\begin{array}{lllll}
\text { 3fs. } & x \partial z y & -a & -l i & \text { 'I saw her' } \\
\text { 3pl. } & x \partial z y & -i & -l i & \text { 'I saw them' } \\
\text { 3ms. } & \text { qam-xäz- } & \text { on } & -\boldsymbol{n} \boldsymbol{e} & \text { 'I saw him' }
\end{array}
$$

In fact, ${ }^{*} q$ til-a-le is completely obsolete in numerous dialects, including C. Nerwa (NW Iraq), C. Koy Sanjaq (NE Iraq) and C. Sanandaj (W Iran), where the qam-qatal-construction is the only means of expressing transitive verbal person marking in the perfective past, i.e. qam-xaz-an-na 'I saw her', but ** $x \partial z y$ $a$-li is impossible.

The two transitive preterits correlate with respect to the person-role constraint and are at the same time paradigmatically linked. qam-qaţal-le is a transitive perfective past construction dedicated to mark the object differently for dialect-dependent reasons.

A number of scholars, namely Hoberman $(1989,52-53)$ for J. 'Amedia (NW Iraq), Fox $(1997,83)$ for C. Jilu (SE Turkey), Cohen (2012, 238) for J. Zakho (NW Iraq) have argued that qtil-a-le is favored in the differential indexing of object NPs, while qam-qațal-le is largely confined to the expression of pronominal

\begin{tabular}{|c|c|c|c|c|c|c|}
\hline$[\mathrm{V}-\mathrm{s}]$ & {$[s]$} & {$[\mathrm{V}-$} & A & $-\mathrm{P}]$ & & \\
\hline$\underline{t} e-l e$ & $b a b-e$ & $u$ & qam-xaze & $-\varnothing$ & $-l e$ & bə-bxaya \\
\hline $\begin{array}{l}\text { come }_{\mathrm{PFV}}-\mathrm{S}: 3 \mathrm{MS} \\
\text { 'His father cam }\end{array}$ & father & and & $\begin{array}{l}\text { PFV-see } \\
\text { crying.' }\end{array}$ & $-A: 3 M S$ & -P:3MS & in-crying \\
\hline
\end{tabular}
objects. ${ }^{85}$ This can be illustrated by the following sentences from J. 'Amedia:

(30) J. 'Amedia (NW Iraq; Hoberman 1989, 186.3)
$\left[\begin{array}{lll}\mathrm{V} & -\mathrm{P} & -\mathrm{A}\end{array}\right] \quad[\mathrm{P}]$
b. $x z e \quad-\varnothing \quad$-le bron-e bə-bxaya
see $_{\mathrm{PFV}}-\mathrm{P}: 3 \mathrm{MS}$-A:3MS son-his in-crying
'He saw his son crying.'

Thus qam-qațl-le is not always used in the same contexts, as illustrated for J. 'Amedia below.

(31) J. 'Amedia (NW Iraq; adapted from Hoberman 1989; Greenblatt 2011)
qtal-le
qam-qațal-le
a. šmi-a-lu
c. qam-šam'-i-la

'They heard her.'

85 Cf. also Cohen (2012, 238) for J. Zakho. 
TABLE 29 Distribution of qam-qațal-le and qțil-a-le within texts

\begin{tabular}{lrrrrrr}
\hline & \multicolumn{2}{c}{ J. cAmedia } & \multicolumn{3}{c}{ J. Betanure } & \multicolumn{2}{c}{ C. Barwar } \\
& $\boldsymbol{N}$ & $\mathbf{\%}$ & $\boldsymbol{N}$ & $\mathbf{\%}$ & $\boldsymbol{N}$ & $\mathbf{\%}$ \\
& & & & & & \\
& & & & & & \\
qam-qațal-le & 103 & 76 & 218 & 71 & 234 & 70 \\
qțil-a-le & 33 & 24 & 94 & 29 & 101 & 30 \\
TotaL & 136 & 100 & 308 & 100 & 335 & 100 \\
\hline
\end{tabular}
b. šmi-a-lu baxta
d. $\left(^{* *}\right) q a m-$ šam $^{\prime}-i$-la baxta

'They heard the woman.'

This suggests that, when both are available, qam-qațal-le is only secondarily included in the differential indexing of definite NPS.

A more recent description of J. 'Amedia (Greenblatt 2011), however, indicates that both forms can be used in differential object indexing. Thus, both preterits are used in differential object indexing and their distribution seems to be free, except for the following factors. Noorlander and Molin (2020) show that about $25-30 \%$ of the transitive preterits involve qțil-a-le against about a $70-75 \%$ majority of qam-qatal-le in narrative texts from J. 'Amedia (Greenblatt 2011), ${ }^{86} \mathrm{~J}$. Betanure (Mutzafi 2008a) and C. Barwar (Khan 2008a), as shown in Table 29 above. This is irrespective of person restrictions, since J. 'Amedia shows no person restrictions. These are indications that a verbal paradigm is gradually being replaced by another.

This replacement can presumably be attributed to the influence of Iraqi koine in some Christian communities. Among my younger informants of C. Marga (SE Turkey), who have grown up in Iraq, qam-qațal-le is preferred in general, while older informants originally from Turkey prefer to use qțil-a-le for all persons. The same seems to hold for other villages, e.g. C. Bebede (NW Iraq), where the younger speakers favor qam-qatal-le.

The qam-qațal-preterit does not appear to be combinable with prepositional arguments that take s-like subjects. Forms like ** $q a m-r a$ 'əš- $\varnothing$ 'abbi 'He noticed me' do not appear to be possible, only raš-le 'abbi 'He noticed me'. Consequently primary transitive verbs, such as $x z y$ 'see', are treated differently: 
(32) J. Zakho (NW Iraq; Cohen 2012)
$\left[\begin{array}{ll}\mathrm{v} & -\mathrm{s}\end{array}\right]$ [OBL]
$\left[\begin{array}{lll}\mathrm{V} & -\mathrm{A} & -\mathrm{P}\end{array}\right]$
a. $r^{\prime} \partial s^{2}-l e$ 'abbi
b. qam-xaze $\quad-\varnothing \quad-l i$
'He noticed me.'
'He saw me.'

Clauses with an indefinite full NP, therefore, are indistinct from intransitive predicates, to illustrate:
$\left[\begin{array}{ll}\mathrm{V} & -\mathrm{A}\end{array}\right] \quad[$ full NP$]$
c. xze -le xmara
'He saw a donkey'.

Such sensitivity to transitivity is largely morphological and lexical.

It is noteworthy that dialects tend to favor qțil-a-le for intransitive verbs with a dummy, non-referential object that display transitive morphology, e.g. 'riq-ale 'He fled (lit. fled $\mathrm{it}_{\mathrm{F}}$ )' (Noorlander and Molin 2020). It has been reported that such verbs are not always excluded altogether from the qam-qatal-formation, such as J. Zakho qam-gamss-i-la 'They smiled', lit. 'They smiled (lit. it $\mathrm{F}_{\mathrm{F}}$ )' (Cohen 2012, 142). Nevertheless, Noorlander and Molin found no such examples in the texts for J. 'Amedia, J. Betanure, C. Barwar, C. Urmi and C. Marga. Moreover, qtil$a$-le is by far the more common expression for object indexing of the reflexive pronoun gyan-. This seems to be the source of the dummy 3 fs. object coding, e.g. 'riq-a-le 'He fled (lit. fled it ${ }_{\mathrm{F}}$ )', originating in 'riq-a-le gyan-e lit. 'He fled himself'.

Similarly, ditransitive verbs, such as ' $m r$ 'say', are used differently in these dialects. The dialects without person restrictions, like J. 'Amedia, freely use the E-suffix to express also recipients of the first/second person, e.g. mir-at-ti 'I told you $_{\mathrm{Ms}}$ ' In person-restricted constructions this would not be possible, and alternative expressions must be used, e.g. J. Betanure mar-ri talox 'I told you ${ }_{\mathrm{ms}}$ '. Consequently, ditransitive constructions like qam-'əmr-ən-nox 'I told you ${ }_{\mathrm{Ms}}$ ' are less common than the free form mar-ri in such dialects, because only the latter combines with prepositional objects.

\subsubsection{Ergativity and Split Agent-Marking}

The qam-qatal-le-construction is the most extreme case of adapting transitive coding to the qatal-model of unmarked transitive clauses. There is a constructional split between clauses where all arguments are marked by dependent person markers and those where only A is dependent. Full nominal objects are thus treated differently. Like the L-E-series discussed in the previous section, this does not lead to accusative person marking, but arguably something closer to ergative morphology. 
A fundamental difference between the two type of preterits is that qamqatal-le obligatorily takes patient indexes, while qtal-le need not, as the following examples show: (33e) P is not expressible, (33f) is omitted or (33g) its referentiality is reduced to an indefinite NP, so that qam-qațal-le cannot be used.

(33) J. 'Amedia (NW Iraq, person-unrestricted; adapted from Hoberman 1989) qtal-le

\section{qam-qațal-le}

a. dməx-lu

e. **qam-damx-i

(no P)

'They went to sleep.'

b. $x a l-l u$

f. ${ }^{* *} q a m-{ }^{3} a x l-i$

(implicit P)

'They ate.'

c. xil-i-lu xabuše

g. **qam-'axl-i xabuše

(indef $\mathrm{P}$ )

'They ate apples.'

d. $x i l-i-l u$

h. qam-'axl-i-lu

(pron P)

'They ate them.'

There is no a priori morphological reason why objectless forms, like ** qam'axl-i 'They ate', or intransitive verbs, such as **qam-damx-i 'They slept', should be avoided. The qatal-form without an object L-suffix ( ('axl-i- 'They eat') could,

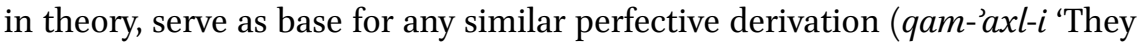
ate'), but it is not readily used as such. Polotsky $(1961,21 \mathrm{fn}$.), referring to C. Urmi, mentions that such objectless forms sporadically do occur. It seems that such forms occur alongside another qam-qatal-construction that does have object coding, e.g. qam-doq-a (Ø) l-ha mənne qam-mahy-a-la l-arra 'She seized one of them (and) hit him to the ground' (C. Urmi, Socin 1882 67.10; transcription simplified). Examples such as these indicate the possibility of omitting an object suffix at least when implied in the immediate context, but they are not possible for a corresponding intransitive valence, when the patient is unexpressed (e.g. ***am-'axl-i 'They ate').

qam-qațal-le, then, is a transitive perfective past construction dedicated to two dependent person markers, serving as a device to mark the object differently in the preterit. Thus, qam-qațal-le constitutes an integral part of the paradigm of $q t a l-l e$, just as much as qțil-a-le. qam-qațal-le is not an integral part of the other inflections based on qatal-, but should be considered a separate stem for transitive coding as a suppletive alternant of qtil-. Transitive clauses involving transitive verbal person marking are thus treated differently from intransitives. This affects transitivity alternations: compare the verb $p \underline{t} x$ 'open' in (34a) and (34b) taken from the closely related dialect of Betanure. qtal-le always expresses the intransitive valence pattern, while qam-qatal-le is used when the same referent tar'a 'the door' is indexed differentially. 
(34) J. Betanure (NW Iraq; Mutzafi 20o8a, 256.399, 266.426)

$[\mathrm{s}] \quad[\mathrm{v}-\mathrm{s}]$

a. tar'a $^{3}$ țax-le

(intr., qțil-pret.)

door:Ms open ${ }_{\mathrm{PFV}}-\mathrm{S}: 3 \mathrm{MS}$

'The door opened.'

[P] [V-A-P $]$

b. tar'a $^{3}$ qam-pāt $x-i-l e \quad$ tal-u (tr. , qam-pret.)

door:MS PFV-open ${ }_{\text {IPFV }}$ A:3PL-P:3MS DAT-3MS

'They opened the door for him.'

The qatal-base is the lesser marked for TAM of the two inflectional bases, while qțil-is more marked for such properties. The presence of qam-as well as two distinct verbal person markers of $\mathrm{A}$ and $\mathrm{P}$ indicates that the clause is transitive as well as perfective past. This is consistent with the tendency for agreement affixes to become devices to differentiate between intransitive and transitive verbs (Givón 1976, 168). In NENA, the TAM-marker qam is thus specified for perfective pastness as well as two-argument clauses. Prioritizing the transitive morphology of qatal- comes at the cost of indirectly also affecting the encoding of $\mathrm{A}$ in the same paradigm, just like the L-E series in C. Artun.

The distinction between transitive and intransitive clauses is even more conventionalized in varieties, where **tili-a-le is completely absent. ${ }^{87}$ The perfective TAM-marker qam- is combined with qatal- as the only expression of the perfective past with a P index. A form like xze-le 'He saw' cannot be combined with an object person form of any kind (neither E-set, **xazy-a-le, nor L-set, **xzé-le-la), but shifts to a form like qam-xaze- $\varnothing$-le 'He saw him' instead. We can illustrate this system with the following examples from C. Nerwa (NW Iraq):

(35) C. Nerwa (NW Iraq) [v-s] [s]
a. dmax-la
baxta
'The woman slept.'
$(\mathrm{s}=\mathrm{L}-\mathrm{set})$
[v-A]
[P: fNP]
b. $x z e-l e$
xa baxta
'He saw a woman.'
(A = L-set)
[V-A-P]
c. qam-xaze- $\varnothing \quad-l i$
'He saw me'.
( $\mathrm{P}=\mathrm{L}$-set $)$

87 cf. Mengozzi (2002b, 42). 

d. qam-xaze- $\varnothing \quad-l a$
'He saw her.'
e. qam-xaze- $\varnothing$-la baxti
'He saw my wife.'

Although qam-qatal-le is obviously partly parasitic on the morphosyntax of qatal- due to its inflectional base, there is a conspicuous morphosyntactic division in the inflectional paradigm of the perfective past based on the transitive coding, which, strictly speaking, does not unambiguously select a particular set of grammatical functions, but a combination thereof. The L-set is used to mark $S$ and $\mathrm{A}$ for a qțil-based form only and at the same time only P for a qam-qațalbased form. It is the A that is treated differently in a particular context, while $s$ and P remain unaffected. We can approach the split between the two preterits from the perspective of co-argument sensitivity (Witzlack-Makarevich et al. 2016). The morphosyntax splits along two distinct constructions, of which one is associated with A in the presence of an object index, i.e. qam-qațal-le, and another with all other clause types. The L-suffixes serve to signal the more salient argument in both constructions. As qtal-le is confined to clauses with one dependent person marker and qam-qatal-le to clauses with two dependent person markers. There is a neat split between accusative and arguably ergative alignment due to special marking of $\mathrm{A}$, which, in turn, is conditioned by referential properties of $P$.

This is precisely what we would expect for an ergative pattern (see § 4.4.1.1.): a higher degree of morphosyntactic transitivity, namely the presence of a type of object, triggers distinct marking of A, illustrated in Table 30 below. When there is no object agreement or $\mathrm{P}$ is low in ranking, such as indefinite full nominals, $\mathrm{S}$ and $\mathrm{A}$ are grouped together accusatively by means of the L-set, hence $d m a x$-le and qtal-le. The P role is isolated in not being coded overtly on the verb. When there is morphosyntactically a pronominal object and/or P is high in ranking, such as first/second person and definite full nominals, $\mathrm{s}$ and $\mathrm{P}$ are arguably grouped together ergatively by means of the L-set, hence $d m a x$-lux 'You ${ }_{\mathrm{MS}}$ slept' and qam-xaz-ax-lux 'We saw you ${ }_{\mathrm{MS}}$ '. The A function is isolated in being coded by the E-set (qam-xaz-ax-lux 'We saw you $_{\text {мs' }}$ ). What is grouped together in both domains, is marked by the L-set.

Furthermore, a few dialects on the Nineveh Plains, such as C. Telkepe, combine differential object indexing with differential object flagging, as illustrated in (36) below. Here, the qam-qațal-construction is also invoked when the object requires prepositional marking. This differential treatment of $\mathrm{P}$ in flagging thus combines with a special construction, which incidentally also results into special indexing of A distinct from s, so that the nominal marking is accusative, but the cross-indexing is ergative in its morphology. 
TABLE 30 Verbal person marking alignment in the preterit for qam-qațal-

\begin{tabular}{|c|c|c|c|c|c|c|}
\hline \multirow[t]{2}{*}{ ACCUSATIVE } & \multirow[t]{2}{*}[\mathrm{P}=\text{full}\mathrm{NP}]{} & \multirow[t]{2}{*}{ intr. } & \multirow{2}{*}{$\begin{array}{l}\text { qtil- } \\
\text { qțil- }\end{array}$} & \multirow{2}{*}{\multicolumn{2}{|c|}{$\begin{array}{cc} & \text { S } \\
& \text { L-set } \\
\text { A } & \\
\text { L-set } & \end{array}$}} & \\
\hline & & & & & & $\begin{array}{l}\mathrm{P} \\
\varnothing\end{array}$ \\
\hline \multirow[t]{2}{*}{ ERGATIVE } & {$[\mathrm{P}=$ pronoun $]$} & intr. & qțil- & & \multirow[t]{2}{*}{$\begin{array}{c}\text { s } \\
\text { L-set }\end{array}$} & \\
\hline & & tr. & qam-qațal- & $\begin{array}{c}\text { A } \\
\text { E-set }\end{array}$ & & $\begin{array}{c}\mathbf{P} \\
\text { L-set }\end{array}$ \\
\hline
\end{tabular}

(36) C. Telkepe (NW Iraq; Coghill 2010, 231, glossing slightly modified)

a. gorn npal -la

man:Ms fall ${ }_{\mathrm{PFV}} \mathrm{A}: 3 \mathrm{MS}$

'The/a man fell.' (lit. Him fell)

b. qtal -la gorn

(A and indef. P)

kill $_{\mathrm{PFV}}$ A:3MS man:MS

'He killed a man.' (lit. Him killed a man)

c. kam-qātal - $\varnothing \quad$-la $\quad$ ta- gorn

(A and def. P)

PFV-kill- -A:3MS -P:3MS DOM man:MS

'He killed the man.' (lit. He killed him to-man)

In conclusion, the complete adaptation of transitive verbal person marking from qațal-into the perfective past results incidentally in the special treatment of clauses where both A and P are dependent person markers, i.e. crossindexes. The resulting ergative person marking is similar to the L-E-series of Artun (Hertevin) (see § 4.4.4) and manifests ergativity under conditions opposite to those found in the Southeastern Trans-Zab Jewish varieties (see $\S$ 3.3.1.), namely, in this case, higher ranking persons. 


\subsection{Conclusion: Cross-System Harmonization}

It is a common assumption ${ }^{88}$ that NENA started out with an ergative alignment pattern in the perfective past. The dialectal microvariation is said to display a development from 'split ergative' in the direction of fully accusative alignment, as predicted by the prominence scale, which is grounded on the functional view of typology that, in an alignment split conditioned by referential properties, lower ranking arguments will pattern ergatively, but higher ranking ones will not (Silverstein 1976; Dixon 1995, 83-94). Thus, where there is a person restriction, some Aramaicists tend to attribute this to ergativity, and where the morphology is adjusted to the 'imperfective' transitive morphosyntax of qațal-, they speak of a shift towards accusative alignment.

The basic assumptions that the inverted qtil-a-le is an ergative construction-because of a presumed coherent ergative original - and that constructions that are influenced by qaț l-, by definition, display accusative morphology have obscured clearly observable facts about NENA alignment typology. After all, when alignment is identified on the basis of the similar or distinct treatment of s, A and P, qtil-a-le cannot be simply characterized as ergative, nor the L-E-series in C. Artun (Hertevin) and the qam-qațal-construction as accusative. If this is correct, this has important repercussions for how the NENA data are to be understood typologically as well as historically. If these strategies to adjust the morphology to that of the unmarked morphosyntax incidentally lead to ergative verbal person marking, they cannot be said to promote accusative morphological alignment nor to comply with the prominence scales for alignment splits. The ergative morphological marking is thus an incidental outcome of dialect-specific contingencies, where the NENA microvariation is driven by other factors such as cross-system harmonization, and not by the prominence hierarchy.

In the end, s, A and P may each 'lead a life of their own' in NENA. Variation and change, therefore, are strictly based on the interaction of intransitive constructions and transitive constructions by means of verbal person marking, nominal marking, independent pronouns and system-internal factors, which are largely independent of how one classifies the entire arrangement as a whole. Overall, it is not always possible to group $\mathrm{S}, \mathrm{A}$ and $\mathrm{P}$ in a general and/or coherent fashion. The same person marking sets can express the very opposite grammatical function depending on the dialect, e.g. Borb-Ruma qțil-i-le 'They have killed him'

88 See Section 1.5. and Mengozzi (2005), Khan (2007a; 2017), Doron and Khan (2012), Barotto $(2015,237)$. 
vs. the rest of NENA qțil-i-le 'He killed them'. Sometimes originally independent sets of person markers can hardly be kept apart from the dependent markers, because they have almost entirely fallen together by phonological changes.

All of the dialects discussed in this chapter group s and $\mathrm{A}$ in some respect, and when dialects use qtil-a-le for transitive coding alongside $q t$ tol-le for transitive and intransitives alike, no ergative grouping is manifested in phonological form. P (i.e. the E-set) is distinct from S and A (i.e. the L-set). Person marking syntax is in general non-distinct from the corresponding qatal-constructions apart from the role reference inversion.

Indeed, it is the role reference inversion that tends to be avoided for dependent first and second person markers, irrespective of alignment type. Systeminternal factors particularly target transitive verbal person marking and incidentally result in the special treatment of transitive verbal person marking. Several constructions, listed in Table 31 below, serve as alternatives for qțil-a-le, displaying an increasing adjustment to the unmarked morphosyntax of qațl-.

These transitive constructions appear to have one basic principle in common: they make the pronominal object that occurs in postverbal position the regular expression of object indexes, which in the case of the L-suffixes becomes the same throughout the verbal system. This is modelled on the unmarked verbal forms based on qatal-, while maintaining whatever coding of the agent adjacent to the verbal base, i.e. V-A-P affix order. The transitive coding becomes closer to the more basic and dominant morphosyntax of qațl-in increasing adaptation of the verbal coding of $\mathrm{A}$ and $\mathrm{P}$.

However one would analyze these constructions in terms of alignment, a higher degree of morphosyntactic transitivity triggering marking of A distinct from $\mathrm{S}$ is evidently not what we would expect for an accusative pattern. As it is only two-argument verbal person marking that is affected, the intransitive constructions remain independent of this cross-system harmonization. This was also observed for the compound verbal forms in dialects where the copula and 'all-series fall together with the E-suffixes and L-suffixes in transitive clauses with two dependent person markers. Similarly, the resulting alignment patterns in the simplex verbal forms, i.e. perfective past and/or perfect, are thus the incidental outcomes of this harmonization of transitive clauses with two cross-indexes across the system as a whole. Yet it would be misleading to say that such system-internal pressure from the main inflectional system therefore also results in the demise of ergativity. As we have seen, it is not ergativity or any other alignment type in itself that is being avoided, but rather the parallelism with the unmarked qatal-constructions that is favored for transitive clauses in general and first/second person As in particular. 
TABLE 31 Transitive constructions that parallel qațal-

\begin{tabular}{|c|c|c|c|c|c|}
\hline \multirow[b]{2}{*}{ qțil } & $\mathrm{P}$ & A & \multirow{2}{*}{\multicolumn{2}{|c|}{ inverted role marking }} & \multirow{2}{*}{$\begin{array}{l}\text { 'You }{ }_{\mathrm{MS}} \text { saw me' } \\
\text { griš-ən-nux }\end{array}$} \\
\hline & $-E$ & $-\mathrm{L}$ & & & \\
\hline & \multicolumn{2}{|c|}{ A } & $P$ & & 'You ${ }_{\mathrm{MS}}$ saw me' \\
\hline qțil & \multicolumn{2}{|c|}{$-\mathrm{L}$} & PP & prepositional object & graš-lux ’alli \\
\hline qțil & \multicolumn{2}{|c|}{$-\mathrm{L}$} & $-\mathrm{L}$ & stacking of L-suffixes & gráš-lux-li \\
\hline qțil & $-l$ & $-E$ & $-\mathrm{L}$ & mixing & grášs-l-át-ti \\
\hline qțil & & & $-\mathrm{L}$ & $\begin{array}{l}\text { transitive realis perfect } \\
\left(={ }^{\prime} \mathrm{You}_{\mathrm{MS}} \text { have seen me') }\right.\end{array}$ & griš-ət-li \\
\hline qam-qațal & & & $-\mathrm{L}$ & perfective past preverb & qam-garš-ət-ti \\
\hline ْqațal & & & $-\mathrm{L}$ & $\begin{array}{l}\text { unmarked verbal inflection } \\
\left(=\text { ' } \mathrm{You}_{\mathrm{MS}} \text { see } \mathrm{me}^{\prime}\right)\end{array}$ & $\stackrel{\circ}{g} a r s ̌-\partial t-t i$ \\
\hline
\end{tabular}

An additional complicating sociolinguistic factor in Iraq that one has to consider is dialect mixture due to displacement. New generations of speakers are adapting their speech to Iraqi koine, which favors the qam-qațal-construction, or alternatively use prepositional objects. Areal factors are also to be considered, since it is possible the person-role constraints in the perfective past and their relationship to the affix order are due to parallels in neighboring Iranian languages, reflecting distinct contact situations in the history of the NENA dialects. A case in point is the inverted $q$ țil-a-le, which parallels the same inversion of person markers and V-P-A order in Gorani (Stilo 1981), presumably an old contact language of at least some of the NENA varieties, whereas relatively more recent contact languages are notably different. Central Kurdish, for instance, exhibits V-A-P order, except for the combinations where $\mathrm{A}$ is third person (Mackenzie 1961, 113; Öpengin 2013). A systematic study could reveal whether there is a connection with similar preferences in NENA dialects. Also the fact that the agentless qțil-construction and prepositional agent constructions are interpretable as transitive is possibly at least partially due to influence from the Badini Kurdish agentless and ergative constructions (Haig 2008, 
262-268), although, of course, the intransitive constructions in these dialects of NENA are rather distinct from Kurdish.

The agentless qțil-forms could be considered a restricted type of ergativity for definite nouns in trigger potential only, though, since the absence of agent indexing seems to be pragmatically conditioned, its distinction from the

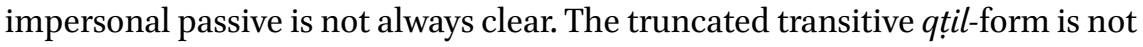
typically passive, presumably because the patient indexes are the same for the object in the fully transitive coding, but distinct from s. The pragmatically conditioned agentless coding correlates with agent focalization and prepositional marking, which is not only an important difference from the majority of NENA, where agent agreement is obligatory, but also from the Southeastern Trans-Zab Jewish varieties, where the same morphological marking expresses fully intransitive morphosyntax.

Meeting NENA from the west on the other side of the river Tigris, we will see in the following chapter that the Neo-Aramaic dialects of Țur 'Abdin are typologically distinct from all these NENA dialects, in showing both ergative verbal person marking and (optional) ergative prepositional marking, but they do have features in common with the Western Christian dialects of NENA as well as, interestingly, the easternmost outposts of NENA, namely the Trans-Zab Jewish subgroup. 


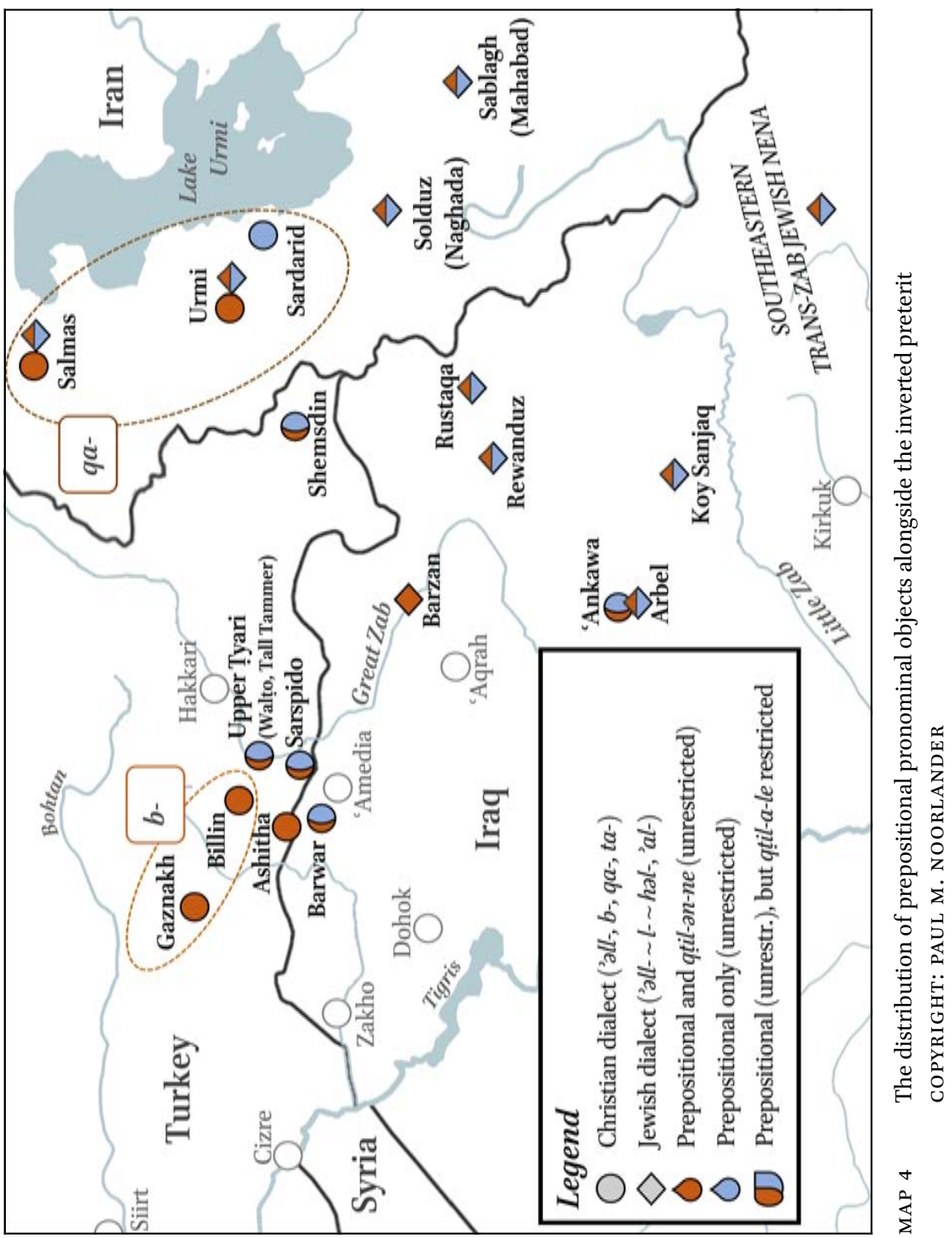




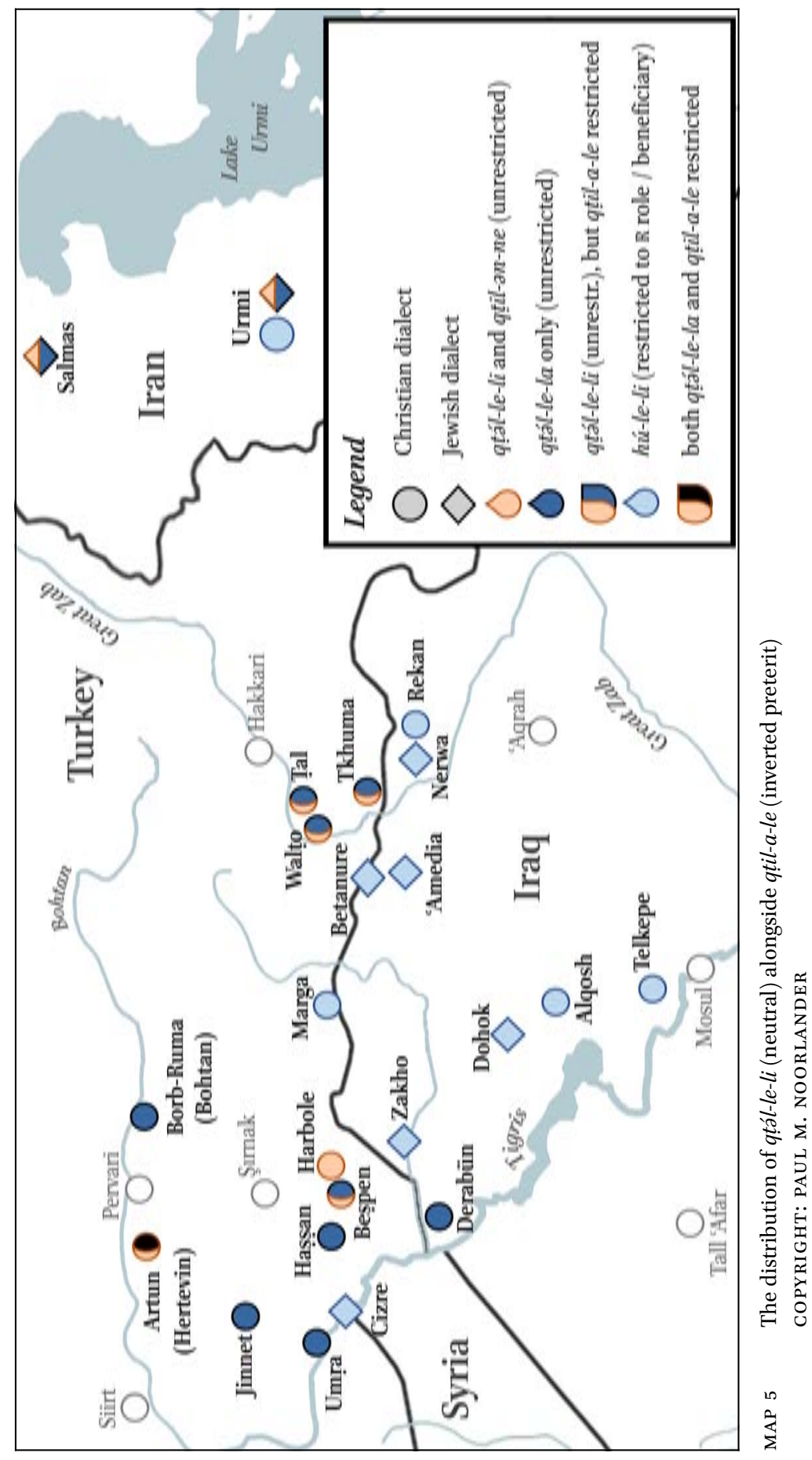




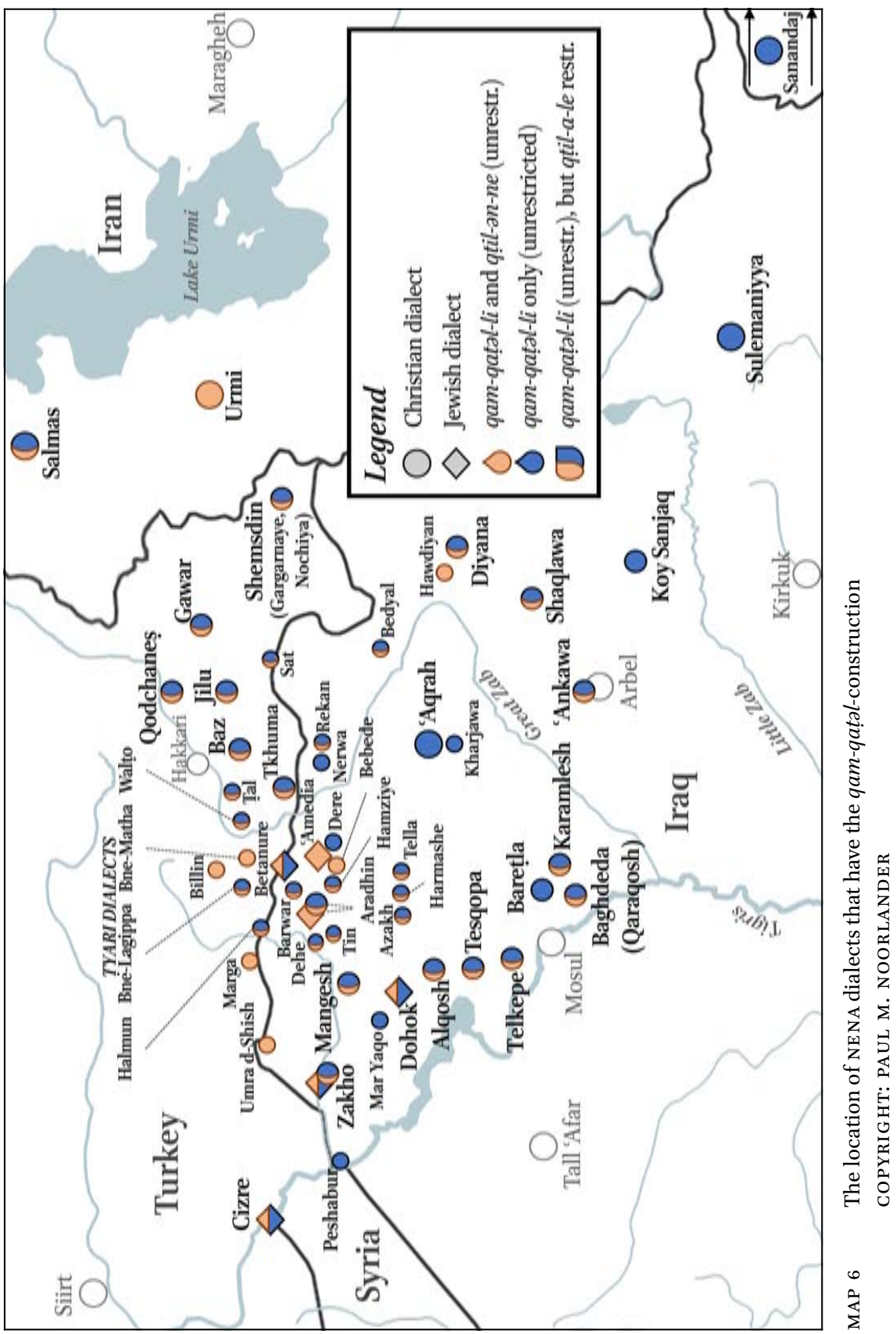

